Alexandre Mendonça Munhoz

\title{
Estudo crítico da anatomia arterial do retalho vascularizado pela artéria perfurante muscular da artéria epigástrica inferior
}

Dissertação apresentada à Faculdade de Medicina da Universidade de São Paulo para obtenção do título de Mestre em Ciências.

Área de concentração: Cirurgia Plástica Orientador: Prof. Dr. Rolf Gemperli

São Paulo

2004 


\section{FICHA CATALOGRÁFICA}

Preparada pela Biblioteca da

Faculdade de Medicina da Universidade de São Paulo

Creprodução autorizada pelo autor

Munhoz, Alexandre Mendonça

Estudo crítico da anatomia arterial do retalho vascularizado pela artéria perfurante muscular da artéria epigástrica inferior / Alexandre Mendonça Munhoz. -- São Paulo, 2004.

Dissertação(mestrado)--Faculdade de Medicina da Universidade de São Paulo. Departamento de Cirurgia.

Área de concentração: Cirurgia Plástica.

Orientador: Rolf Gemperli.

Descritores: 1.MÚSCULOS ABDOMINAIS/anatomia \& histologia 2.MÚSCULOS ABDOMINAIS/cirurgia 3.MÚSCULOS ABDOMINAIS/irrigação sangüínea 4.RETALHOS CIRÚRGICOS/classificação 5.RETALHOS CIRÚRGICOS/irrigação sangüínea 6.RETALHOS CIRÚRGICOS/fisiologia 7.RETALHOS CIRÚRGICOS/utilização 8.ARTÉRIAS EPIGÁSTRICAS/anatomia \& histologia 9.ARTÉRIAS EPIGÁSTRICAS/cirurgia 10.ARTÉRIAS EPIGÁSTRICAS/ transplante

USP/FM/SBD-109/04 
“Nós somos o que repetidamente fazemos.

Excelência, portanto, não é um ato, mas um hábito"

Aristóteles (385 - 322 a.C) 
Dedicatória 
Aos meus pais, Diogo e Cristina, pelo amor e carinho.

O constante apoio e estímulo a seguir em frente foram decisivos em minha formação como médico e pessoa.

Aos meus irmãos, André e Liana.

Por compreenderem minha ausência durante todos esses anos. 
Agradecimentos 
A execução dessa dissertação só foi possível graças à colaboração de muitas pessoas, a quem externo minha profunda gratidão, em especial:

Ao Prof. Dr. Rolf Gemperli, Professor Associado da Disciplina de Cirurgia Plástica da Faculdade de Medicina da Universidade de São Paulo, meu orientador, conselheiro e amigo, pela presença e a orientação marcante em diversas etapas da minha formação profissional e científica.

Ao Prof. Dr. Marcus Castro Ferreira, Professor Titular da Disciplina de Cirurgia Plástica da Faculdade de Medicina da Universidade de São Paulo, pelo estímulo e apoio na execução, não apenas desta tese, mas em diversas outras etapas da minha carreira universitária.

Ao Prof. Dr. José Aristodemo Pinotti, Professor Titular do Departamento de Ginecologia da Faculdade de Medicina da Universidade de São Paulo, por todas as oportunidades e pela confiança no início das minhas atividades na reconstrução mamária.

À minha querida Cláudia Aldrighi, pelo seu amor, carinho e compreensão em despender horas de nossos momentos, em troca da minha vida científica.

Ao Dr. Fábio Busnardo, fraterno amigo de longa data, pela presença, o auxílio e a orientação em diversos momentos da minha vida.

Ao Dr. Dov Charles Goldenberg, pela amizade, a orientação e o auxílio na minha vida profissional.

Ao Dr. Luiz Henrique Ishida, grande amigo e responsável direto pela pesquisa pioneira em retalhos vascularizados por artérias perfurantes. Se houve um início, foi com ele no serviço de verificação de óbitos. 
Ao Dr. José Roberto Filassi, pelas orientações, o apoio, a confiança e a receptividade no início da minha vida profissional.

Ao Dr. Rogério Izar Neves, amigo e incentivador, pela ajuda nos momentos iniciais da minha carreira.

Ao Prof. Dr. José Mendes Aldrighi, pelas valiosas correções e sugestões proferidas nesta dissertação.

Ao Dr. José Carlos Marques de Faria, pelos sólidos ensinamentos na área da microcirurgia.

Ao Dr. Gustavo Gibim Duarte, pela grande ajuda no início da estruturação do grupo de reconstrução mamária.

Aos Prof. Dr. Henri Friedhofer, Diógenes Laércio da Rocha, Júlio Morais Besteiro, Jorge Ishida, Miguel Modolin e Luiz Kamakura, pelos ensinamentos valiosos, as sugestões e os conselhos externados durante o período da residência e, sobretudo, pela postura ética com que encararam a vida profissional.

Aos Drs. Eduardo Montag, Klaus Werner Fels e Eduardo Gustavo Pires de Arruda, amigos e companheiros, pelo auxílio no grupo de reconstrução mamária e em diversos momentos desta tese e de outros trabalhos científicos. Meus sinceros reconhecimentos.

Aos colegas mastologistas, pela oportunidade de constituir um grupo sólido: Doutores Antônio Carlos Nisida, Carlos Ruiz, Eliza Muranaka, Elisabeth Mesquita, Lincon Mori, José Roberto Piato, Luiz Carlos Prado, Marcos Desidério Ricci, Marianne Pinotti, Sílvio Bromberg e Sergio Mendes. Muitas das indagações e questionamentos que levaram a esta tese partiram da convivência no âmbito da reconstrução mamária. 
Aos Drs. Felipe Lehman Coutinho, Maria Luiza Ramos e Carlos Komatsu, pela oportunidade dos meus primeiros contatos com a área de reconstrução mamária.

Aos residentes de cirurgia plástica Fábio Lopes Saito, Hugo Nakamoto, Gustavo Sturtz e Alberto Yoshikazu pelo auxílio nas dissecções e na elaboração desta tese.

Ao residente de cirurgia geral Hélio Ricardo Nogueira Alves, pela revisão bibliográfica e o auxílio nas dissecções anatômicas realizadas nesta tese e em outros trabalhos.

À Sra. Maria Paula Zanardi Chicarino Rosa, pela colaboração na análise e revisão estatística dos dados apresentados nesta dissertação.

Ao Sr. Falcetti Junior, pela atenção e ilustrações realizadas nesta tese.

À Sra. Maria Aparecida de Lourdes Castro Santos, bibliotecária do Setor de Indexação da Biblioteca Central da Faculdade de Medicina da Universidade de São Paulo, pela atenção especial na elaboração da ficha catalográfica.

À secretária Edna Maria Rodrigues dos Santos, pelo carinho, a paciência e a orientação nas etapas burocráticas da pós-graduação.

Aos técnicos de dissecção anatômica do serviço de verificação de óbitos, pelo auxílio na preparação dos cadáveres utilizados neste estudo.

A todos os membros da Disciplina de Cirurgia Plástica da Faculdade de Medicina da Universidade de São Paulo, que tiveram participação direta e indireta na produção desta dissertação. 
Sumário 


\section{SUMÁRIO}

\section{Lista de Abreviaturas}

Lista de Símbolos

\section{Resumo}

\section{Summary}

1.

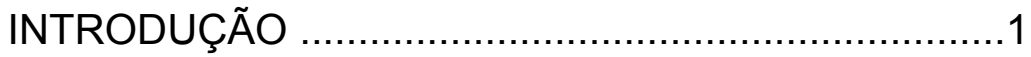

2. REVISÃO DA LITERATURA .................................11

3. CASUÍSTICA E MÉTODO.................................23

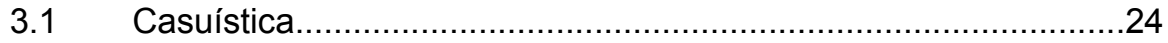

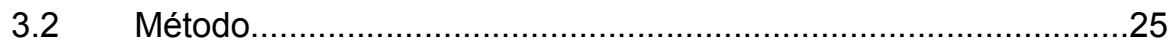

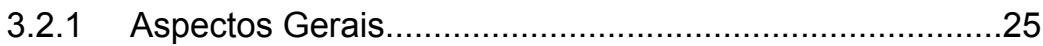

3.2.2 Técnica de estudo anatômico.......................................26

3.2.2.1 Mapeamento das artérias perfurantes..................30

3.2.2.2 Estudo da anatomia intramuscular.......................34

3.2.2.3 Artéria epigástrica inferior e ramificações.............36

3.2.2.4 Comprimento da artéria perfurante e do pedículo arterial...............................................36

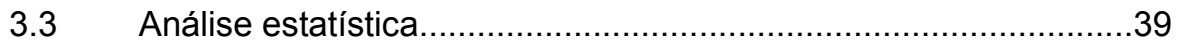


4.

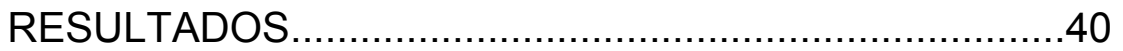

4.1 Mapeamento das artérias perfurantes.............................................

4.1.1 Número e localização das artérias perfurantes...........41

4.1.2 Calibre e localização das artérias perfurantes...........42

4.2 Trajeto intramuscular das artérias perfurantes................................45

4.3 Artéria epigástrica inferior e ramificações............................................51

4.3.1 Artérias perfurantes e ramos da artéria

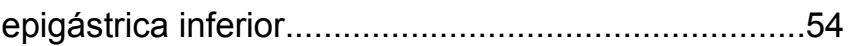

4.4 Comprimento da artéria perfurante e do pedículo arterial....................61

4.4.1 Comprimento da artéria perfurante...........................61

4.4.2 Comprimento do pedículo arterial.............................63

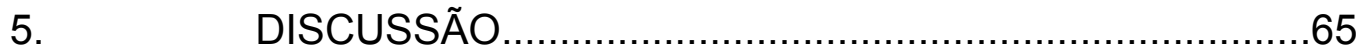

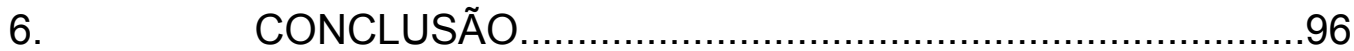

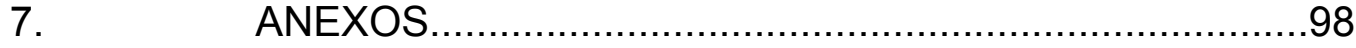

8. REFERÊNCIAS BIBLIOGRÁFICAS ............................111 
Lista de Abreviaturas 


\section{LISTA DE ABREVIATURAS}

A

$A^{\prime}$

ABNT

a.C.

apud

B

B1

B2

BR.

C

C'

cap.

cols.

CAP

CP

CFTA

DIEP

dir.

Dr. limite inferior da região abdominal inferior

origem da artéria epigástrica na artéria ilíaca externa

Associação Brasileira de Normas Técnicas

antes de Cristo

citado por

limites laterais da região abdominal inferior

região de entrada da artéria perfurante no músculo reto

do abdome

região de saída da artéria perfurante no músculo reto do

abdome

Brasil

limite superior da região abdominal inferior

região de entrada da artéria perfurante no panículo

adiposo

capítulo

colaboradores

comprimento da artéria perfurante

comprimento do pedículo vascular do retalho

Comissão Federativa da Terminologia Anatômica

retalho perfurante da artéria epigástrica inferior

direito

Doutor 


$\begin{array}{ll}\text { Dra. } & \text { Doutora } \\ \text { ed. } & \text { edição } \\ \text { esq. } & \text { esquerdo } \\ \text { et al. } & \text { e outros } \\ \text { FIAA } & \text { Federação Internacional de Associações de Anatomistas } \\ \text { fig. } & \text { figura } \\ \text { FMUSP } & \text { Faculdade de Medicina da Universidade de São Paulo } \\ \text { Lat. } & \text { região lateral do músculo reto do abdome } \\ \text { Med. } & \text { região medial do músculo reto do abdome } \\ \text { n. } & \text { número } \\ \text { obl. } & \text { trajeto oblíquo da artéria perfurante } \\ \text { Prof. } & \text { Professor } \\ \text { p. } & \text { página } \\ \text { TRAM } & \text { retalho transverso do músculo reto do abdome } \\ \text { ret. } & \text { trajeto retilíneo da artéria perfurante } \\ \text { rev. } & \text { revista } \\ \text { R.L. } & \text { ramo lateral da artéria epigástrica inferior } \\ \text { R.M. } & \text { ramo medial da artéria epigástrica inferior } \\ \text { R.U. } & \text { ramo único médio-lateral da artéria epigástrica inferior } \\ \text { SVOC } & \text { Serviço de Verificação de Óbitos da Capital } \\ \text { trad. } & \text { Universidade de São Paulo } \\ \text { USA } & \end{array}$


Lista de Símbolos 
LISTA DE SÍMBOLOS

$\begin{array}{ll} \pm & \text { mais ou menos } \\ \% & \text { porcentagem } \\ = & \text { igual } \\ > & \text { maior } \\ < & \text { menor } \\ \mathrm{cm} & \text { centímetro } \\ \mathrm{kg} & \text { kilograma } \\ \mathrm{m} & \text { metro } \\ \mathrm{MHz} & \text { megahertz } \\ \mathrm{ml} & \text { mililitro } \\ \mathrm{mm} & \text { milímetro } \\ \text { (B) } & \text { marca registrada } \\ \mathrm{P} & \text { direitos reservados } \\ \mathrm{x} & \text { versus }\end{array}$


Resumo 
Munhoz, Alexandre M. Estudo crítico da anatomia arterial do retalho vascularizado pela artéria perfurante muscular da artéria epigástrica inferior. São Paulo, 2004. 129p. Dissertação (mestrado) - Faculdade de Medicina da Universidade de São Paulo. Disciplina de Cirurgia Plástica

A utilização dos retalhos músculo-cutâneos na cirurgia plástica possibilitou grande avanço nas técnicas de reconstrução. Apesar de atualmente se apresentarem como técnica conhecida e reprodutível, existem ainda limitações quanto à morbidade na área doadora advinda da ressecção muscular. O desenvolvimento dos retalhos perfurantes e a aplicação clínica do retalho vascularizado na artéria perfurante muscular da artéria epigástrica inferior (DIEP) possibilitaram nova opção terapêutica em decorrência da completa preservação músculo-aponeurótica. Apesar dos benefícios funcionais em relação aos tradicionais retalhos músculo-cutâneos, o retalho DIEP exibe limitações como o tempo cirúrgico prolongado, a dificuldade técnica e o risco de lesão da artéria perfurante no trajeto intramuscular, todos decorrentes do calibre reduzido das artérias e da variabilidade anatômica. Embora a anatomia do músculo reto do abdome tenha sido exaustivamente estudada, escassas e imprecisas são as informações sobre a distribuição das artérias perfurantes, o trajeto intramuscular e as características do pedículo arterial. No presente estudo, a distribuição, o trajeto intramuscular e as dimensões do pedículo do retalho DIEP foram estudados em 15 cadáveres frescos não formolizados (30 retalhos) por técnica de coloração com tinta azul látex e posterior dissecção. Constatou-se 6,3 artérias perfurantes por retalho, sendo que a maior parte das artérias de médio e grande calibre localizavam-se na região lateral do músculo reto do abdome. $\mathrm{Na}$ análise do trajeto intramuscular foram classificadas de artérias com trajeto retilíneo, aquelas localizadas exclusivamente no septo muscular e sua dissecção foi realizada sem secção das fibras musculares. No trajeto oblíquo, se evidenciou mais de um septo muscular e houve a necessidade de se realizar a secção muscular. As artérias perfurantes da região lateral apresentaram trajeto retilíneo em maior número quando comparadas às artérias da região medial do músculo reto do abdome. Na maioria das 
dissecções, a artéria epigástrica inferior mostrou dois ramos principais sendo o calibre do ramo lateral maior ao do ramo medial. A maioria das artérias perfurantes de médio e grande calibres apresentaram origem no ramo lateral dominante da artéria epigástrica inferior. As artérias perfurantes e o pedículo arterial do retalho revelaram comprimento médio de 5,3 e 15,7 cm respectivamente. $O$ pedículo arterial com a artéria perfurante proveniente da região medial apresentou comprimento maior do que o pedículo que continha a artéria proveniente da região lateral. O presente estudo permitiunos concluir que a maior concentração de artérias perfurantes de maior calibre e a presença do trajeto retilíneo na região lateral do músculo reto do abdome, constituíram parâmetros anatômicos importantes no planejamento da técnica. As conclusões obtidas reforçam a relevância dos estudos anatômicos na programação da reconstrução com retalhos vascularizados por artérias perfurantes. 
Summary 
Munhoz, Alexandre M. A critical analysis of the arterial anatomy of the deep inferior epigastric perforator flap. São Paulo, 2004. 129p. Dissertação (mestrado) - Faculdade de Medicina da Universidade de São Paulo. Disciplina de Cirurgia Plástica.

The introduction of musculocutaneous flaps in plastic surgery has resulted in a great step forward in reconstructive procedures. In spite of their well-known and reproducible technique, their use is limited by morbidity in the donor area resulting from muscle resection. The development of perforator flap and the clinical application of the deep inferior epigastric flap (DIEP) has provided a new therapeutic option resulting from complete muscle-aponeurotic preservation. Despite the functional benefits achieved in comparison to traditional musculocutaneous flaps, the DIEP flap has limitations. The latter include prolonged operative time, technical difficulty and the risk of injury to the perforating artery in the intramuscular pathway. These factors result from reduced diameter of the arteries and to anatomic variation. Although anatomy of the rectus abdominus muscle has already been studied, information regarding distribution of the perforator arteries, intramuscular pathway, and characteristics of the arterial pedicle is lacking and inaccurate. In this thesis, the distribution, intramuscular pathway and pedicle size of the DIEP flap were studied in 15 fresh cadavers. Thirty flaps were analyzed by staining with blue latex dye and subsequent dissection. An average of 6.3 perforator arteries per flap were observed, and the major concentration of medium and large diameter arteries in the lateral region of the rectus muscle. The intramuscular pathway analysis classified the arteries as rectilinear, those located solely in the muscle septum and their dissection was performed without muscle fibers section. In the oblique pathway, not a single septum was observed and muscle section was necessary. A larger number of the perforator arteries of the lateral region presented a rectilinear path compared to the arteries of the medial region. In the majority of dissections, the inferior epigastric artery exhibited two main branches with the lateral branch diameter greater than that of the medial branch. The majority of the perforator arteries of medium and large diameter originated in the dominant lateral branch of the IEA. The perforator arteries and the arterial pedicle of the flap displayed a mean length of 5.3 and $15.7 \mathrm{~cm}$ respectively. The arterial pedicle presenting the perforator artery originating from the medial region was longer than the pedicle containing the artery originating from the lateral region. The major concentration of perforator arteries of larger diameter besides being rectilinear in the lateral region of the rectus muscle establishes 
important parameters for technical planning. The results obtained in this study emphasize the importance of the anatomic studies in planning reconstructions with perforator flaps. 
1. Introdução

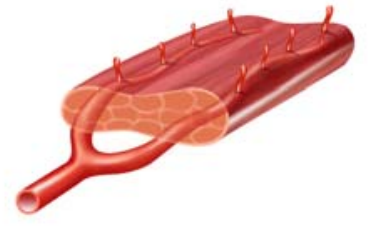


No último século a reconstrução de partes moles decorrentes de deformidades congênitas, traumáticas e oncológicas tem sido um permanente tópico de pesquisa e desafio à cirurgia plástica.

O desenvolvimento de novos procedimentos, associado ao aprimoramento técnico, possibilitou o tratamento de inúmeras afecções com resultados satisfatórios do ponto de vista estético e funcional.

Nesta evolução, a descoberta empírica dos retalhos cutâneos por SUSHRUTA SAMHITA (600 a.c.) apud SMITH; PRIBAZ (2000) resultou no início não apenas da cirurgia reparadora mas também da prática cirúrgica em geral.

Apesar de séculos de avanços e inúmeros progressos pontuais no âmbito cirúrgico, somente a partir do século XX, com a presença de defeitos complexos oriundos da cirurgia oncológica e das grandes guerras mundiais, surgiram novas formas de abordagem e tratamento com melhores resultados e um menor índice de complicações (MCCARTHY, 1990; SMITH; PRIBAZ, 2000).

O desenvolvimento dos retalhos musculares e a associação com segmentos de tecido cutâneo adjacente, característica dos retalhos músculocutâneos, propiciaram novas alternativas de tratamento frente aos retalhos cutâneos tradicionais (HUESTON; MCCONCHIE, 1968; MCCRAW; DIBBEL 1977, MCCRAW et al., 1977; MATHES; ESHIMA, 1990). 
No entanto, em algumas situações específicas como nas reconstruções mamárias pós mastectomias, nas deformidades traumáticas dos membros inferiores e em defeitos complexos do segmento cefálico eram escassas as possibilidades de reconstrução com tecido autógeno (MCCARTHY, 1990). De acordo com a região a ser reconstruída, as principais técnicas disponíveis se restringiam aos retalhos cutâneos tubulares (GILLES, 1920; MILLARD, 1976), aos retalhos abdominais (DREVER, 1977) e ao retalho músculo-cutâneo do grande dorsal (TANZINI, 1906 apud SMITH; PRIBAZ, 2000; BOSTWICK et al., 1978). Apesar de algumas técnicas se apresentarem reprodutíveis, a falta de volume e a extensão cutânea limitada destes retalhos tornavam as reconstruções inviáveis ou insatisfatórias do ponto de vista estético.

A partir da década de 70 , objetivando melhores resultados, o estudo de novos retalhos se tornou objeto de pesquisa em inúmeros centros, além de uma constância na cirurgia reconstrutora (SERAFIN et al., 1978; MCCRAW et al., 1979; HARTRAMPF et al., 1982; MCCARTHY, 1990; SMITH; PRIBAZ 2000)

O advento da microcirurgia e a melhor compreensão da anatomia vascular cutânea trouxeram inúmeras novas contribuições técnicas ao arsenal do cirurgião plástico (JACOBSEN; SUAREZ, 1960; BUNCKE; SCHULZ, 1965; DANIEL; TAYLOR, 1973; HARII et al., 1974; FERREIRA et al., 1975). A possibilidade da manipulação cirúrgica de estruturas de menor calibre e a transferência de tecidos à distância pela realização de 
anastomoses microcirúrgicas propiciaram o maior número de opções de áreas doadoras e de tecidos com melhor qualidade.

A introdução do retalho transverso do músculo reto do abdome (TRAM) por HOLMSTRÖM (1979) e a associação com a transferência microcirúrgica promoveram grande avanço em termos de resultado estético e funcional no tratamento de determinadas afecções. A versatilidade do retalho TRAM associado à sua anatomia constante e reprodutível colocaram-no como um dos retalhos mais utilizados, não apenas na reconstrução mamária, mas também em outras regiões do corpo (HARTRAMPF; BENNETT, 1987; CARRAMASCHI et al., 1989; GROTTING et al., 1989; ELLIOT; HARTRAMPF, 1990; CARRAMASCHI et al., 1992; KROLL; MARCHI, 1992; SCHUSTERMANN, 1992; BESTEIRO et al., 1994; MUNHOZ et al., 2002a; MUNHOZ et al., 2002b).

Ainda que inicialmente descrito na forma de retalho livre, o retalho TRAM teve sua maior divulgação na forma pediculada a partir dos trabalhos de HARTRAMPF et al. (1982). Além do resultado satisfatório na área doadora, a principal vantagem relacionava-se ao volume de tecido suficiente para as grandes reconstruções. Por isso, a reconstrução da mama pós mastectomia apresentou grande impulso técnico advindo das características presentes no retalho TRAM. O volume de pele e tecido gorduroso adequados, a presença de vascularização segura aliado ao benefício da cicatriz resultante se assemelhar à dermolipectomia estética, representaram as principais vantagens do emprego do retalho TRAM na cirurgia oncológica da mama. 
A despeito destas características, na execução do retalho TRAM havia a necessidade de incorporar um segmento do músculo reto do abdome ao retalho cutâneo-gorduroso, visando assegurar a presença das artérias perfurantes. Desta forma, no retalho TRAM pediculado utilizava-se o músculo reto do abdome em toda a sua extensão, uni ou bilateralmente, dependendo da preferência do cirurgião e da extensão do defeito a ser reparado (HARTRAMPF et al., 1982). Já no retalho TRAM microcirúrgico, um segmento de músculo proveniente da região infraumbilical era dissecado em conjunto com o retalho cutâneo-gorduroso permitindo-se, assim, a preservação das artérias perfurantes principais (HÖLMSTROM, 1979; CARRAMASCHI et al., 1992; SCHUSTERMAN et al., 1992; MUNHOZ; FERREIRA, 2000).

Entretanto, o retalho TRAM não se isentava de morbidade e complicações. A partir da década de 80 surgiram questionamentos em relação à ressecção do músculo reto do abdome e suas implicações na dinâmica da parede do abdome (BUNKIS et al., 1983; SCHEFLAN; DINNER, 1983; HARTRAMPF, 1984; HARTRAMPF; BENNETT, 1987; GROTING et al., 1989; KOSHIMA; SOEDA, 1989; LE JOUR; DOME, 1991; KROLL; MARCHI, 1992; SCHUSTERMAN et al., 1992; ELLIOT et al., 1993; FELLER, 1994; MIZGALA et al., 1994; SUOMINEM et al., 1996; MUNHOZ; FERREIRA, 2000; MUNHOZ et al., 2002a; MUNHOZ et al., 2002b; CRAIGIE et al., 2003; MUNHOZ et al., 2003; MUNHOZ et al., 2004a; GILL et al., 2004). 
Com a introdução do conceito de retalhos perfurantes por KOSHIMA e SOEDA em 1989 e a aplicação clínica do retalho vascularizado pela artéria perfurante muscular da artéria epigástrica inferior (DIEP) por ALLEN e TREECE em 1994, surgiu nova opção terapêutica decorrente da completa preservação muscular.

O retalho DIEP apresenta o segmento de pele e panículo adiposo semelhante ao dos retalhos TRAM pediculado e microcirúrgico. A vascularização ocorre pela artéria epigástrica inferior e os ramos perfurantes principais. O detalhe técnico da dissecção das artérias perfurantes contidas no músculo reto do abdome permite a preservação do tecido muscular e, portanto a separação do tecido muscular do tecido cutâneo-gorduroso do abdome.

Dessa maneira, cria-se a possibilidade de transferência de regiões semelhantes de pele e de panículo adiposo correspondentes aos retalhos TRAM pediculado e microcirúrgico, sem as desvantagens inerentes à transferência muscular (KOSHIMA; SOEDA, 1989; KOSHIMA et al., 1992; ALLEN; TREECE, 1994; BLONDEEL, 1997; BLONDEEL et al., 1998; HAMDI et al., 1998; BLONDEEL et al., 1999; MUNHOZ et al., 2001; ISHIDA et al., 2002; VANDEVOORT et al., 2002; CRAIGIE et al., 2003; MUNHOZ et al., 2003; MUNHOZ et al., 2004a; GILL et al., 2004).

Apesar dos benefícios funcionais do retalho DIEP em relação aos retalhos músculo-cutâneos, esta técnica também não se isentava de limitações como o tempo cirúrgico prolongado e o risco de lesão das artérias perfurantes durante a dissecção do trajeto intramuscular. Estas 
desvantagens são decorrentes da necessidade de instrumentos apropriados de microcirurgia, do amplo conhecimento da anatomia local e da familiaridade com a técnica.

A anatomia da distribuição das artérias perfurantes em específico e, principalmente, detalhes em relação ao trajeto intramuscular constituem limitações para a reprodutibilidade do procedimento (KOSHIMA; SOEDA, 1989; BLONDEEL et al., 1999; MUNHOZ et al., 2001; VANDEVOORT et al., 2002; MUNHOZ et al., 2004a).

Neste sentido, a anatomia topográfica descritiva desempenha importante papel, pois é imprescindível o preciso conhecimento da anatomia local no planejamento, na dissecção e na transferência do retalho para a região a ser reparada.

Inúmeros são os estudos que avaliaram no âmbito da cirurgia geral a anatomia do músculo reto do abdome, interessando o tecido muscular, fáscias e aponeuroses e sua relação com o tratamento das deformidades da parede do abdome. A maioria relata especificamente a anatomia das artérias epigástricas sem descrições detalhadas sobre os ramos musculares e músculo-cutâneos, o trajeto intramuscular e a distribuição das artérias perfurantes na região do abdome inferior. A ausência de aplicação prática destas informações concentrou a investigação anatômica da parede do abdome ao conjunto de fáscias e aponeuroses musculares e suas implicações na dinâmica funcional (VESALIUS, 1543; TESTUT; LATARGET, 1902; GARDNER et al., 1975; HOLLINSHEAD, 1980; KAMINA, 1983; MOORE, 1985; ROSSE; GADDUM-ROSSE, 1997). Embora tenham sua 
importância no contexto descritivo anatômico e apresentam relevância no tratamento destas afeç̧ões, não permitem chegar à elucidação da distribuição e do trajeto das artérias perfurantes do músculo reto do abdome e, portanto da real reprodutibilidade do retalho DIEP.

Os estudos mais detalhados surgiram a partir da aplicação clínica dos retalhos cutâneos e, sobretudo dos retalhos músculo-cutâneos, associado à necessidade do conhecimento detalhado da anatomia vascular na programação cirúrgica.

Da mesma forma, o aprimoramento da técnica da lipo-abdominoplastia e a necessidade do melhor conhecimento da anatomia arterial do abdome com objetivo de preservação das artérias perfurantes estimularam novas pesquisas anatômicas no âmbito da cirurgia estética do abdome (AVELAR, 2000; SALDANHA et al., 2001; GRAF et al., 2004).

Diferentemente dos trabalhos precedentes publicados em livros textos e atlas de anatomia descritiva, os estudos mais meticulosos sobre a anatomia vascular da região do abdome foram comunicados em revistas específicas de cirurgia plástica. Nestes trabalhos as investigações descritivas decorreram de dissecções anatômicas em cadáveres frescos, mapeamentos radiológicos e da utilização da ultra-sonografia Doppler.

Associado a estas descrições anatômicas, diversos autores informaram sobre suas experiências clínicas o que permitiu a obtenção de dados mais detalhados sobre a vascularização dos músculos reto do abdome, as artérias perfurantes e a sua distribuição no tecido subcutâneo e na pele (MILLOY et al., 1960; HADDAD, 1968; BROWN et al., 1975; NAHAl et al., 
1976; HOLMSTRÖM, 1979; BOYD et al., 1984; HESTER et al., 1984; TAYLOR et al., 1984; MILLER et al., 1988; MOON; TAYLOR, 1988; KOSHIMA et al., 1992; ITOH; ARAI, 1993; ALLEN; TREECE 1994; BLONDEEL et al., 1998; BLONDEEL et al., 1999; HAMDI et al., 1999; HEITMANN et al., 2000; MUNHOZ et al., 2001; MRAKBY; MILNER, 2002; VANDEVOORT et al., 2002; CRAIGIE et al., 2003; GRAF et al., 2004; MUNHOZ et al., 2004a; MUNHOZ et al., 2004b).

Contudo, após 40 anos da descrição das artérias perfurantes da artéria epigástrica inferior (MILLOY et al., 1960) persistem dados contraditórios em relação à sua localização e distribuição e pouco se conhece sobre o seu trajeto no músculo reto do abdome e, sobretudo da relevância destas informações no planejamento e na execução do retalho DIEP (BLONDEEL et al., 1999; MUNHOZ et al., 2001; VANDERVOORT et al., 2002; MUNHOZ et al., 2004a). 
Por esses motivos, interessamo-nos em definir os aspectos da anatomia vascular arterial do retalho DIEP em cadáveres frescos do sexo feminino a partir dos seguintes itens:

I. A distribuição espacial e o calibre das artérias perfurantes musculares do músculo reto do abdome na região infra-umbilical.

II. O trajeto intramuscular das artérias perfurantes e a relação com o padrão de distribuição das artérias perfurantes.

III. Os ramos da artéria epigástrica inferior e a relação com as artérias perfurantes.

IV. O comprimento da artéria perfurante e do pedículo arterial. 
2. Revisão da Literatura 
Atribui-se a ANDREAS VESALIUS, em 1543, na obra intitulada "De Humani Corporis Fabrica", a primeira observação sobre a vascularização dos músculos retos do abdome. O autor, então professor de anatomia na Universidade de Pádua, Itália, observou e descreveu em pinturas sobre o corpo humano, sem nomear, os músculos retos do abdome e as artérias epigástricas inferiores (RUTKOW, 1993).

TESTUT; LATARGET (1902) baseados em estudos anatômicos descreveram a vascularização do músculo reto do abdome e nomearam a artéria mamária interna, na região epigástrica superior e a artéria epigástrica, na região do abdome inferior; descreveram, ainda, a anastomose entre as duas artérias na região posterior do músculo reto do abdome.

MILLOY et al. (1960) dissecando cadáveres formolizados relataram a anatomia dos músculos retos do abdome, as inserções tendíneas e a vascularização proveniente das artérias epigástricas; ademais, descreveram que em $86 \%$ das dissecções a presença de um ramo único da artéria epigástrica inferior e em $14 \%$ a presença de dois ramos na região posterior do músculo reto do abdome. Notaram ainda, a anastomose intramuscular entre as artérias epigástricas superiores e inferiores, além da presença dos ramos perfurantes musculares provenientes da artéria epigástrica inferior.

HADDAD (1968), utilizando material radiopaco, avaliou a vascularização arterial da parede ântero-lateral do abdome e confirmou a presença das artérias epigástricas superior e inferior; o estudo relatou a presença de anastomoses vasculares entre as artérias epigástricas e a descrição das artérias perfurantes peri-umbilicais, bem como em uma das 
peças anatômicas constatou-se a presença de artérias perfurantes de maior calibre na região próxima ao umbigo, sugerindo sua importância na vascularização da parede do abdome.

BROWN et al. (1975), na execução de dermolipectomias abdominais, observaram a presença de inúmeras artérias perfurantes com calibre entre 0,5 e $1,5 \mathrm{~mm}$, provenientes do músculo reto do abdome; notaram que a distribuição preferencial das artérias era na região compreendida entre as linhas semilunares e próximas à região do umbigo.

GARDNER et al. (1975) descreveram o trajeto ascendente da artéria epigástrica inferior e a vascularização do músculo reto do abdome, tecidos adjacentes e a pele, sem a nomeação do ramo específico para cada estrutura.

NAHAl et al. (1976), baseados em constatações clínicas, salientaram a importância do conhecimento da vascularização do abdome e a relação com o planejamento das incisões cirúrgicas. Descreveram a arcada epigástrica formada pela anastomose entre as artérias epigástricas superior e inferior e confirmaram os achados de BROWN (1975) sobre as artérias perfurantes músculo-cutâneas e sua importância na vascularização da pele do abdome.

HOLMSTRÖM (1979) descreveu o retalho transverso do músculo reto do abdome (TRAM) e fez considerações sobre a anatomia das artérias epigástricas inferiores e as artérias perfurantes. Previamente à realização do primeiro caso clínico, realizou o estudo da vascularização da região do abdome inferior pela arteriografia da artéria epigástrica inferior e dos ramos perfurantes. Relatou que o comprimento médio do pedículo vascular era de 
$12 \mathrm{~cm}$ e existia maior número de artérias perfurantes na região periumbilical.

HOLLINSHEAD (1980), em livro texto de anatomia descritiva, discorreu sobre a região posterior do músculo reto do abdome e as artérias epigástricas superiores e inferiores. Descreveu a anastomose arterial na região intramuscular e as anastomoses laterais das artérias epigástricas com os ramos das artérias intercostais.

PENNINGTON et al. (1980) relataram a utilização do TRAM em dois casos clínicos de reconstrução da região cefálica. Descreveram as características do pedículo vascular do retalho TRAM que apresentava comprimento médio de $15 \mathrm{~cm}$ e o calibre das artérias perfurantes entre $2,5 \mathrm{e}$ $3,0 \mathrm{~mm}$.

KAMINA (1983), em publicação de atlas e dicionário de anatomia humana, descreveu a artéria epigástrica inferior e a sua origem na artéria ilíaca externa, próxima à região localizada a $1 \mathrm{~cm}$ acima do ligamento inguinal. Descreveu os ramos musculares e cutâneos e a anastomose intramuscular entre as artérias epigástricas inferior e superior.

BOYD et al. (1984), aplicando injeções intra-arteriais de substância radiopaca em cadáveres, descreveram detalhadamente a distribuição das artérias perfurantes e a anatomia das artérias epigástricas. Dividiram o músculo reto do abdome em 15 regiões principais de acordo com limites anatômicos padronizados. Relataram três tipos principais de artérias perfurantes: as artérias músculo-cutâneas provenientes do músculo reto do abdome, as artérias fáscio-cutâneas originárias da linha alba e as artérias 
fáscio-cutâneas provenientes da aponeurose do músculo oblíquo externo. Classificaram ainda dois tipos de artérias perfurantes de acordo com o calibre: as que apresentavam calibre maior do que $0,5 \mathrm{~mm}$ foram classificadas como artérias de grande calibre e as que apresentavam o calibre inferior a $0,5 \mathrm{~mm}$, de pequeno calibre. Verificaram que existia maior concentração de artérias perfurantes nos dois terços mediais do músculo reto do abdome. Adicionalmente havia maior concentração de artérias na região peri-umbilical, e menor na região próxima ao púbis. As artérias músculo-cutâneas eram, em sua maioria, de grande calibre e as artérias fáscio-cutâneas, de pequeno calibre. Em relação à anatomia da artéria epigástrica inferior, observaram que existia a divisão em dois ramos principais e ocasionalmente em três ramos na região compreendida entre a sínfise púbica e o umbigo. As artérias perfurantes tinham origem nos ramos laterais e mediais e apresentavam trajeto através do músculo reto do abdome em direção ao panículo adiposo.

HESTER et al. (1984), estudando a anatomia vascular da parede do abdome, descreveram a importância das artérias epigástricas na irrigação sanguínea do abdome. Salientaram que a origem primária da irrigação sanguínea da região do abdome inferior provinha das artérias perfurantes oriundas das artérias epigástricas inferiores.

TAYLOR et al. (1984), descreveram as principais regiões de vascularização da região do abdome inferior e a sua correlação na programação do retalho TRAM. Verificaram que existiam artérias perfurantes de maior calibre na região peri-umbilical e a formação de conexões 
vasculares com outros territórios no tecido subcutâneo e no plexo subdérmico.

MOORE (1985) descreveu a vascularização da parede ântero-lateral do abdome e enfatizou os principais pedículos vasculares desta região. Citou a importância das artérias epigástrica inferior e circunflexa profunda do íleo na região do abdome inferior e da artéria epigástrica superior na região do abdome superior. Relatou a linha arqueada como a região de entrada da artéria epigástrica inferior na bainha posterior do músculo reto do abdome.

MILLER et al. (1988) descreveram a origem da artéria epigástrica inferior na artéria ilíaca externa e o seu trajeto ascendente até a região localizada $6 \mathrm{~cm}$ acima do púbis. Nesta região, a artéria atingiu a margem lateral do músculo reto do abdome e dividiu-se em dois ramos principais com calibres semelhantes. Definiram que a maioria das artérias perfurantes músculo-cutâneas tinham origem na região próxima ao umbigo.

MOON; TAYLOR (1988) descreveram três padrões de divisão da artéria epigástrica inferior: no tipo I, observado em $29 \%$ das dissecções, a artéria epigástrica não apresentou divisões e seguiu o trajeto ascendente próximo à margem lateral do músculo reto do abdome. No tipo II, representado em $57 \%$ das dissecções, a artéria epigástrica se dividiu em dois ramos principais (lateral e medial) e no tipo III, representado em $14 \%$ das dissecções, a artéria epigástrica se dividiu em três ramos principais. Descreveram o trajeto da artéria epigástrica inferior e a relação dos ramos perfurantes com a linha arqueada. A maioria das artérias perfurantes músculo-cutâneas tiveram origem na região localizada superiormente a linha 
arqueada e, em específico, na região peri-umbilical. Todavia, as artérias perfurantes musculares localizaram-se inferiormente a linha arqueada.

KOSHIMA; SOEDA (1989) relataram os primeiros dois casos clínicos de reconstrução com retalho DIEP e enfatizaram que a maioria das artérias perfurantes, em número de 4 a 5 artérias por segmento do músculo reto do abdome, estavam localizadas na região próxima ao umbigo. Citaram o calibre reduzido, a variabilidade na distribuição anatômica e a dificuldade técnica de dissecção como as maiores limitações para a ampla aplicação clínica do retalho.

KOSHIMA et al. (1992), baseados na experiência clínica, relataram a técnica cirúrgica do retalho DIEP em 13 reconstruções dos membros inferiores e de cabeça e pescoço. As artérias epigástricas inferiores apresentaram o trajeto na região posterior do músculo reto do abdome e emitiram os ramos perfurantes próximos à região do umbigo. Descreveram o trajeto intramuscular retilíneo, no qual havia a presença de vários ramos musculares que irrigavam as fibras do músculo reto do abdome.

ITOH; ARAI (1993), relataram os ramos da artéria epigástrica inferior e a distribuição dos ramos perfurantes. Em $82,4 \%$ das dissecções, foram observados dois ramos principais sendo que, em $88,2 \%$, o ramo definido como lateral apresentava maior calibre que o ramo medial. Em 17,6\% havia a presença de três ou mais ramos. Em relação à distribuição das artérias perfurantes, foi observada a média de 6,5 artérias com calibre superior a 0,5 mm e com maior concentração na região médio-lateral do músculo reto do abdome. 
ALLEN; TREECE (1994) relataram a primeira experiência clínica da utilização do retalho DIEP na reconstrução da mama pós mastectomia. Os autores, assim como KOSHIMA em 1992, descreveram a técnica cirúrgica e a dissecção das artérias perfurantes no músculo reto do abdome. Houve o relato da abertura do músculo reto do abdome no sentido das fibras musculares e a presença do trajeto intramuscular retilíneo com vários ramos musculares.

MATHES; NAHAI (1997), em uma análise descritiva de retalhos músculo-cutâneos, relataram as principais características anatômicas do retalho TRAM. Citam a maior concentração de artérias perfurantes na região peri-umbilical e comprimento da artéria epigástrica de aproximadamente 5 $\mathrm{cm}$.

ROSSE; GADDUM-ROSSE (1997) descreveram o trajeto ascendente da artéria epigástrica inferior no espaço entre o músculo reto do abdome e a fáscia transversal. As artérias perfurantes são mencionadas como ramos arteriais cutâneos que acompanhavam os nervos em direção à pele.

BLONDEEL et al. (1998) realizaram o mapeamento da parede do abdome através do aparelho de Doppler unidirecional de $5 \mathrm{MHz}$. No retalho DIEP foram observados de 4 a 5 artérias perfurantes por músculo reto do abdome tendo, em sua maioria, origem na intersecção tendínea muscular. Houve maior concentração de artérias perfurantes na região compreendida pelos limites: $2 \mathrm{~cm}$ no sentido superior e $6 \mathrm{~cm}$ no sentido inferior ao umbigo e 2 a $6 \mathrm{~cm}$ lateral à linha alba. Na análise das artérias epigástricas, foram identificados dois padrões anatômicos distintos. Em 72\% foram observados 
dois ramos principais, sendo que em $54 \%$ o ramo lateral apresentou maior calibre que o ramo medial. Em $28 \%$ das análises foi observada a presença de um único ramo central da artéria epigástrica inferior.

BLONDEEL et al. (1999), na descrição de aspectos técnicos da dissecção do retalho DIEP, realizaram importantes observações em relação ao tipo de trajeto intramuscular e a correlação com a localização da artéria perfurante. As artérias perfurantes localizadas na região lateral do músculo reto do abdome apresentavam o trajeto intramuscular perpendicular ao ramo lateral da artéria epigástrica inferior e, portanto com maior facilidade técnica na dissecção. Contudo, as artérias perfurantes localizadas na região medial apresentavam o trajeto intramuscular mais extenso e não retilíneo e, portanto de dissecção mais difícil.

HAMDI et al. (1999) descreveram a experiência em 50 reconstruções mamárias com retalho DIEP e a presença de artérias perfurantes na região lateral e medial do músculo reto do abdome. Houve o relato da abertura longitudinal das fibras do músculo reto do abdome com a exposição do trajeto intramuscular retilíneo das artérias perfurantes.

HEITMANN et al. (2000) realizaram dissecções anatômicas em cadáveres frescos e mapearam a distribuição das artérias perfurantes com calibre superior à $1 \mathrm{~mm}$. Na maioria das dissecções, as artérias perfurantes de maior calibre encontravam-se a uma distância máxima de $4 \mathrm{~cm}$ do umbigo e o pedículo do retalho apresentou o comprimento médio de 10,3 $\mathrm{cm}$. 
MUNHOZ et al. (2001) relataram a anatomia intramuscular das artérias perfurantes da artéria epigástrica inferior por meio do estudo anatômico em cadáveres frescos. As artérias perfurantes apresentaram dois tipos de trajeto intramuscular através do músculo reto do abdome: o tipo retilíneo onde a artéria apresentava o trajeto curto, único e perpendicular através das fibras musculares e o tipo oblíquo onde artéria apresentava o trajeto longo e de maneira oblíqua através do músculo reto do abdome.

MRAKBY; MILNER (2002), estudaram a anatomia da artéria epigástrica inferior e a distribuição das artérias perfurantes em dissecções de 20 cadáveres frescos e formolizados. Em $80 \%$ das dissecções a artéria epigástrica inferior apresentou dois ramos principais localizados nas regiões lateral e medial do músculo reto do abdome. Nesta situação, em $80 \%$, o ramo lateral apresentou maior calibre que o ramo medial e o maior número de artérias perfurantes. Em 20\% das dissecções, constatou-se a presença de um terceiro ramo situado próximo ao umbigo. Em relação à distribuição das artérias perfurantes, houve a maior concentração na região súperolateral do músculo reto do abdome.

VANDEVOORT et al. (2002), em observações clínicas realizadas em 100 retalhos DIEP, relataram a primeira observação sobre o tipo de trajeto intramuscular e a correlação com a facilidade técnica de dissecção e o tempo operatório. Foram observados 5 tipos diferentes de trajeto intramuscular: o trajeto intramuscular curto (65\%), o trajeto através da intersecção tendínea (16\%); o trajeto intramuscular longo (9\%); o trajeto paramediano $(5 \%)$ e o trajeto subfascial $(5 \%)$. Nas situações onde a artéria 
perfurante apresentou o trajeto intramuscular curto houve maior facilidade na dissecção e o menor tempo operatório. Todavia, nas situações onde a artéria perfurante apresentou o trajeto intramuscular longo, através da intersecção tendínea e subfascial, houve maior dificuldade técnica na dissecção e, por conseguinte, maior tempo operatório. Na situação em que a artéria perfurante apresentou o trajeto tipo paramediano, a artéria era de pequeno calibre e não houve aplicação clínica.

CRAIGIE et al. (2003) descreveram os detalhes técnicos da dissecção do retalho DIEP e a aplicação na reconstrução mamária. Verificaram que existiu a distribuição preferencial das artérias perfurantes mais próximas às regiões lateral e medial do músculo reto do abdome. Na dissecção, houve a preferência na utilização das artérias localizadas na região lateral caso estas se apresentassem com calibre adequado. Na presença de artérias perfurantes com calibre pequeno, os autores preferiram a escolha das artérias situadas na região medial. Houve ainda a descrição do comprimento do pedículo vascular entre 9 e $14 \mathrm{~cm}$.

MUNHOZ et al. (2004a) relataram a anatomia intramuscular das artérias perfurantes da artéria epigástrica inferior e a relação com a experiência clínica em 31 reconstruções mamárias com o retalho DIEP. A característica do trajeto das artérias perfurantes nas fibras do músculo reto do abdome influenciou na dificuldade técnica de dissecção do retalho DIEP. Apesar da maior facilidade de dissecção das artérias perfurantes da região lateral, os autores enfatizaram a importância do calibre arterial no critério de escolha da artéria principal do retalho. 
GILL et al. (2004) em estudo retrospectivo de 758 reconstruções mamárias com retalho DIEP analisaram os resultados e os fatores de risco para complicações. As pacientes com antecedentes para doença cardiovascular, a presença de radioterapia prévia e o maior número de artérias perfurantes por retalho representaram fatores de risco para a maior incidência de complicações.

GRAF et al. (2004) realizaram o estudo das artérias perfurantes e a fluxometria em pacientes submetidas à lipoabdominoplastia estética. $O$ exame de ultra-sonografia Doppler permitiu a observação da média de 5 artérias perfurantes na região supra-umbilical do músculo reto do abdome.

MUNHOZ et al. (2004b) realizaram a avaliação anatômica da distribuição das artérias perfurantes do abdome por meio do mapeamento com ultra-sonografia Doppler em pacientes submetidas à cirurgia estética do abdome. Houve a presença de em média 4 artérias perfurantes por segmento supra-umbilical de músculo reto do abdome analisado. A maioria das artérias perfurantes apresentou a localização entre 2 e $6 \mathrm{~cm}$ a partir da linha alba. 
3. Casuística e Método

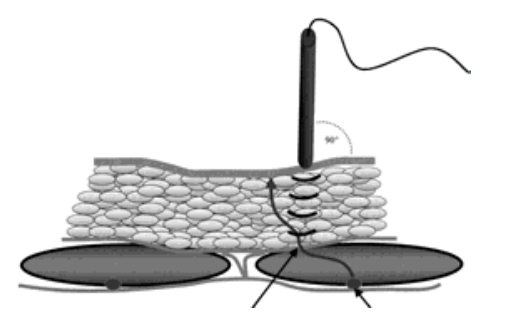




\subsection{Casuística}

Foram analisados 30 músculos retos do abdome associados à pele e à tela subcutânea correspondente na região infra-umbilical. Esta amostra foi pareada e era proveniente de 15 cadáveres humanos adultos frescos não formolizados, do sexo feminino e com no máximo 24 horas de óbito. Com esta padronização realizou-se o estudo anatômico individualizado da vascularização arterial do retalho vascularizado pela artéria perfurante muscular da artéria epigástrica inferior. O estudo foi aprovado pelo comitê de ética e pesquisa do HC-FMUSP e a dissecção seguiu as normas estabelecidas pelo serviço de verificação de óbitos da capital (SVOC). (Anexo)

Estas amostras foram de conveniência (VIEIRA, 1991) e, pelas condições possíveis onde foi colhida, obedeceram a seleção quanto aos critérios de inclusão e exclusão pertinentes ao estudo.

Considerou-se como critério de exclusão para a utilização do cadáver, a presença de antecedentes para doença arteriosclerótica caracterizados por: hipertensão arterial sistêmica, diabetes melitus, tabagismo, insuficiência arterial periférica e insuficiência coronariana. Foram também excluídos os cadáveres que apresentavam antecedentes ou sinais de cirurgias abdominais prévias caracterizadas por: laparotomias transversas, medianas 
e paramedianas localizadas na região infraumbilical e procedimentos cirúrgicos na região inguinal.

Incluíram-se no estudo oito cadáveres da raça branca, seis da raça negra e um da raça amarela. A idade variou entre 48 a 66 anos com média de 54 anos. O peso variou entre 65 a $79 \mathrm{~kg}(71,7 \pm 6,3)$ e a estatura, entre 1,55 a $1,69 \mathrm{~m}(1,65 \pm 8,1)$.

\subsection{Método}

\subsubsection{Aspectos Gerais}

Inicialmente foram coletados os dados referentes à identificação do cadáver, discriminados em idade, peso, altura e raça. A seguir, por meio da investigação do prontuário médico, coletaram-se os dados relacionados à "causa mortis" e aos antecedentes pessoais pertinentes para exclusão ou inclusão do cadáver no estudo anatômico.

Por meio do exame físico do abdome e das regiões inguinais, pesquisou-se a presença de cirurgias prévias. 
3.2.2 Técnica de estudo anatômico

Com o cadáver em decúbito dorsal horizontal realizou-se a demarcação cutânea na região abdominal inferior. Esta compreendia a área cutânea convencional do retalho vascularizado pela artéria perfurante muscular da artéria epigástrica inferior (Figuras 1 e 2).

Os limites anatômicos da região abdominal inferior ficaram assim padronizados: limite inferior a sínfise púbica (A); limites laterais as espinhas ilíacas ântero-superiores esquerda e direita (B) e limite superior a margem superior do umbigo (C).

A dissecção foi realizada com a utilização de instrumentos distintos, dependendo da localização das estruturas a serem estudadas. Durante a fase inicial, representada pela dissecção da artéria epigástrica inferior e pelo mapeamento da distribuição das artérias perfurantes, foram empregados instrumentos delicados utilizados habitualmente na cirurgia plástica. Durante a dissecção do trajeto intramuscular das artérias perfurantes foi associado o uso da magnificação com lupa de aumento de 3,5 vezes ${ }^{*}$ e instrumentos de microcirurgia. ${ }^{* *}$

* Lupa cirúrgica de aumento :Surgical Loupe (3,5X, 42 cm / 16") Keeler Instruments Inc.@ -USA.

** Micrins Surgical Instruments Inc.๑ - USA. 


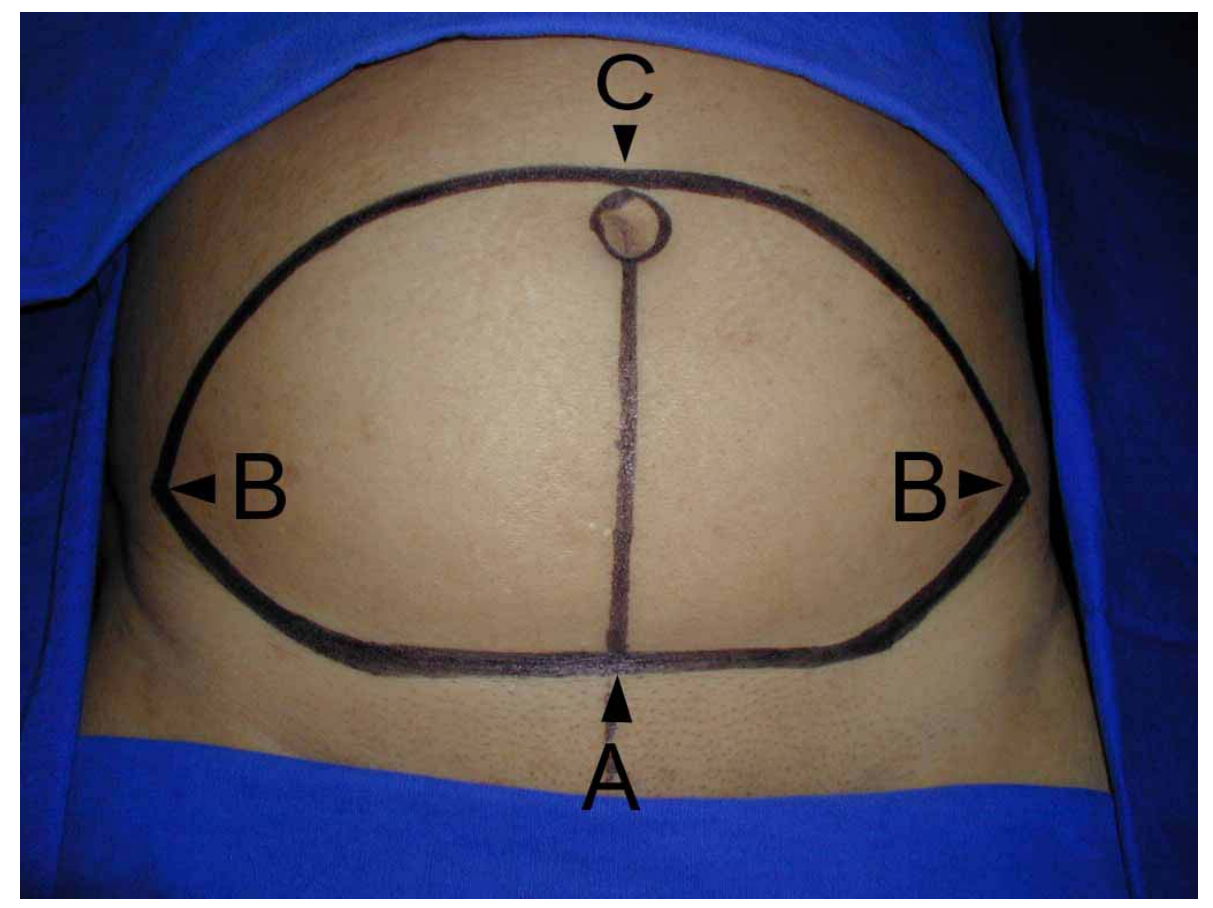

Figura 1. Padronização dos limites anatômicos da região abdominal inferior: sínfise púbica $(A)$, regiões das espinhas ilíacas ânterosuperiores esquerda e direita (B) e margem superior do umbigo (C).

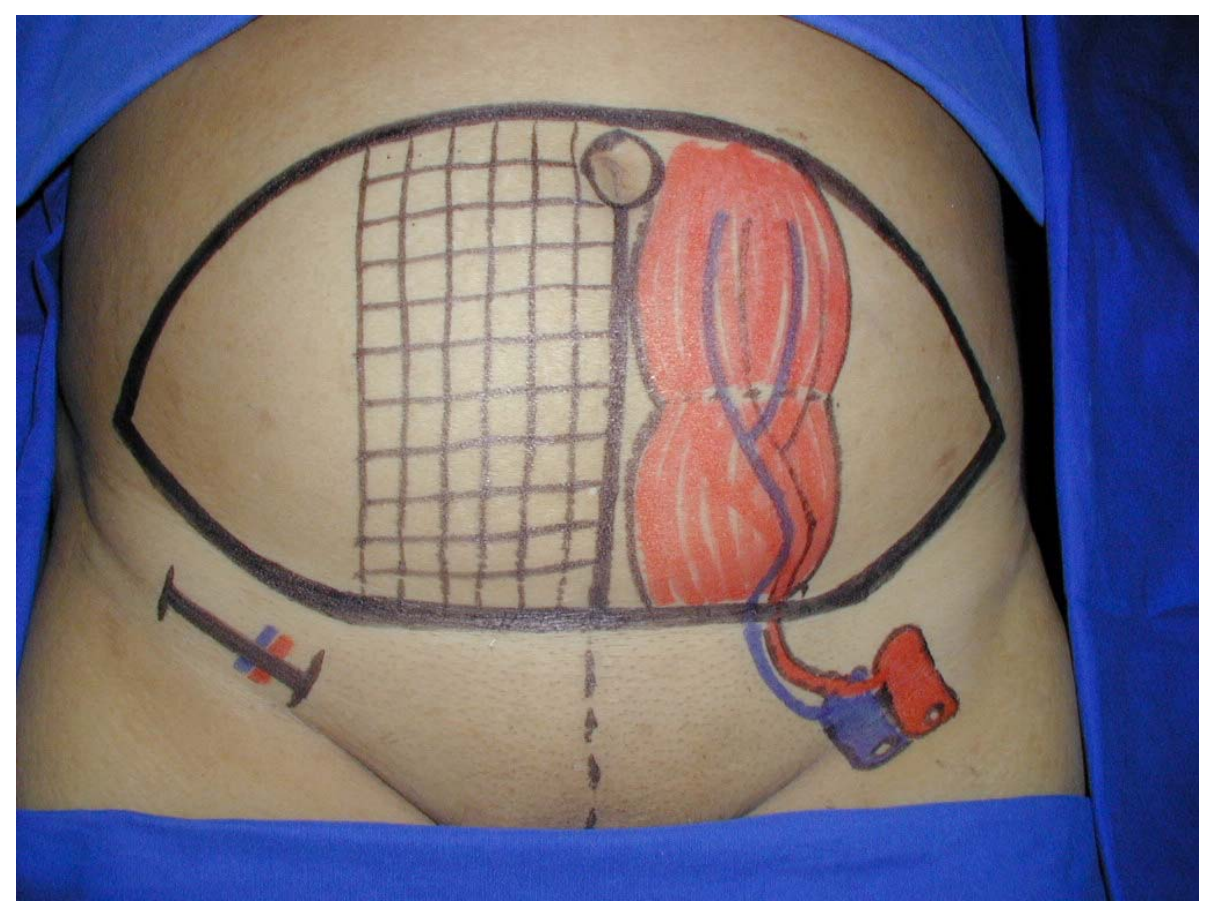

Figura 2. Projeção cutânea do músculo reto do abdome, vasos epigástricos inferiores com os ramos lateral e medial e vasos ilíacos externos. $\mathrm{Na}$ região inguinal direita há a marcação cutânea da via de acesso para os vasos epigástricos inferiores. 
O acesso cirúrgico para a artéria epigástrica inferior foi realizado por meio de incisão de aproximadamente $5 \mathrm{~cm}$ de extensão, localizada na região inguinal bilateralmente (Figura 3). Após a incisão da pele e da tela subcutânea, procedeu-se à dissecção da artéria epigástrica inferior próxima à região da artéria ilíaca externa. Após ampla exposição da artéria epigástrica, realizou-se a introdução de uma agulha de acesso venoso de calibre 16 French $^{*}$. A seguir ocluiu-se da veia epigástrica inferior com fios cirúrgicos de algodão* com o objetivo de se evitar o extravasamento do material de coloração.

Prosseguiu-se com a injeção intravascular de $10 \mathrm{ml}$ de substância corante (tinta azul látex ${ }^{* \star}$ ) (Figura 4). Após o período médio de espera de 10 minutos para a secagem do corante, realizou-se a oclusão da artéria epigástrica inferior com fios cirúrgicos de algodão.

* Jelco ${ }^{\circledR}$ (Cateter Intravascular Periférico - Polímero FEP Radiopaco) - Ethicon - Johnson \& Johnson - USA.

Polycot $\circledast$ (Algodão cirúrgico multifilamentar não absorvível). Ethicon - Johnson \& Johnson - USA.

Tinta azul látex: Resina a base de dispersão aquosa de polímeros vinílicos - Sulvinil $®$ BR. 


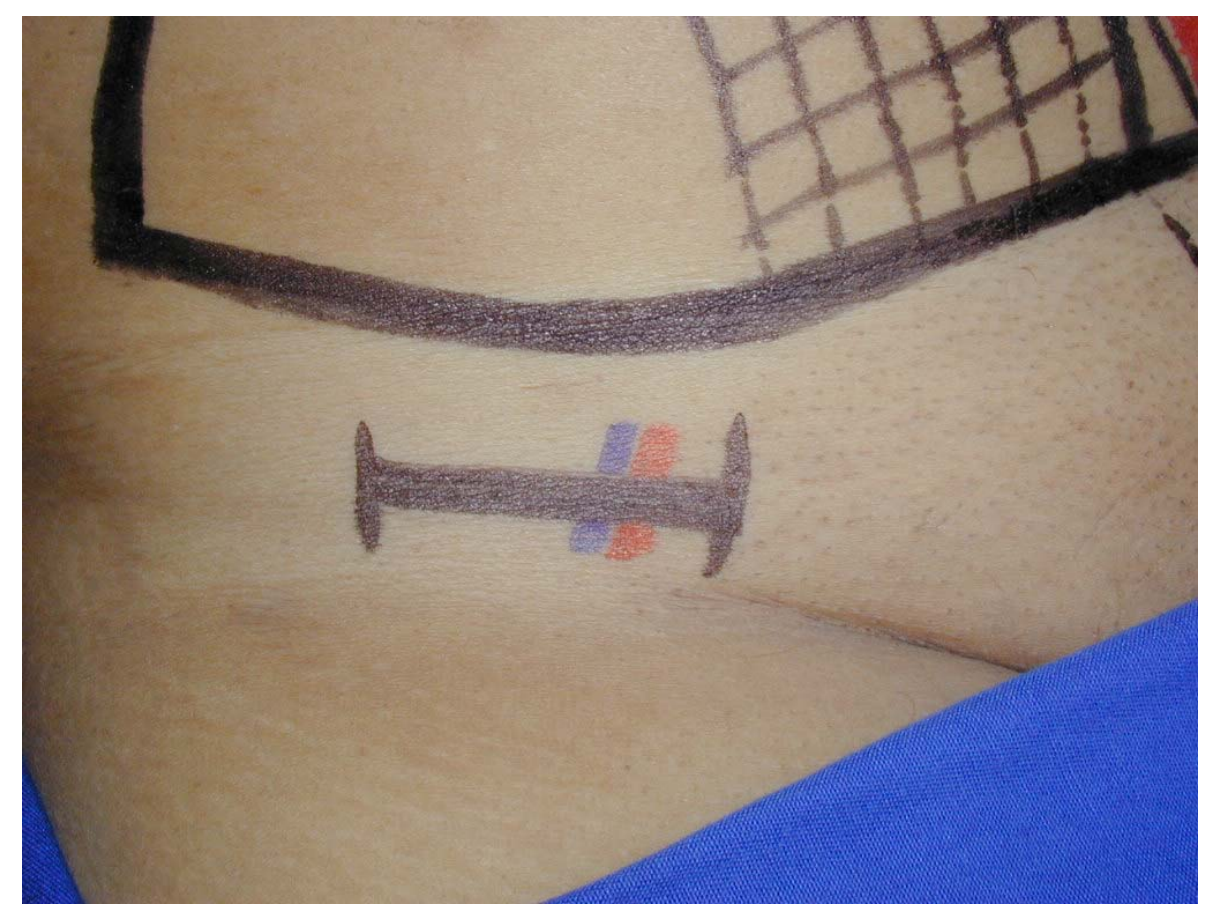

Figura 3. Marcação cutânea referente ao acesso cirúrgico para a artéria epigástrica inferior. Nota-se a incisão de aproximadamente $5 \mathrm{~cm}$ de extensão, localizada na região inguinal direita.

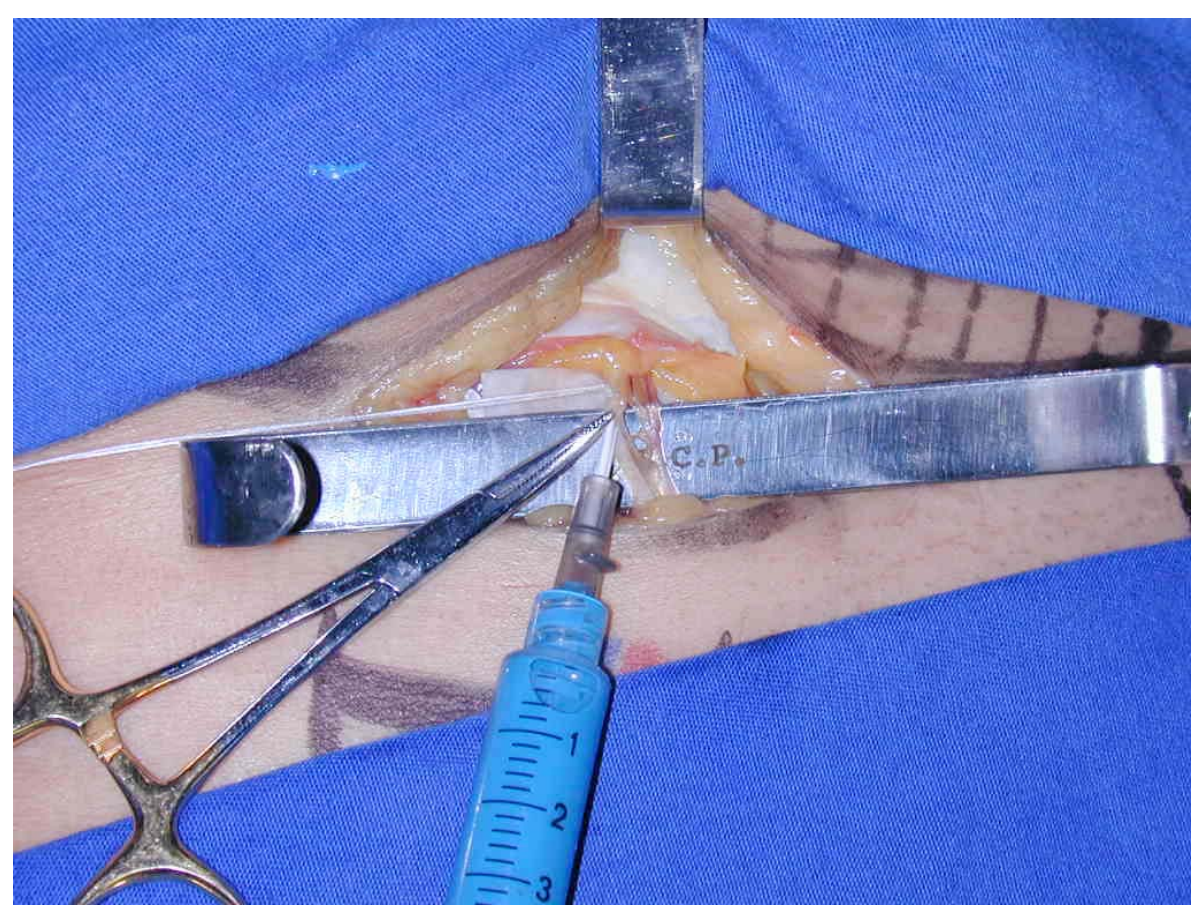

Figura 4. Momento da injeção da tinta corante azul látex através do cateter tipo Jelco na artéria epigástrica inferior direita. 


\subsubsection{Mapeamento das artérias perfurantes}

Após a coloração das artérias perfurantes bilateralmente procedeu-se ao estudo anatômico propriamente dito da distribuição das artérias perfurantes principais.

Realizou-se a incisão da pele na área previamente demarcada da região do abdome inferior (área $A B C$ ) e a dissecção da tela subcutânea até o plano do tecido muscular. Com objetivo de individualização dos segmentos musculares e as áreas de pele e tecido adiposo correspondentes, os retalhos foram divididos na linha alba e procedeu-se à dissecção isolada de cada conjunto (Figuras 5 e 6 ).

Pela individualização dos planos pré-fascial, na região lateral e préaponeurótico, na região medial, realizou-se a dissecção do retalho cutâneogorduroso em direção à linha média do abdome. Após a identificação da margem lateral do músculo reto do abdome, iniciou-se a identificação e dissecção das artérias perfurantes principais, coradas previamente.

Com objetivo de padronização do material a ser coletado e a melhor representação clínica dos resultados, as artérias perfurantes foram classificadas quanto ao calibre e à posição espacial em relação ao músculo reto do abdome. 


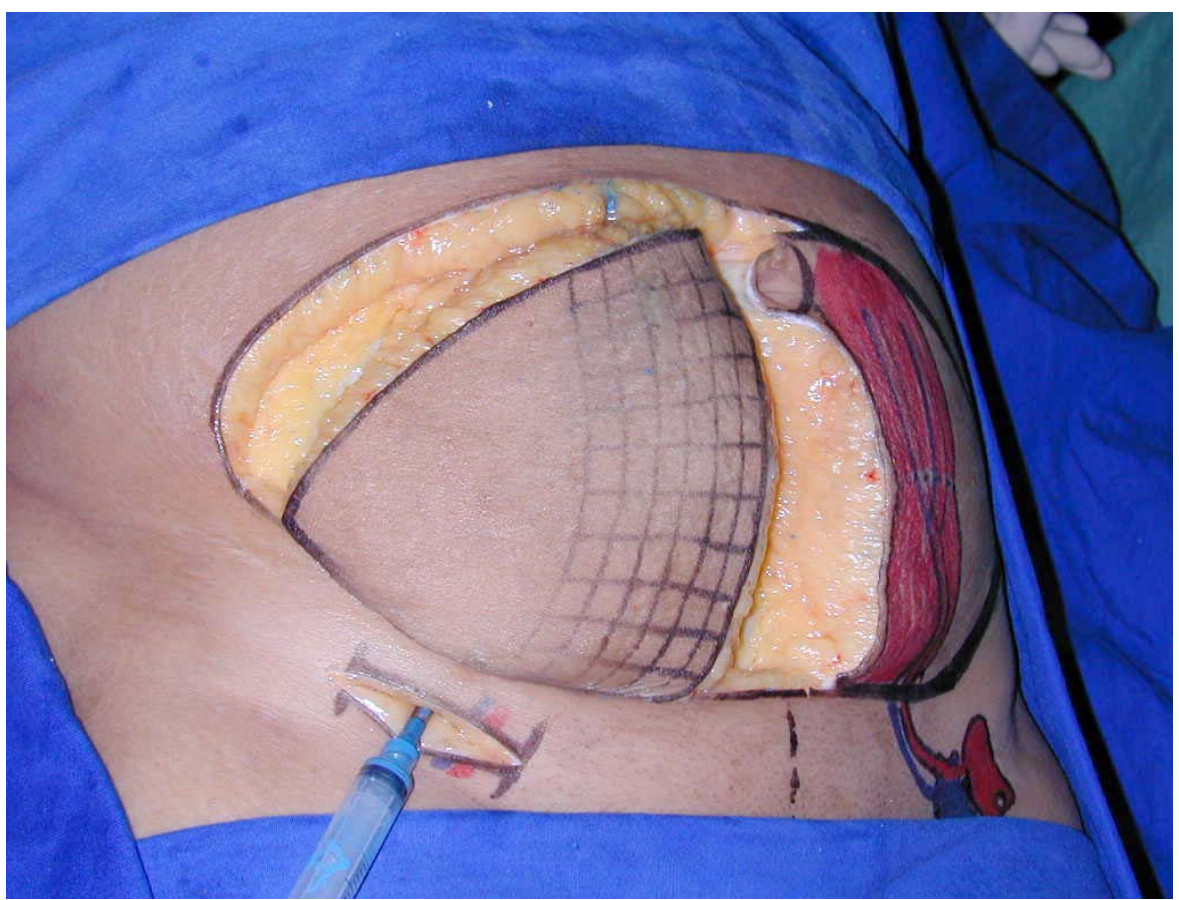

Figura 5. Incisão da pele e da tela subcutânea até o plano pré-fascial.

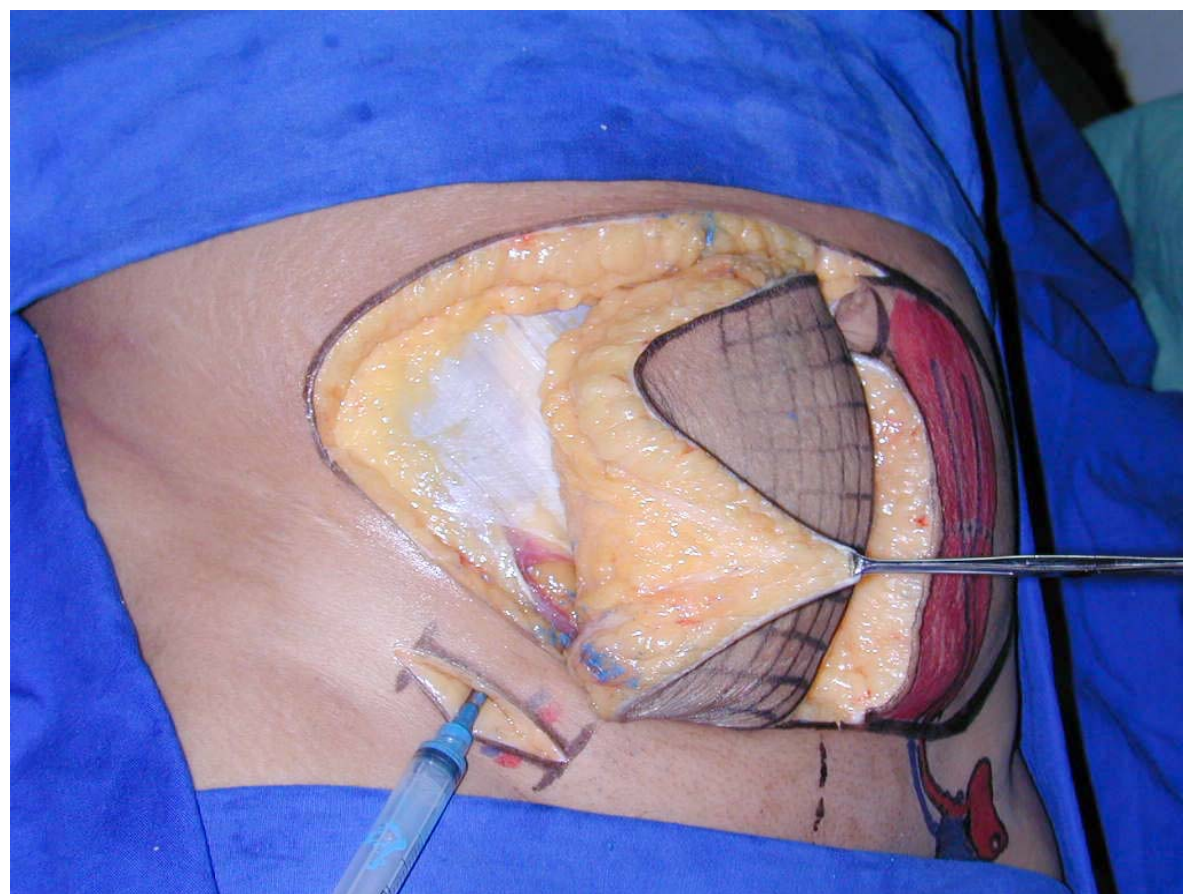

Figura 6. Plano de dissecção do retalho cutâneo-gorduroso no sentido látero-medial. 
Foram identificadas e mapeadas as artérias perfurantes que apresentavam diâmetro superior a $0,5 \mathrm{~mm}$, detectado ao exame com paquímetro eletrônico*. Denominou-se artérias perfurantes de grande calibre as que apresentavam diâmetro superior a $2 \mathrm{~mm}$. Além do calibre, havia a presença do forame anatômico na aponeurose do músculo reto do abdome.

As artérias perfurantes com diâmetro entre 1 e $2 \mathrm{~mm}$, foram denominadas de médio calibre. As artérias com diâmetro inferior a $1 \mathrm{~mm}$ foram apenas mapeadas, não sendo, portanto utilizadas no estudo anatômico intramuscular (Figura 7).

Com objetivo de padronização referente à análise estatística, foi determinado o escore (peso) de 1 para as artérias de pequeno calibre, 2 para as artérias de médio calibre e 3 para as artérias de grande calibre.

Todas as artérias perfurantes identificadas foram localizadas de acordo com sua posição espacial em relação à linha média do abdome e à margem lateral do músculo reto. Denominaram-se de artérias perfurantes laterais, as artérias localizadas na metade lateral do músculo reto do abdome e, de artérias perfurantes mediais, as que se situavam na metade medial (Figura 8).

\footnotetext{
* Mitutoyo $®$ (Instrumento para metrologia dimensional digital 0-200mm) - Mitutoyo - USA.
} 


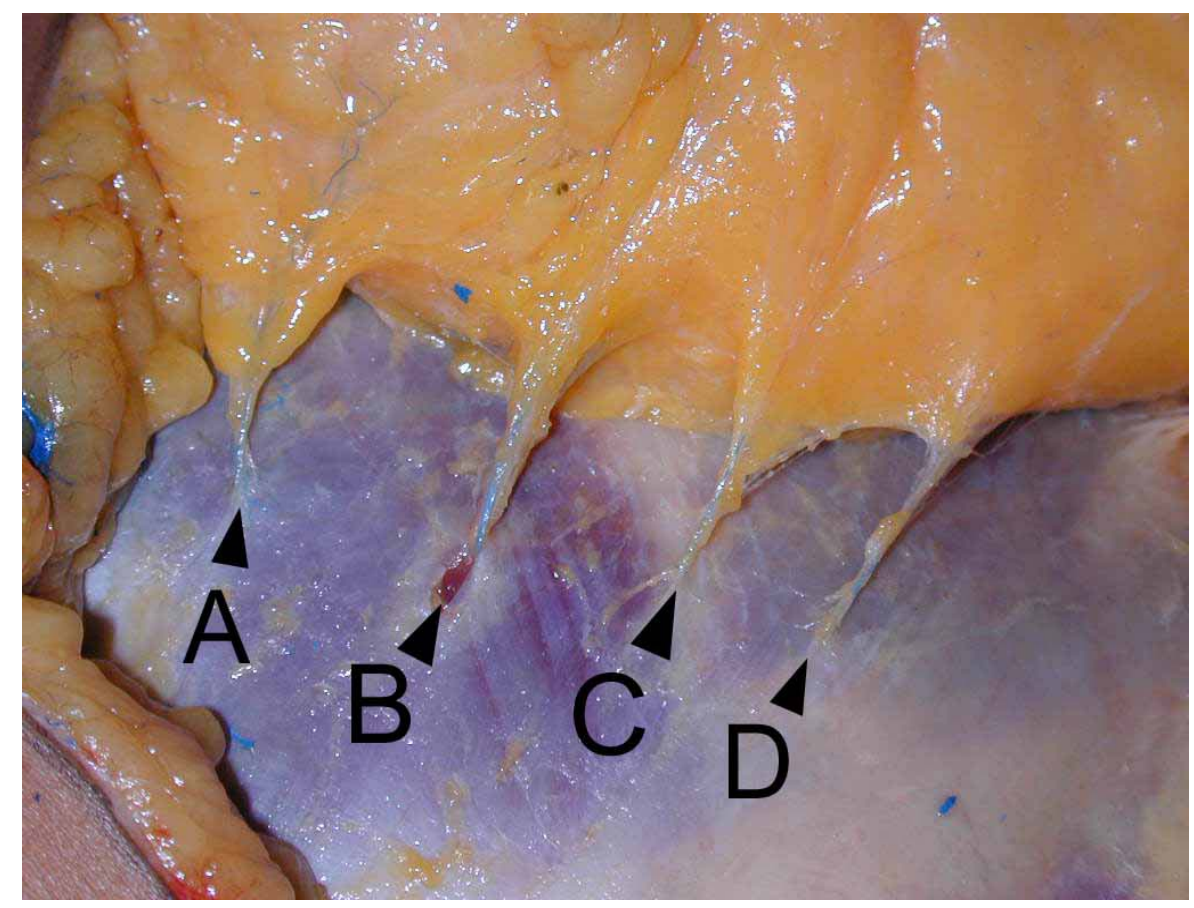

Figura 7. Artérias perfurantes na lâmina anterior da bainha do músculo reto do abdome. Em A nota-se artéria perfurante de médio calibre, em B artéria perfurante de grande calibre, e em $C$ e em $D$, artérias perfurantes de pequeno calibre.

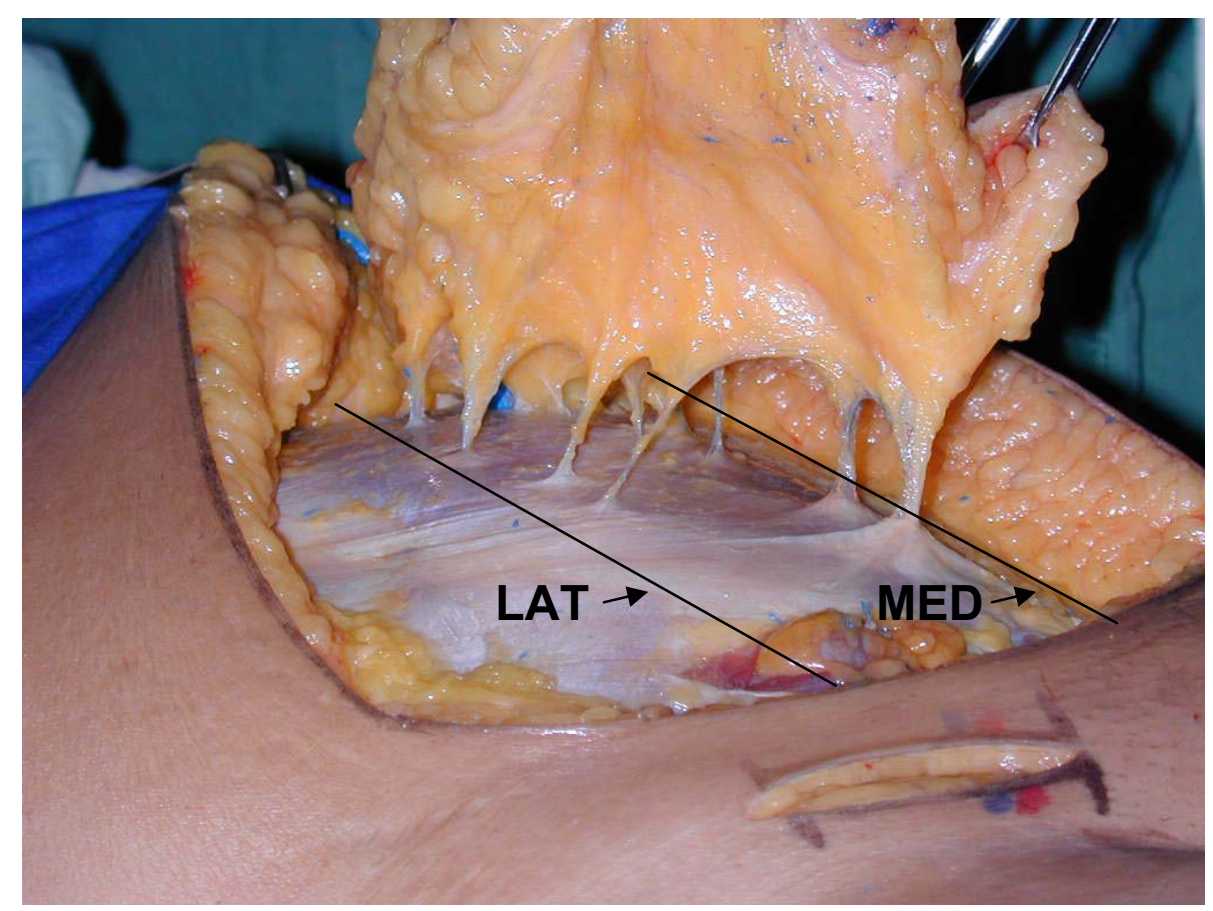

Figura 8. Distribuição das artérias perfurantes identificadas na projeção infraumbilical do músculo reto do hemi-abdome direito. Nota-se a distribuição preferencial das artérias na região mais próxima às margens lateral (LAT) e medial (MED) do músculo reto do abdome. 


\subsubsection{Estudo da anatomia intramuscular}

Foi realizada, através da utilização de bisturi e tesoura, a incisão da lâmina anterior da bainha do músculo reto do abdome próximo à emergência das artérias perfurantes previamente mapeadas. Com o objetivo de se evitar a lesão arterial, a incisão na lâmina anterior foi realizada com uma distância de $0,5 \mathrm{~cm}$ do ponto de emergência da artéria perfurante. Este procedimento possibilitou a abertura da aponeurose com exposição da artéria perfurante e das fibras musculares no plano retro aponeurótico.

Após este procedimento, foi realizada a identificação do septo muscular referente à origem da artéria perfurante. Por meio de manobras de dissecção romba com a utilização de pinça hemostática e da tesoura, realizou-se a exposição do septo muscular e a dissecção do trajeto intramuscular da artéria. Os ramos arteriais musculares menores foram seccionados e os ramos maiores ocluídos com fio de algodão com o objetivo de se evitar o extravasamento da substância corante. O afastamento das fibras musculares foi realizado até a completa exposição da lâmina posterior da aponeurose do músculo reto do abdome e da fáscia transversal (Figuras 9 e 10)

A dissecção da artéria epigástrica inferior prosseguiu até a sua origem na artéria ilíaca externa para a mensuração do comprimento total do pedículo vascular. 


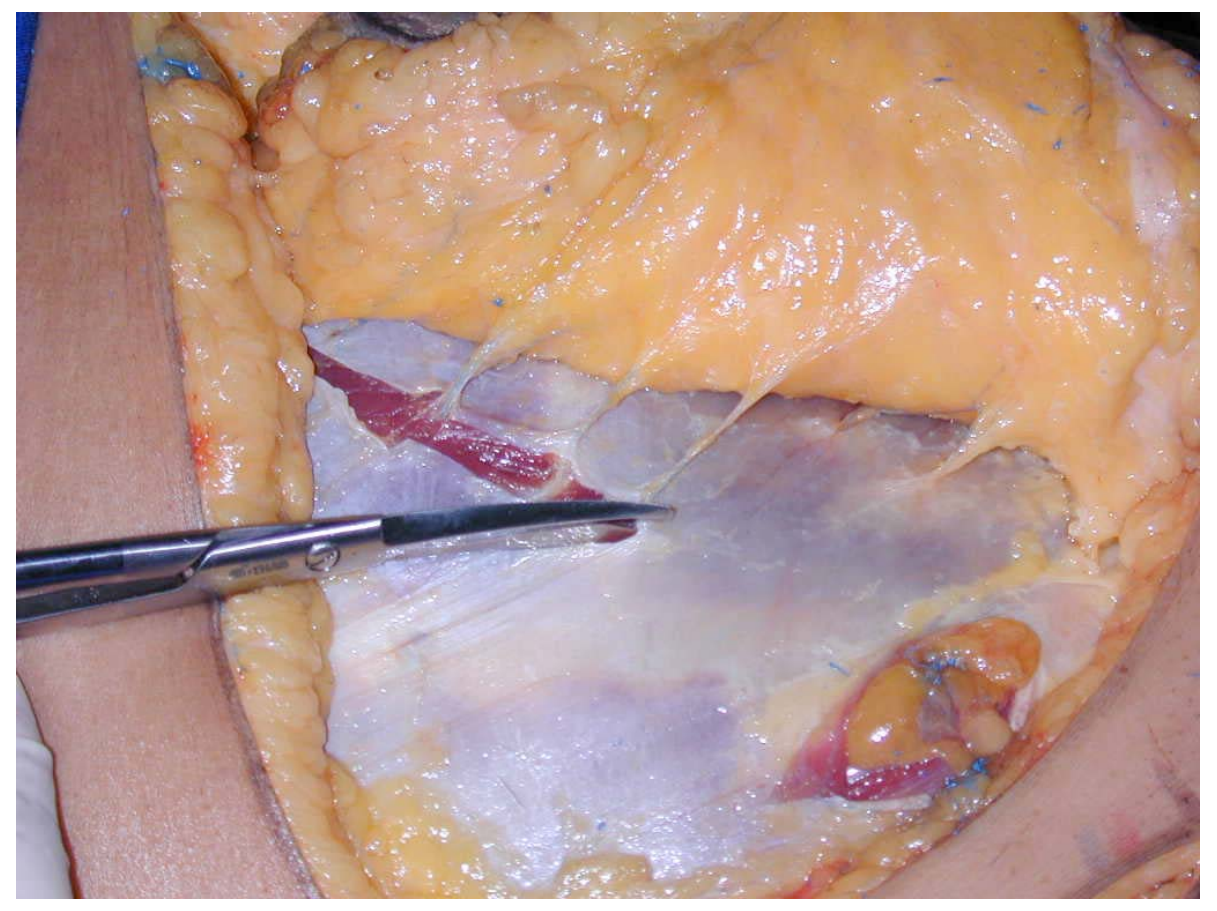

Figura 9. Abertura lâmina anterior da bainha do músculo reto do abdome próximo à emergência das artérias perfurantes.

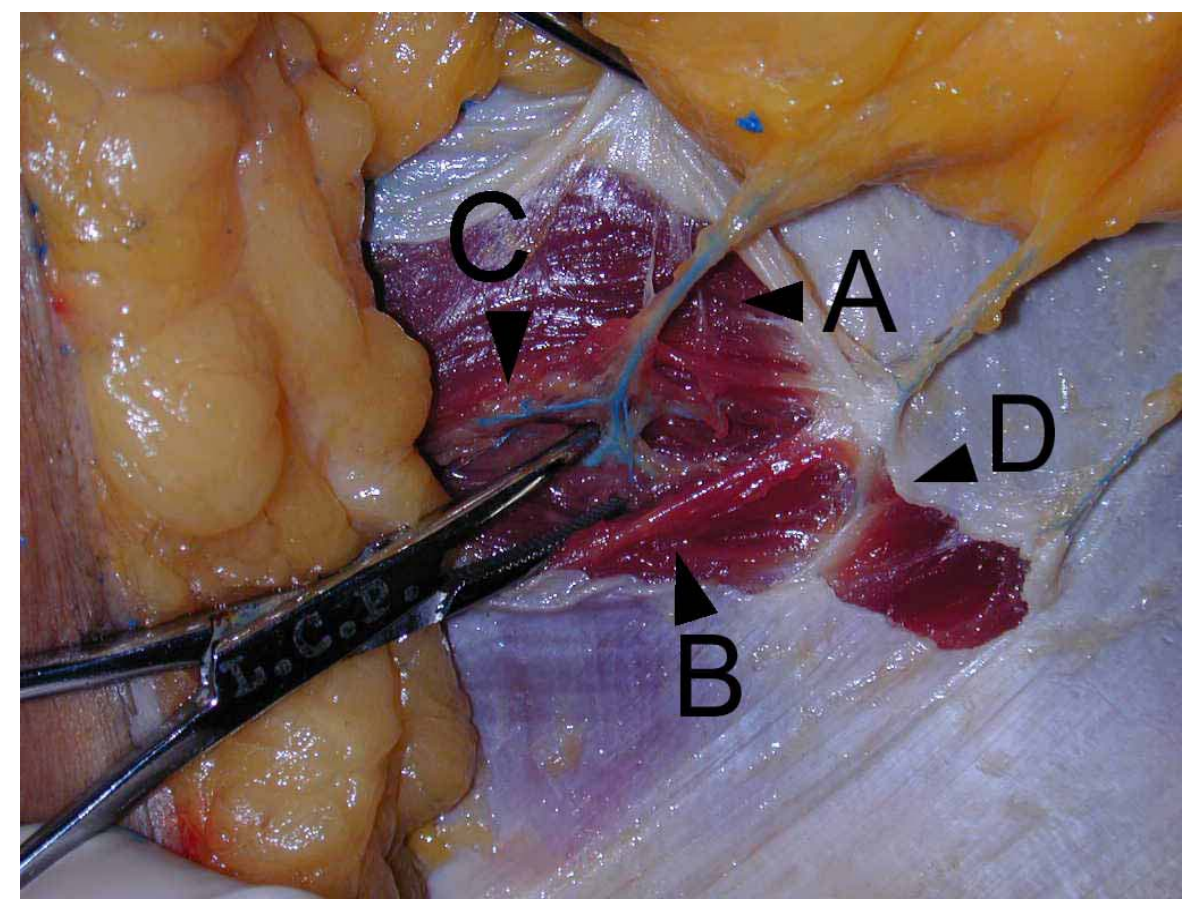

Figura 10. Dissecção do trajeto intramuscular nas fibras do músculo reto do abdome. Nota-se em A, a artéria perfurante, em B as fibras do músculo reto do abdome, em $\mathrm{C}$ o ramo muscular da artéria perfurante e em $\mathrm{D}$ a intersecção tendínea do músculo reto do abdome. 


\subsubsection{Artéria epigástrica inferior e ramificações}

Em todos os retalhos foi realizada a dissecção da artéria epigástrica inferior na região posterior do músculo reto do abdome. Foram analisados o trajeto e os seus principais ramos. Como limites anatômicos para o estudo, estabeleceu-se o umbigo como limite superior e o ponto de entrada da artéria epigástrica inferior, na região lateral do músculo reto do abdome, como limite inferior. Devido à não aplicação clínica no retalho DIEP, os ramos da artéria epigástrica inferior que apresentavam origem em regiões externas aos limites anatômicos estabelecidos não foram submetidos à análise.

3.2.2.4 Comprimento da artéria perfurante e do pedículo arterial

Após a dissecção do trajeto intramuscular e a completa exposição da artéria perfurante, foram realizadas as mensurações dos comprimentos da artéria perfurante e do pedículo arterial do retalho através da utilização do paquímetro eletrônico.

Foram utilizadas duas artérias perfurantes em cada retalho dissecado, sendo uma artéria proveniente da região medial e outra, da região lateral do músculo reto do abdome. Em todos os retalhos a dissecção do pedículo 
arterial se estendeu até a origem da artéria epigástrica inferior na artéria ilíaca externa.

Para a padronização das medidas, foram determinados como pontos de referência: a origem da artéria epigástrica inferior na artéria ilíaca externa (A'), a região de entrada da artéria perfurante nas fibras do músculo reto do abdome (B1), a região de saída da artéria perfurante no músculo reto do abdome (B2) e a região de entrada da artéria perfurante no panículo adiposo (C') (Figuras 11 e 12).

Determinou-se como comprimento do pedículo arterial (CP), a distância compreendida entre a origem da artéria epigástrica inferior $\left(A^{\prime}\right)$ e a região de entrada da artéria perfurante no panículo adiposo (C'). O comprimento da artéria perfurante (CAP) foi determinado pela distância do trajeto intramuscular que é a medida compreendida entre a região de entrada da artéria perfurante (B1) e a região de saída no músculo reto do abdome (B2).

Comprimento da Artéria Perfurante:

$\mathrm{CAP}=\mathrm{B} 1 \rightarrow \mathrm{B} 2$

Comprimento do Pedículo Arterial:

$\mathrm{CP}=\mathrm{A}^{\prime} \rightarrow \mathrm{C}^{\prime}$ 


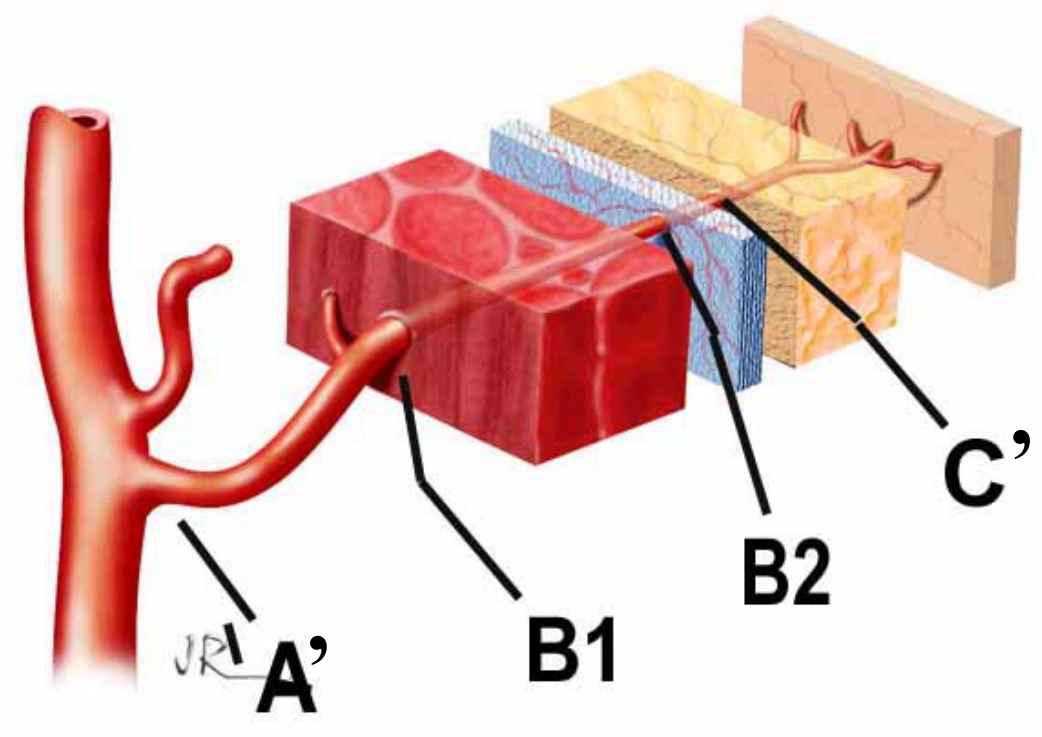

Figura 11. Pontos de referência para a mensuração dos comprimentos do pedículo arterial e da artéria perfurante. Nota-se em A', a origem da artéria epigástrica inferior na artéria ilíaca externa, em B1 a região de entrada da artéria perfurante nas fibras do músculo reto do abdome, em B2 a região de saída da artéria perfurante no músculo reto do abdome e em C' a região de entrada da artéria perfurante no panículo adiposo.

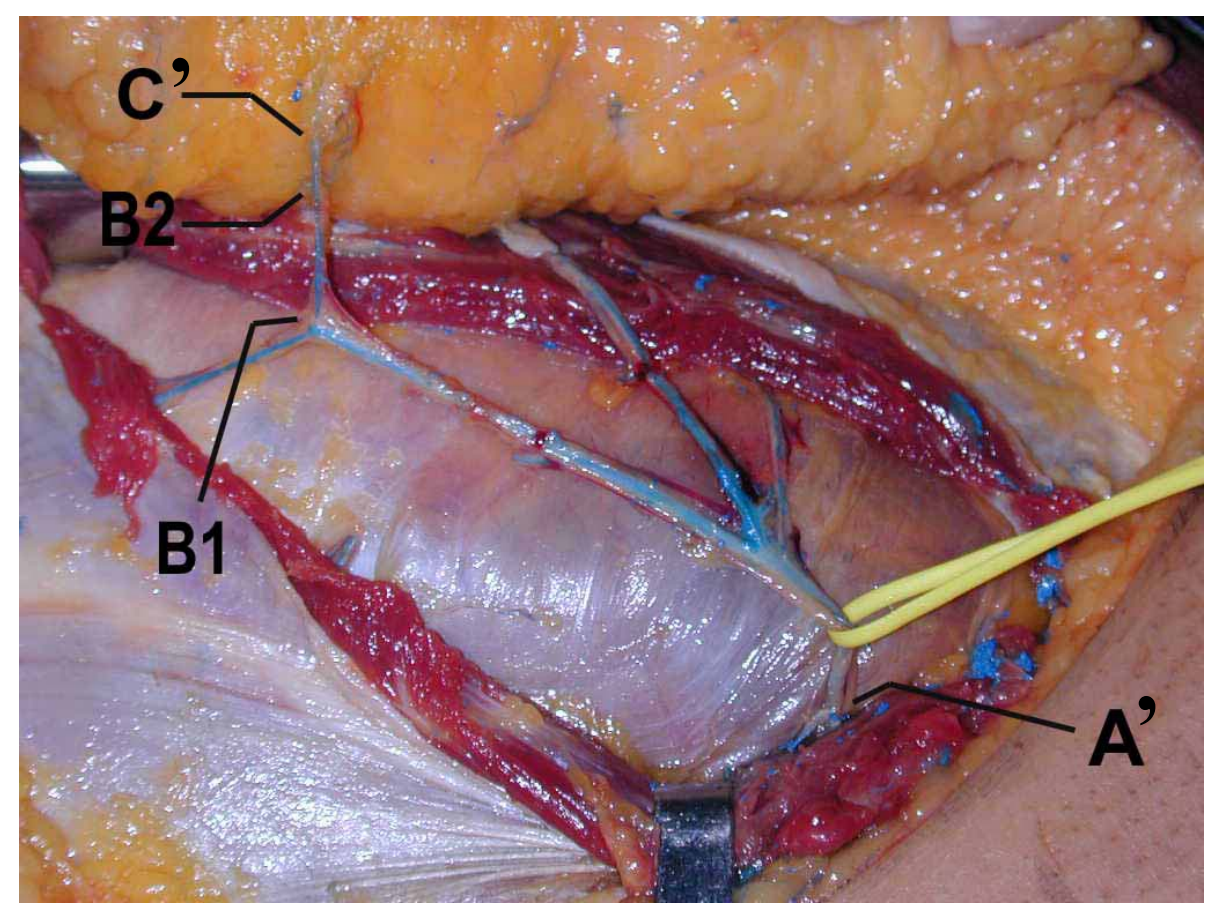

Figura 12. Mensuração das medidas de comprimento do pedículo arterial e da artéria perfurante na peça anatômica. Nota-se em A', a origem da artéria epigástrica inferior na artéria ilíaca externa, em B1 a região de entrada da artéria perfurante nas fibras do músculo reto do abdome, em B2 a região de saída da artéria perfurante no músculo reto do abdome e em C' a região de entrada da artéria perfurante no panículo adiposo. 


\subsection{Análise Estatística}

As variáveis classificatórias foram apresentadas em tabelas contendo freqüências relativas e absolutas. Foram utilizados como métodos estatísticos, o teste exato de Fisher, o teste de Cochran-Mantel-Haenszel e o teste dos intervalos de confiança de $95 \%$ das proporções, ou porcentagens.

Para a análise da relação entre as variáveis qualitativas ou categorizadas utilizou-se o teste exato de Fisher. Na situação onde esta variável apresentou ordenação natural nas categorias (variável ordinal) e o teste exato de Fisher demonstrou resultado significativo aplicou-se o teste de Cochran-Mantel-Haenszel para avaliar qual era a tendência dessa diferença.

As variáveis quantitativas contínuas foram apresentadas descritivamente em tabelas contendo médias, desvio padrão, mediana, valores mínimos e máximos. As médias das variáveis que apresentavam distribuição normal foram comparadas com o teste t-Student. Quando não foi observada distribuição normal, utilizou-se o teste não paramétrico da soma de postos de Wilcoxon.

Os valores de $p<0,05$ foram considerados significantes. 
4. Resultados

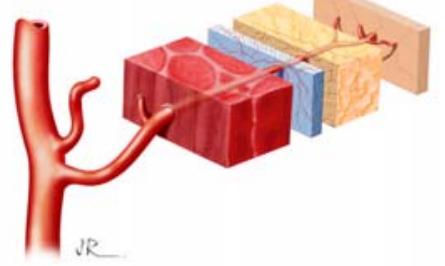




\subsection{Mapeamento das artérias perfurantes}

4.1.1 Número e localização das artérias perfurantes

Foram dissecadas 191 artérias perfurantes em 30 peças anatômicas. Este resultado determinou a média de 6,3 artérias perfurantes de pequeno, médio e grande calibres por segmento de músculo reto do abdome analisado.

Em relação à sua localização, 126 (65,9\%) artérias perfurantes localizaram-se na região medial do músculo reto do abdome e 65 (34,0 \%) artérias lateralmente (Figura. 13).

Em relação à distância da localização da artéria perfurante até a linha alba, as artérias perfurantes que se localizaram na região lateral apresentaram a distância média de $5,2 \mathrm{~cm}(2$ a $10 \mathrm{~cm})$. As artérias que se localizaram na região medial apresentaram a distância média de $1,9 \mathrm{~cm}(0,1$ a $5,5 \mathrm{~cm})$ (Tabela 1).

\begin{tabular}{cccccc}
\hline $\begin{array}{c}\text { LOCALIZAÇÃO } \\
\text { DO VASO } \\
\text { PERFURANTE }\end{array}$ & NÚMERO & $\begin{array}{c}\text { DISTÂNCIA DA } \\
\text { LINHA ALBA (CM) } \\
\text { MÉDIA }\end{array}$ & $\begin{array}{c}\text { DESVIO } \\
\text { PADRÃO }\end{array}$ & MÍNIMO & MÁXIMO \\
\hline Lateral & 65 & 5,21538 & 1,86658 & 2,00000 & 10,00000 \\
Medial & 126 & 1,94682 & 1,21007 & 0,10000 & 5,500000 \\
\hline
\end{tabular}

Tabela 1. Número de artérias perfurantes, localização (regiões lateral e medial) e distância em relação à linha alba. 


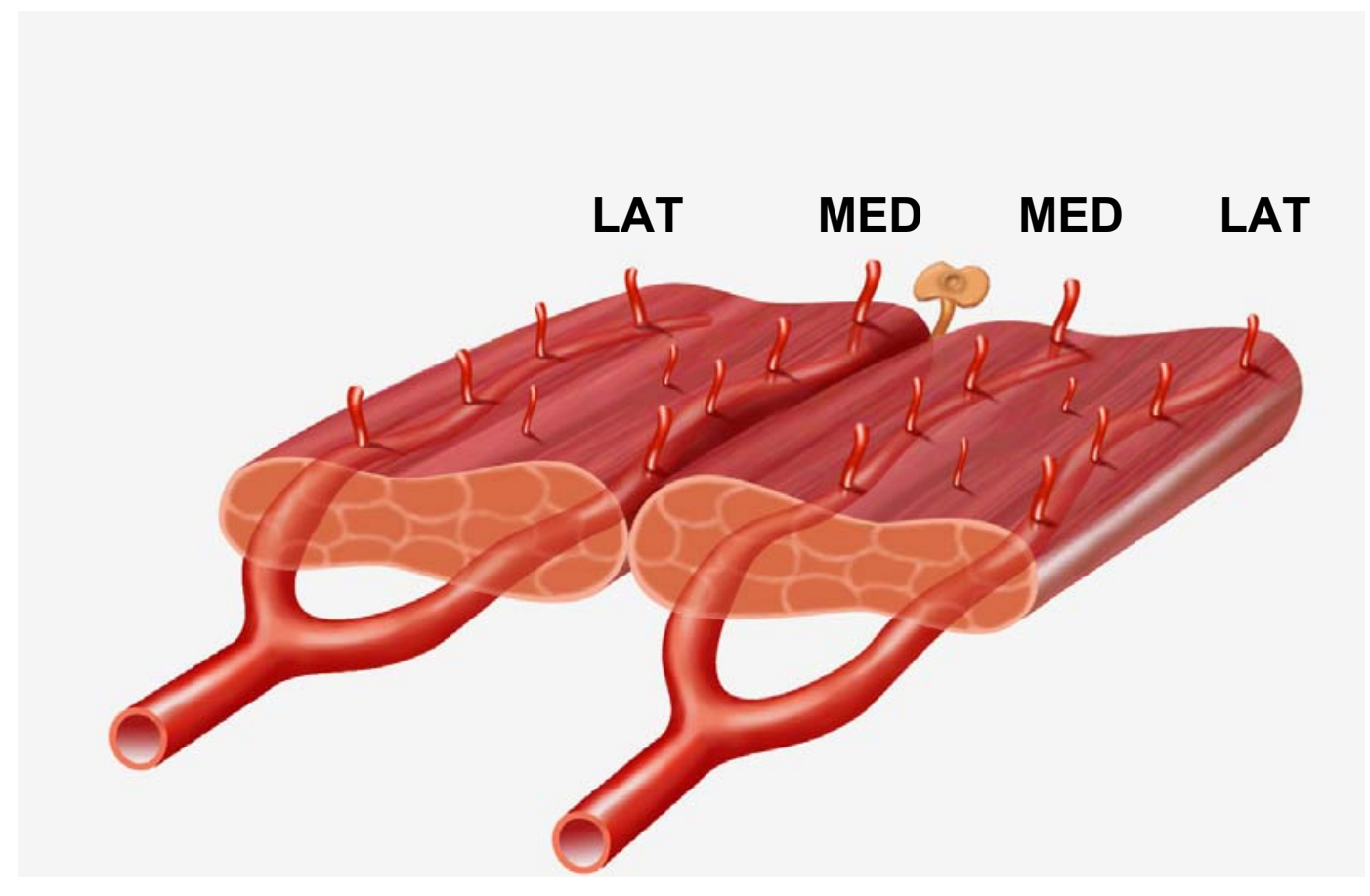

Figura 13. Distribuição das artérias perfurantes em relação às regiões do músculo reto do abdome (lateral (LAT) e medial (MED)).

\subsubsection{Calibre e localização das artérias perfurantes}

Das 191 artérias perfurantes dissecadas, 39 (20,4\%) artérias possuíam grande calibre, 95 (49,7\%), médio calibre e 57 (29,8\%), pequeno calibre.

Na região lateral, $21(32,3 \%)$ artérias perfurantes possuíam grande calibre, $34(52,3 \%)$, médio calibre e $10(15,4 \%)$, pequeno calibre.

Na região medial, $18(14,3 \%)$ artérias perfurantes possuíam grande calibre, $61(48,4 \%)$, médio calibre e $47(37,3 \%)$, pequeno calibre (Tabela 2 e Figura 14). 


\begin{tabular}{|c|c|c|c|}
\hline LOCALIZAÇÃO DO & PEQUENO & MÉDIO & GRANDE \\
\hline
\end{tabular}

\begin{tabular}{ccccc}
\hline $\begin{array}{c}\text { Lateral (n.) } \\
\text { (\%) }\end{array}$ & 10 & 34 & 21 & 65 \\
Medial (n.) & 15,38 & 52,31 & 32,31 & \\
$(\%)$ & 47 & 61 & 18 & 126 \\
TOTAL & 57,30 & 48,41 & 14,28 & 191 \\
\hline
\end{tabular}

Tabela 2. Distribuição das artérias perfurantes em relação ao calibre (pequeno, médio e grande) e à localização na região do músculo reto do abdome (lateral e medial).

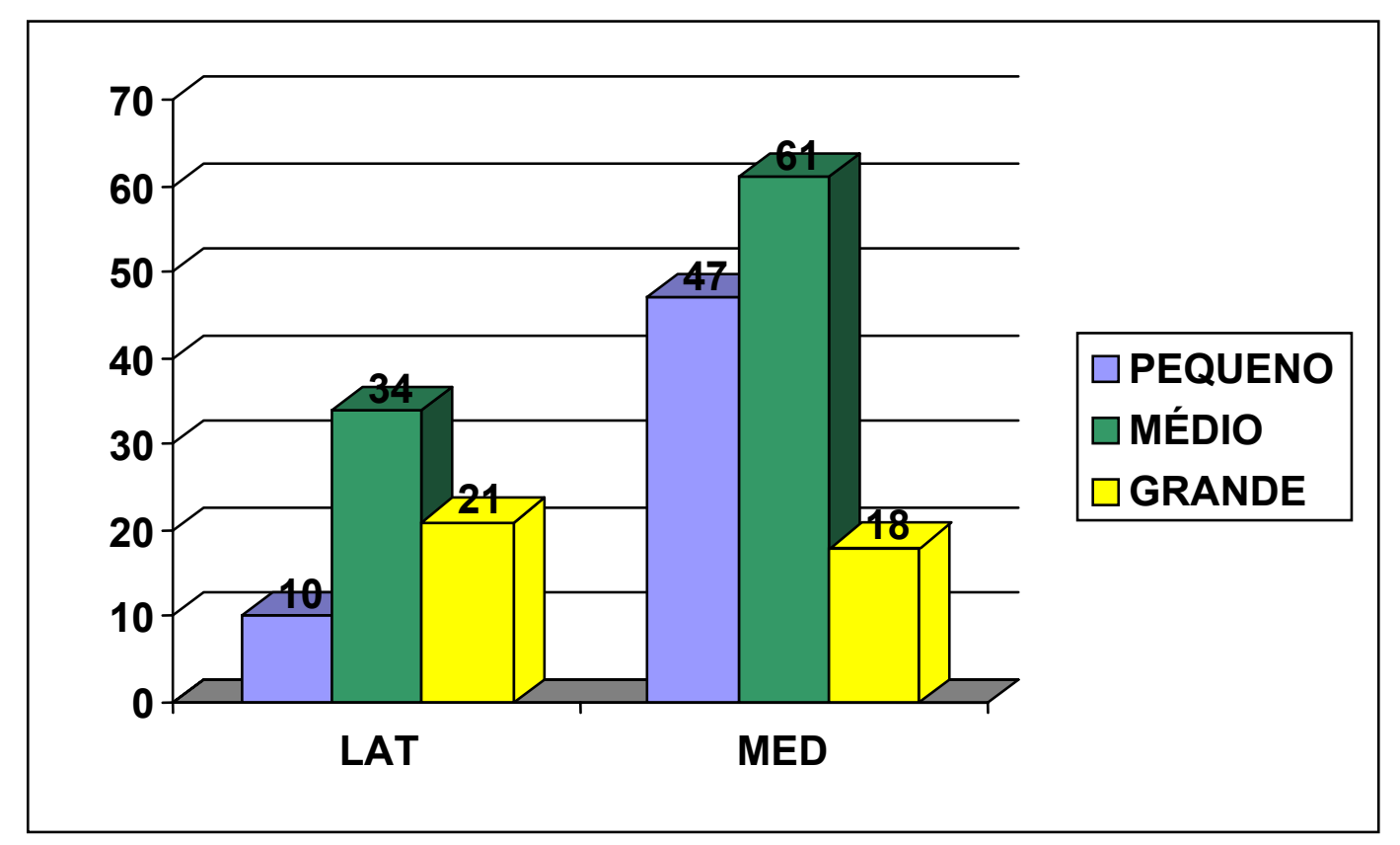

:Figura 14. Distribuição das artérias perfurantes em relação ao calibre (pequeno, médio e grande) e a localização na região do músculo reto do abdome (lateral e medial).

A análise estatística demonstrou significância na comparação da variável calibre das artérias perfurantes (pequeno, médio e grande) com a 
variável localização no músculo reto do abdome (lateral e medial). Pela aplicação do teste de exato de Fisher $(p=0,0009)$ conclui-se que existe relação entre o calibre da artéria perfurante e a localização no músculo reto do abdome.

$\mathrm{Na}$ análise comparativa entre as duas regiões, lateral e medial, pode-se concluir que a região medial apresentou a maior concentração de artérias de menor calibre. Para isso foi considerado o escore de 1 para as artérias de calibre pequeno, 2 para as de calibre médio e 3 para as de calibre grande. Pela aplicação do teste de Cochran-Mantel-Haenszel verificou-se que existe diferença entre os escores médios das regiões lateral e medial ( $p=0,0002)$. Na região lateral observou-se o escore médio de 2,17 e na região medial o escore médio de 1,77 . 


\subsection{Trajeto intramuscular das artérias perfurantes}

O estudo da anatomia intramuscular foi realizado nas artérias perfurantes que apresentaram médio e grande calibres. Por motivos de limitação técnica de dissecção, as artérias que possuíam calibre pequeno não foram incluídas nesta avaliação. Em 26 artérias perfurantes (18 com médio calibre e 8 com grande calibre) não foi possível realizar a dissecção intramuscular, em decorrência de lesão vascular iatrogênica durante a dissecção. Assim, da totalidade de 191 artérias perfurantes mapeadas, realizou-se o estudo da anatomia intramuscular em 108 artérias, representando $56,5 \%$ da casuística inicial.

Em todos os casos estudados, a avaliação do trajeto intramuscular da artéria perfurante foi realizada a partir da origem nos ramos da artéria epigástrica inferior até o ponto de emergência na lâmina anterior da bainha do músculo reto do abdome. Neste percurso, foi possível a identificação de dois padrões de trajeto. As principais diferenças observadas entre estes dois tipos de trajeto estavam relacionadas à extensão e à posição espacial em relação às fibras musculares e a origem nos ramos da artéria epigástrica inferior. (Figura 15). 


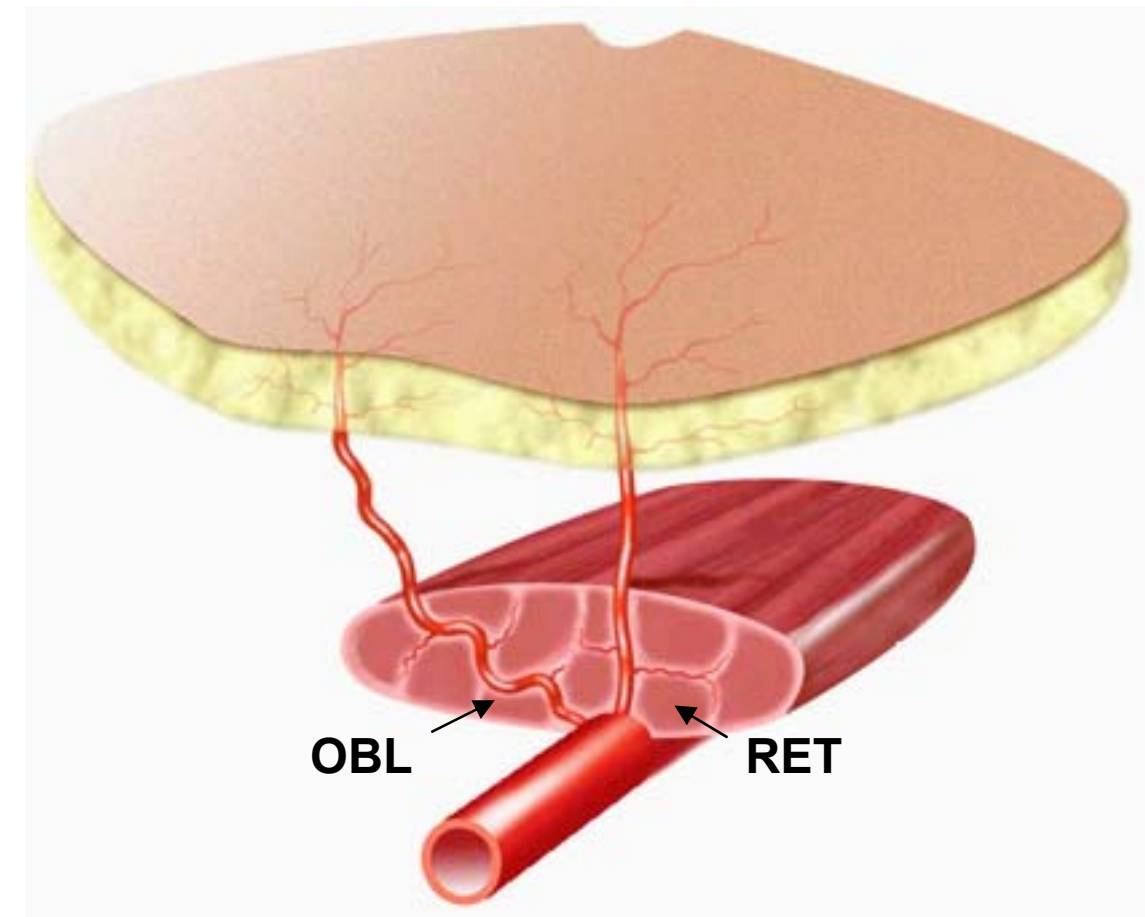

Figura 15. Desenho esquemático da anatomia arterial intramuscular do músculo reto do abdome e das artérias perfurantes do retalho. Nota-se a artéria epigástrica inferior e as artérias perfurantes musculares. No esquema, pode-se identificar a ilustração dos dois tipos de trajeto intramuscular (retilíneo (RET) e oblíquo $(\mathrm{OBL}))$.

Foram classificadas de artérias perfurantes de trajeto retilíneo, as artérias que apresentaram o trajeto localizado exclusivamente no septo muscular. A dissecção era realizada pelo afastamento lateral e medial das fibras musculares sem a necessidade de secção das fibras do músculo reto do abdome (Figuras 16, 17 e 18).

No trajeto oblíquo, após o afastamento das fibras musculares não se evidenciou um único septo muscular pelo qual a artéria perfurante apresentava seu trajeto. Houve a necessidade de secção de algumas fibras musculares com objetivo de individualizar a artéria até a sua origem nos ramos da artéria epigástrica inferior (Figuras 1619 e 20). 
Em relação ao tipo de trajeto intramuscular e a localização da artéria perfurante no músculo reto do abdome, verificou-se diferença significativa. $\mathrm{Na}$ região lateral do músculo reto do abdome, $38 \quad(79,1 \%)$ artérias perfurantes apresentaram o trajeto retilíneo e 10 (20,8\%), o oblíquo. Todavia, na região medial, $10(18,2 \%)$ artérias perfurantes apresentaram o trajeto retilíneo e 45 (81,8\%), o oblíquo.

A análise estatística demonstrou significância na comparação da variável trajeto das artérias perfurantes (retilíneo e oblíquo) com a variável localização no músculo reto do abdome (lateral e medial). Houve comprovação desta afirmação pela aplicação do teste exato de Fisher ( $p=$ 0,001), que concluiu a existência de diferença entre o tipo de trajeto intramuscular da artéria perfurante e a localização no músculo (Tabela 3 e Figura 21).

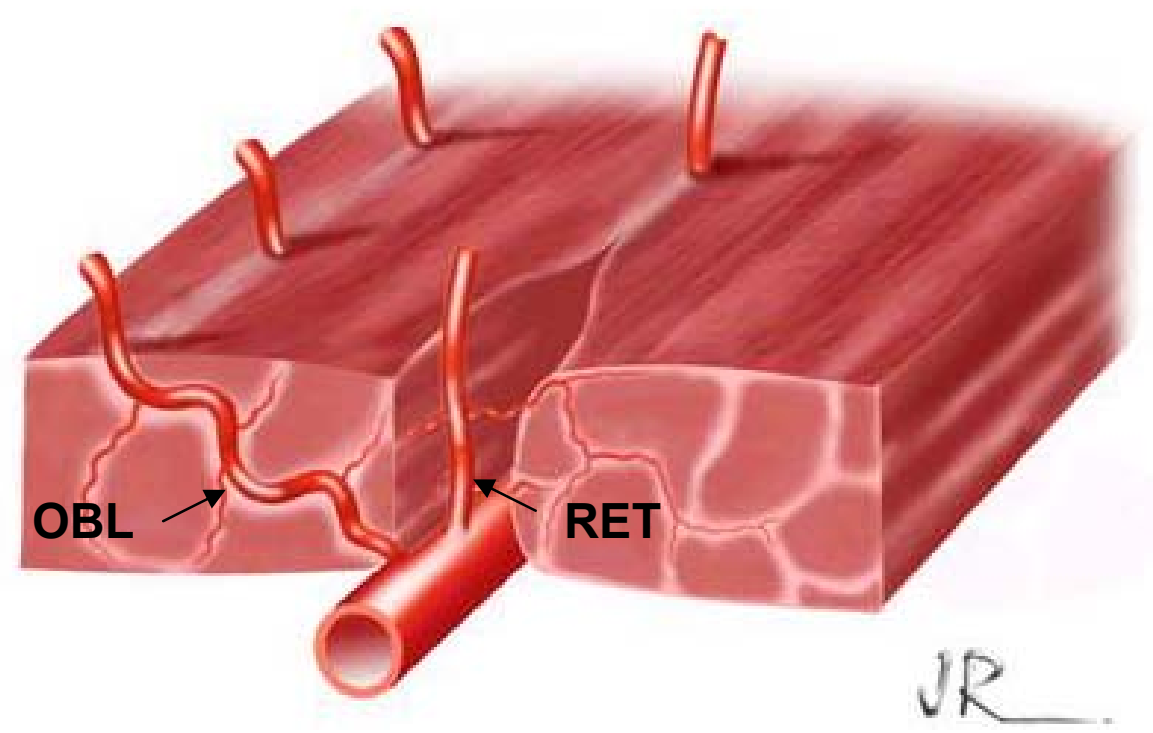

Figura 16. Desenho da anatomia arterial intramuscular do músculo reto do abdome. No trajeto retilíneo (RET), realiza-se o afastamento das fibras musculares e a artéria perfurante apresenta o percurso mais curto quando comparada às artérias com trajeto oblíquo (OBL). 


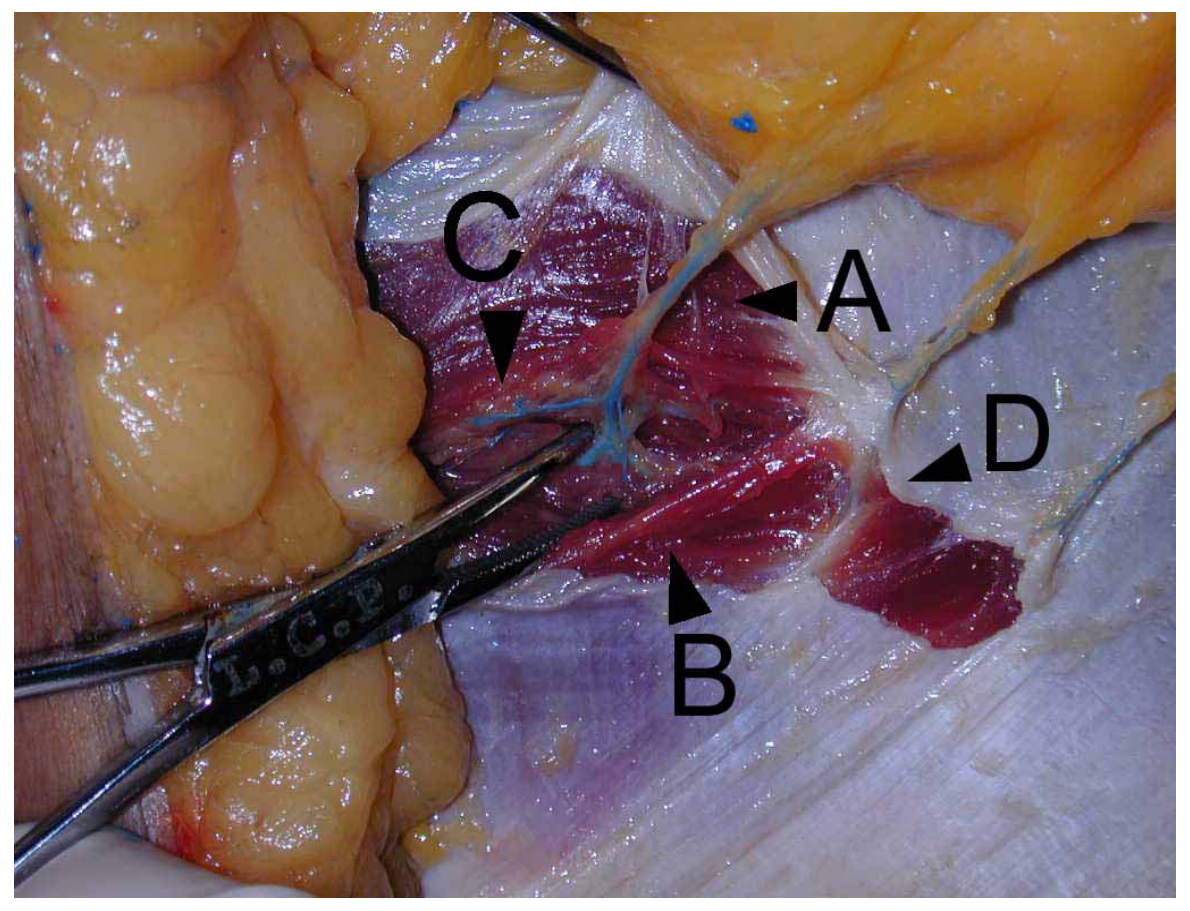

Figura 17. Dissecção da artéria perfurante da região lateral com trajeto retilíneo (A). Nota-se o afastamento das fibras musculares (B e $C$ ) de maneira romba até próximo à região da intersecção tendínea do músculo reto do abdome (D).

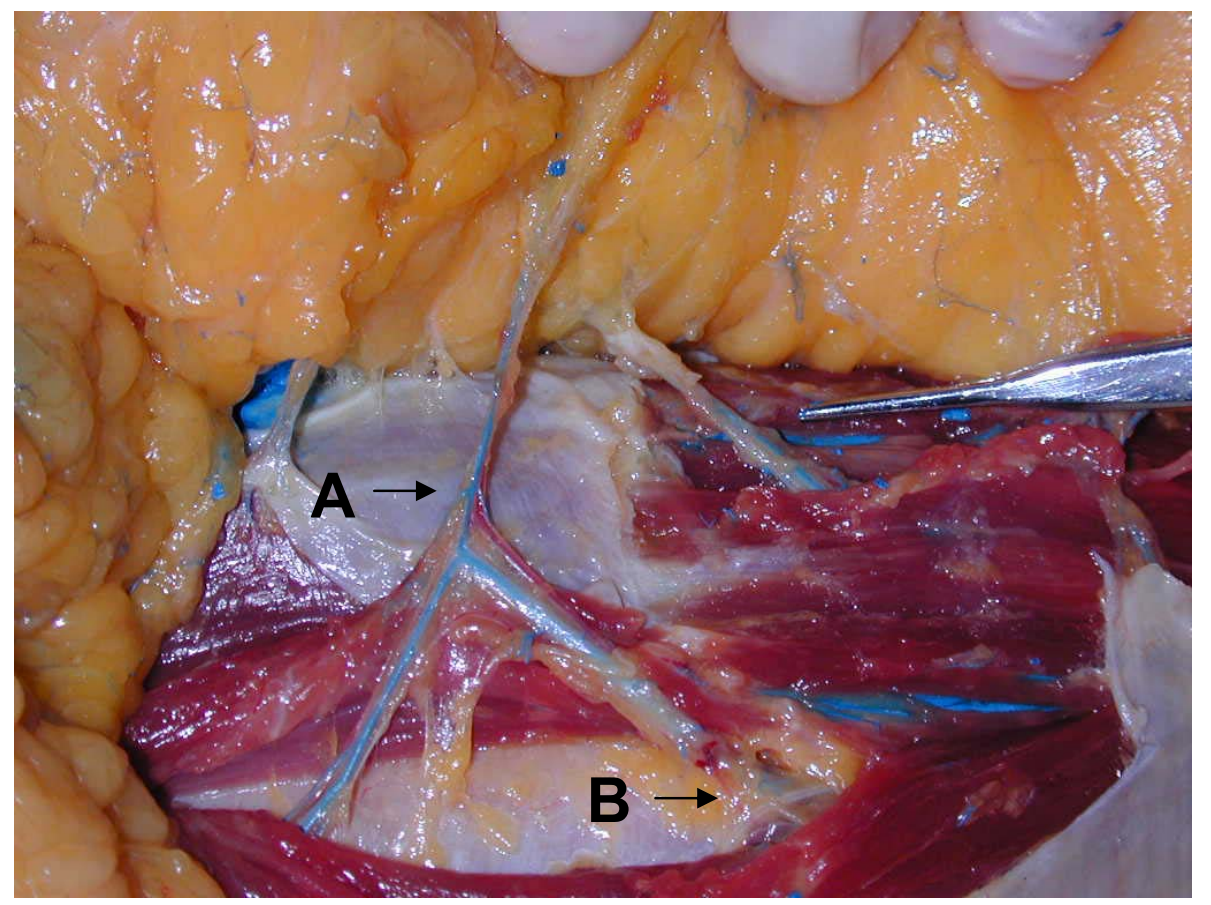

Figura 18. Dissecção completa do trajeto intramuscular retilíneo (A). Notase a preservação das fibras musculares e a individualização da artéria perfurante até o ramo da artéria epigástrica inferior (B). 


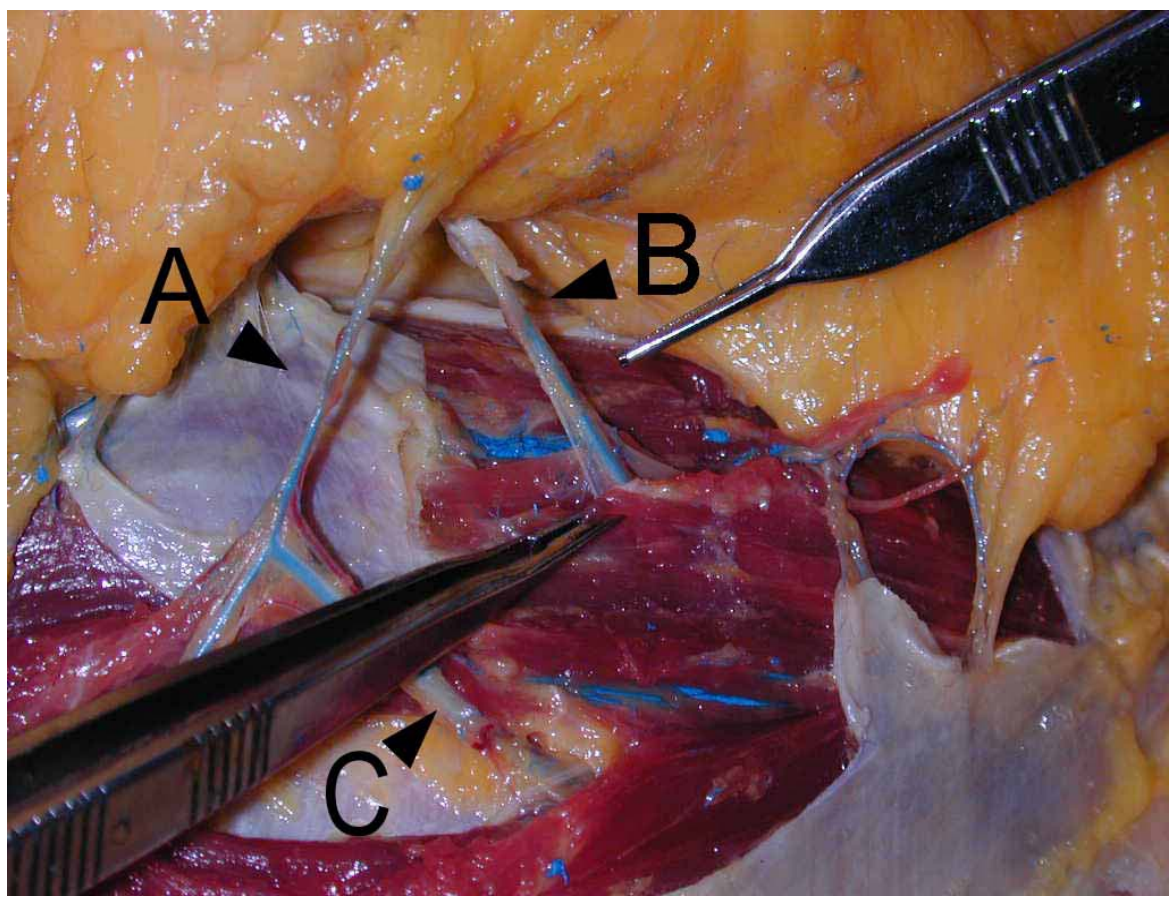

Figura 19. Dissecção da artéria perfurante da região medial com trajeto oblíquo (B). Nota-se em $C$ o ramo lateral da artéria epigástrica inferior, no qual a artéria perfurante apresentava sua origem. Em A, observa-se a artéria perfurante da região lateral com trajeto retilíneo previamente dissecado.

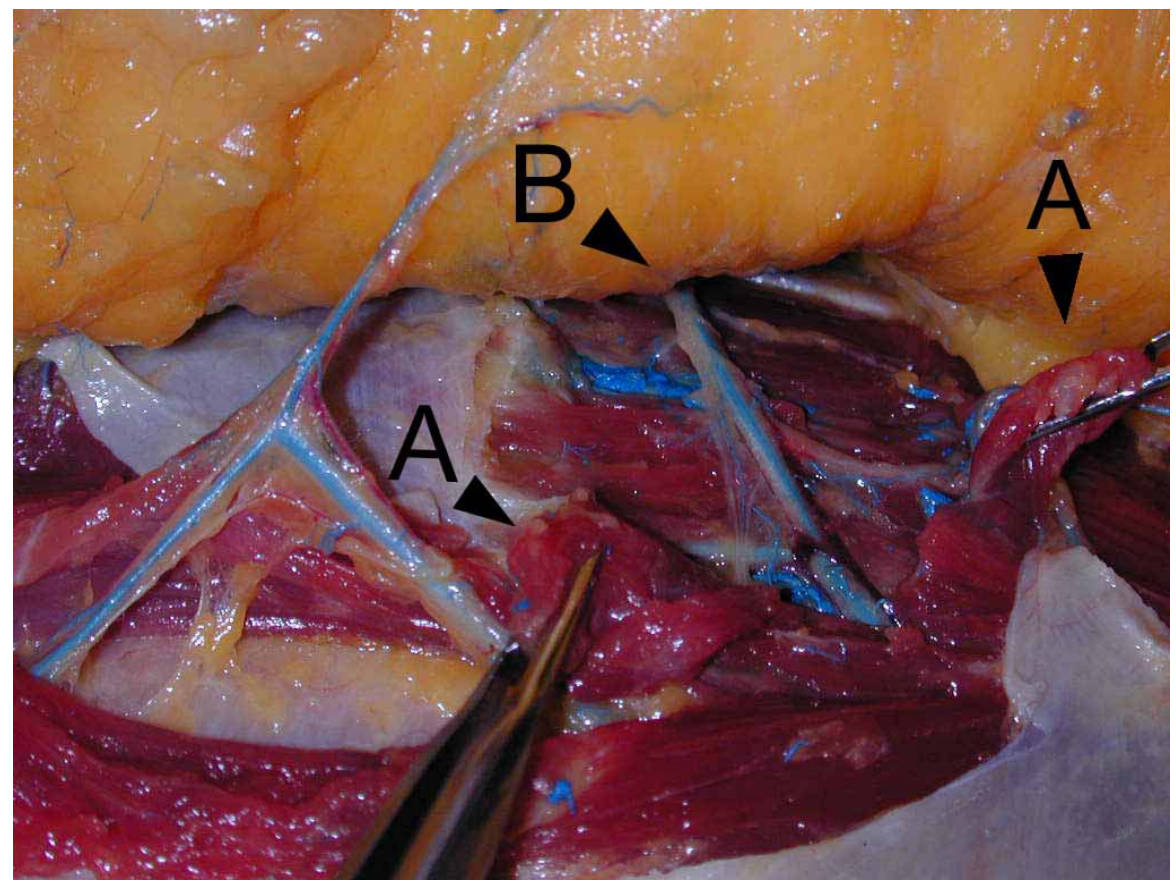

Figura 20. Dissecção completa do trajeto intramuscular oblíquo da artéria perfurante da região medial (B). Nota-se a secção das fibras musculares (A) com objetivo de separar a artéria perfurante do músculo reto do abdome. 


\begin{tabular}{cccc}
\hline $\begin{array}{c}\text { LOCALIZAÇÃO DO VASO } \\
\text { PERFURANTE / TRAJETO } \\
\text { INTRAMUSCULAR }\end{array}$ & OBLÍQUO & RETILÍNEO & TOTAL \\
\hline $\begin{array}{ccc}\text { Lateral (n.) } \\
\text { (\%) }\end{array}$ & 10 & 38 & 48 \\
Medial (n.) & 20,83 & 79,17 & \\
(\%) & 45 & 10 & 55 \\
TOTAL & 81,82 & 18,18 & \\
\hline
\end{tabular}

Tabela 3. Distribuição das artérias perfurantes em relação ao tipo de trajeto intramuscular (retilíneo e oblíquo) e à localização no músculo reto do abdome (lateral e medial). $p=0,001$

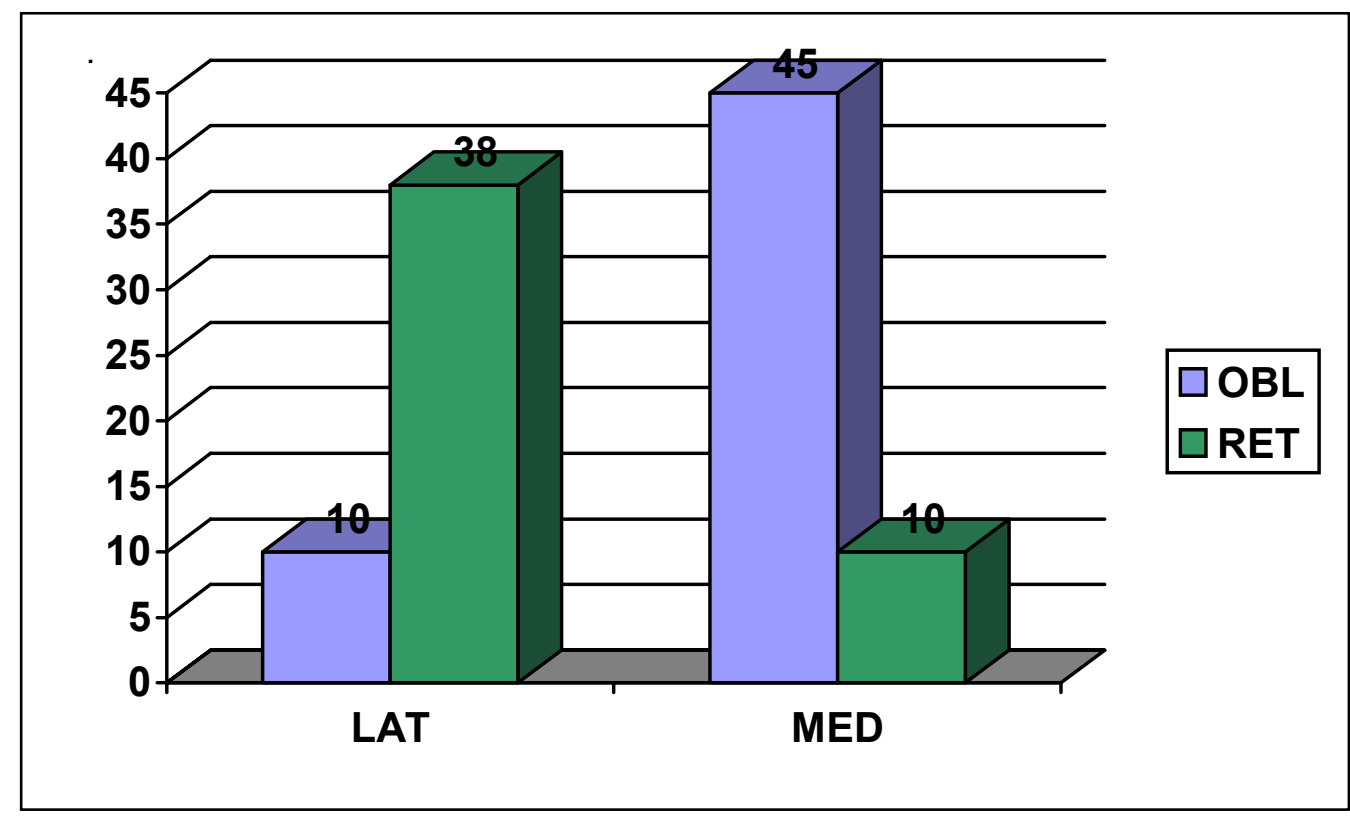

Figura 21. Distribuição das artérias perfurantes em relação ao tipo de trajeto intramuscular (retilíneo (RET) e oblíquo $(\mathrm{OBL})$ ) e à localização no músculo reto do abdome (lateral (LAT) e medial (MED)). $p=0,001$ 


\subsection{Artéria epigástrica inferior e ramificações}

O estudo da artéria epigástrica inferior permitiu a identificação de dois padrões diferentes de ramificação arterial.

O primeiro padrão (padrão I) correspondeu a 25 (83,3\%) artérias epigástricas inferiores dissecadas. Neste tipo foram observados dois ramos principais, ambos com trajeto ascendente e em direção à anastomose com a artéria epigástrica superior. Um ramo apresentava-se localizado mais próximo à margem lateral (ramo lateral) e outro, mais próximo à margem medial (ramo medial) do músculo reto do abdome. Neste grupo, em 20 (80\%) artérias foi observado o calibre do ramo lateral superior ao calibre do ramo medial, e em 5 (20\%) artérias, o ramo medial apresentou calibre superior ao ramo lateral (Figura 22 e 24).

Em um segundo padrão (padrão II) observado, a artéria epigástrica inferior não apresentava ramos. Neste tipo, a artéria apresentou um trajeto ascendente e em posição médio-lateral ao músculo reto do abdome. Esta forma foi observada em $5(16,6 \%)$ artérias epigástricas inferiores. Este padrão foi denominado de ramo único médio-lateral (Figuras 23 e 24). 


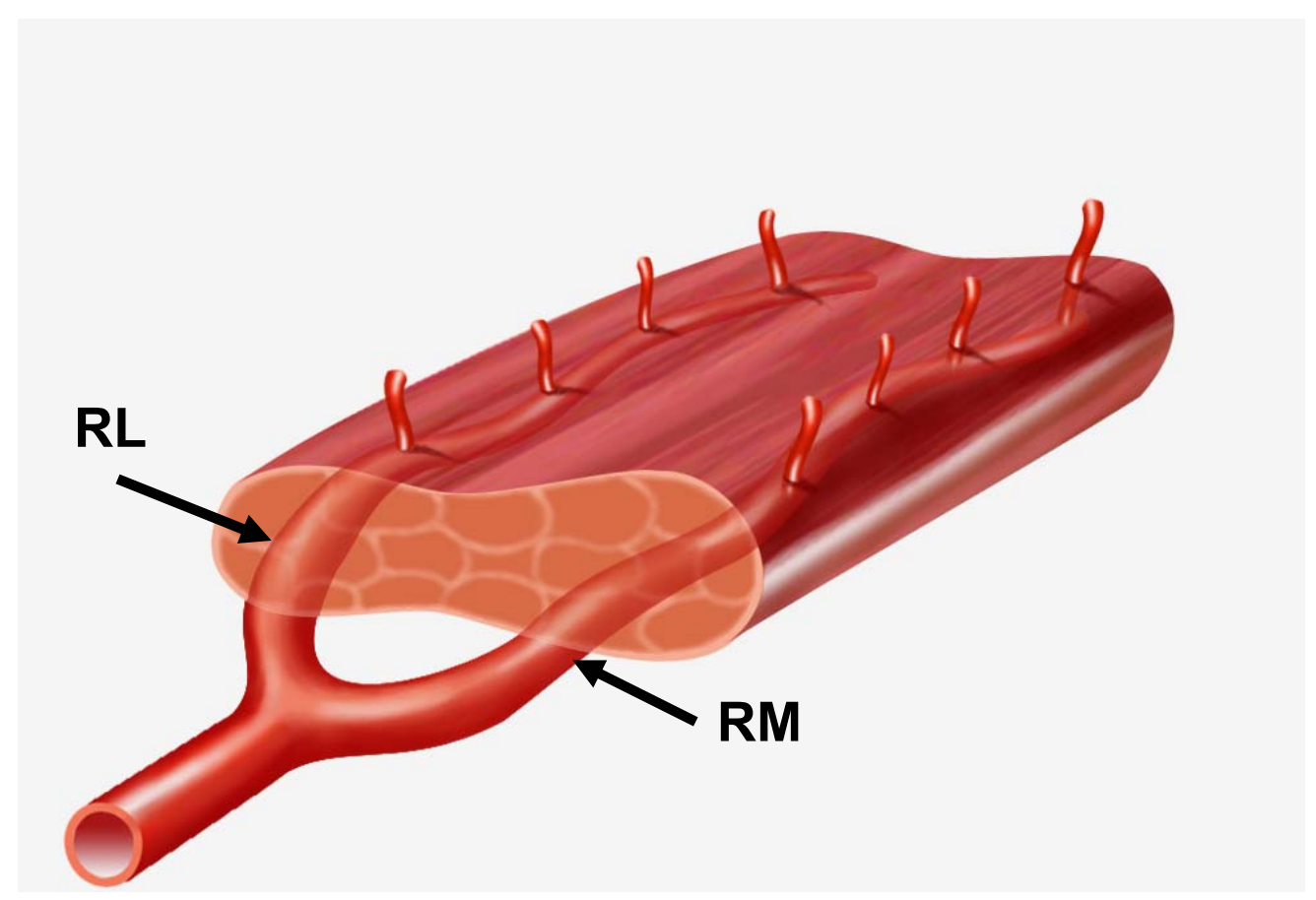

Figura 22. Padrão I de ramificação da artéria epigástrica inferior. Nota-se a presença de 2 ramos principais (lateral $(R L)$ e medial $(R M)$ ).

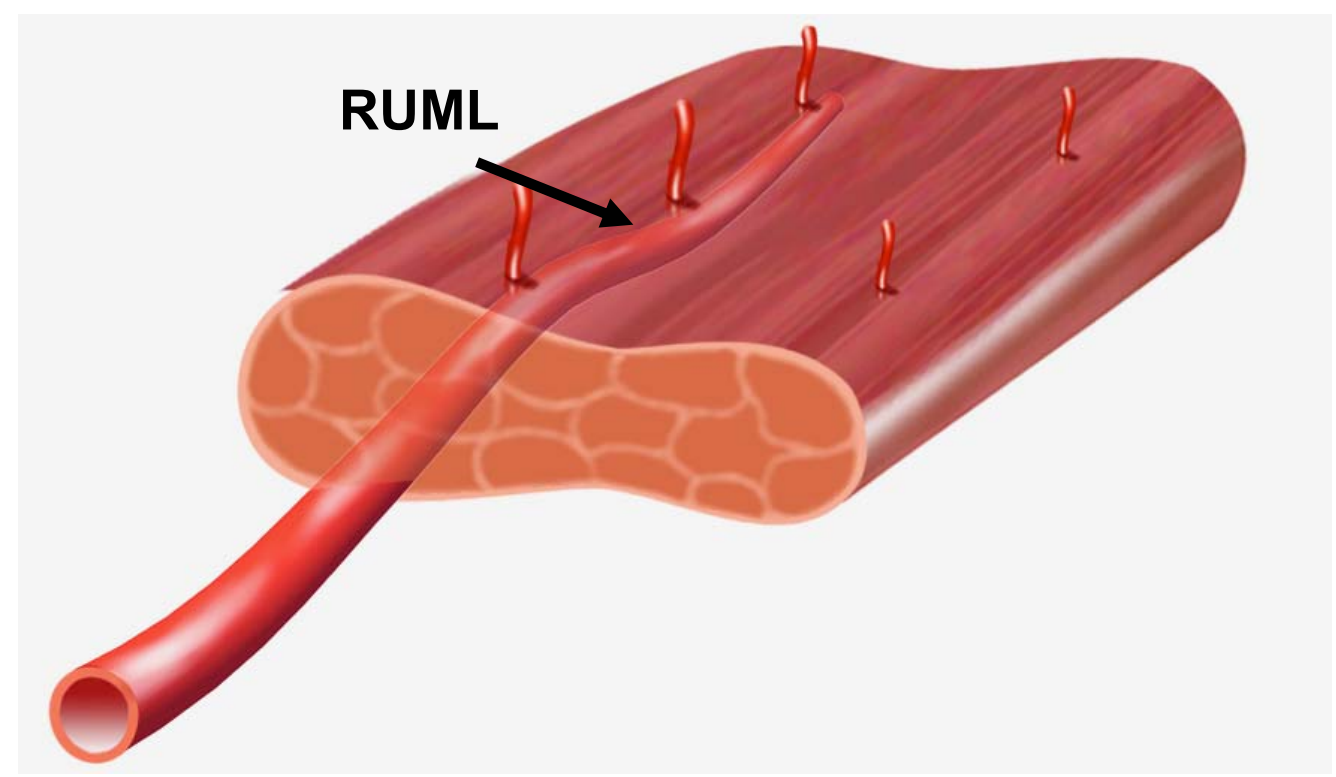

Figura 23. Padrão II de ramificação da artéria epigástrica inferior. Nota-se a presença de um ramo único principal em posição médio lateral (RUML). 


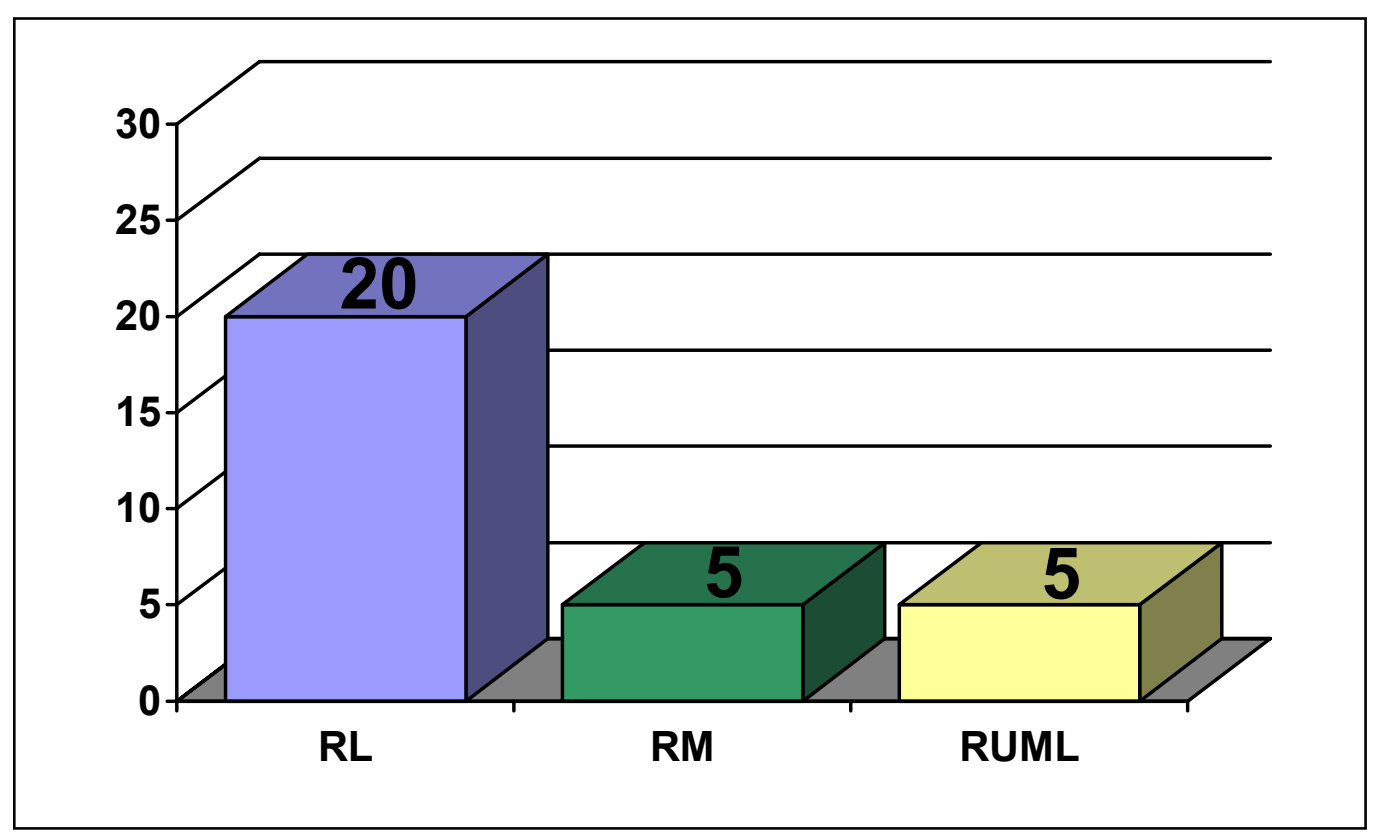

Figura 24. Distribuição dos ramos da artéria epigástrica inferior. RL: dois ramos principais sendo o ramo lateral dominante. RM: dois ramos principais sendo o ramo medial dominante. RUML: ramo único médio lateral. $(n=30)$. 
4.3.1 Artérias perfurantes e ramos da artéria epigástrica inferior

Após a dissecção do trajeto intramuscular das artérias perfurantes prosseguiu-se à identificação da sua origem nos ramos da artéria epigástrica inferior. Sessenta e nove $(66,9 \%)$ das 103 artérias perfurantes estudadas apresentavam origem no ramo lateral da artéria epigástrica inferior, dezoito $(17,4 \%)$ no ramo medial e $16(15,5 \%)$ no ramo único médio-lateral (Figura 25).

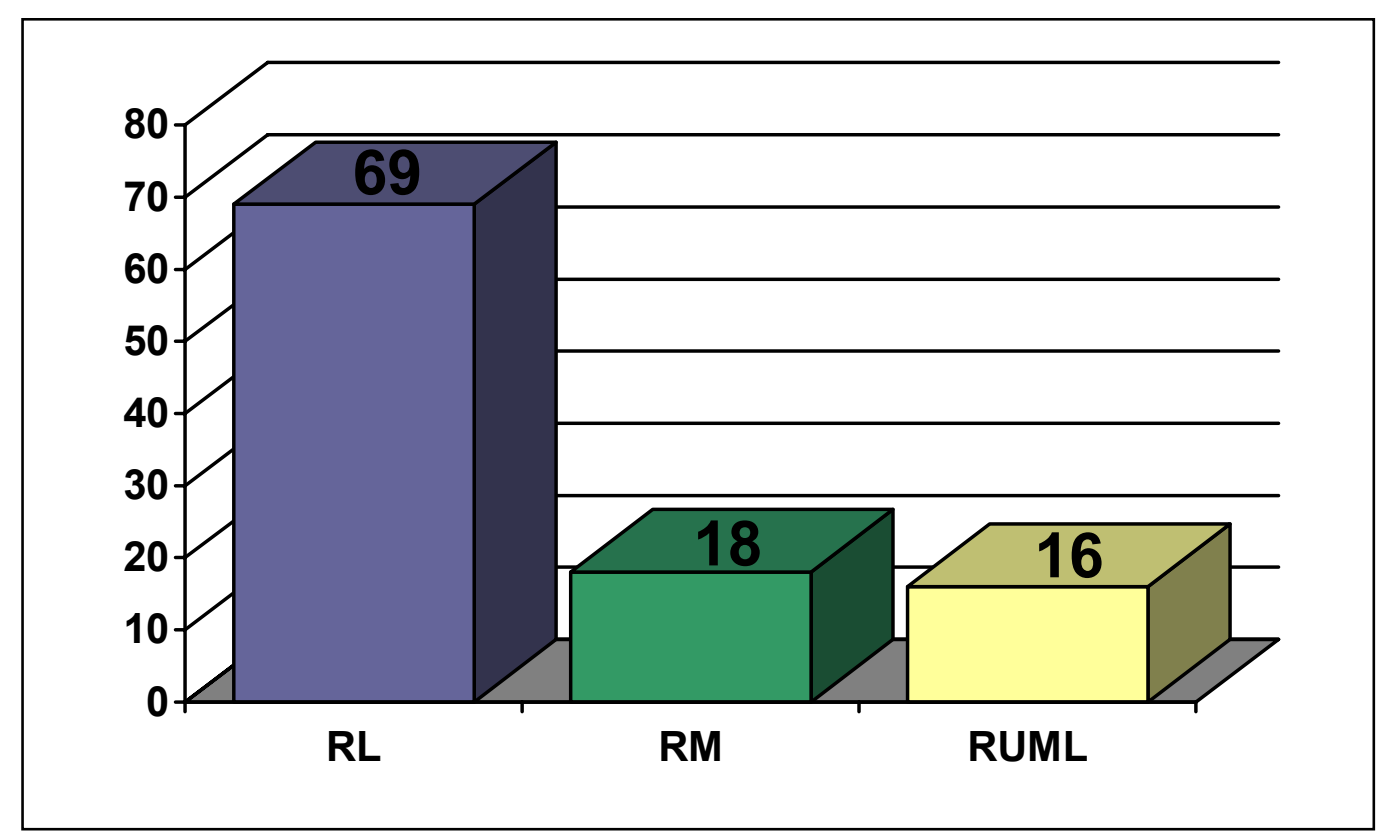

Figura 25. Origem das artérias perfurantes nos ramos da artéria epigástrica inferior. RL: Ramo lateral. RM: Ramo medial. RUML: ramo único em posição médio lateral. (n=103). 
Em relação ao calibre das artérias perfurantes (pequeno, médio e grande) e à origem nos ramos da artéria epigástrica inferior, foram observadas algumas diferenças.

$\mathrm{Na}$ região lateral do músculo reto do abdome, 34 (70,8\%) artérias perfurantes apresentaram origem no ramo lateral sendo 17 (50\%) de médio calibre, $12(35,3 \%)$ de grande calibre e $5(14,7 \%)$ de pequeno calibre. Nove $(18,7 \%)$ artérias perfurantes apresentaram a origem no ramo medial, sendo $5(55,5 \%)$ de médio calibre e $4(44,4 \%)$ de grande calibre. Cinco $(10,4 \%)$ artérias perfurantes apresentaram origem no ramo único médio-lateral sendo $4(80 \%)$ de médio calibre e $1(20 \%)$ com grande calibre. Nestes dois últimos ramos não foram observadas artérias perfurantes de pequeno calibre (Tabela 4 e Figura 26).

Na região medial do músculo reto do abdome, $35(63,6 \%)$ artérias perfurantes tiveram origem no ramo lateral sendo $26(74,3 \%)$ de médio calibre e $9(25,7 \%)$ de grande calibre. Onze (20\%) artérias perfurantes apresentaram origem no ramo único médio-lateral sendo 9 (81,8\%) de médio calibre e $2(18,2 \%)$ de grande calibre. Nove (16,3\%) artérias perfurantes tiveram a origem no ramo medial, sendo todas de médio calibre (Tabela 5 e Figura 27). 


\begin{tabular}{|c|c|c|c|c|c|c|}
\hline LOCAL & CALIBRE & & $\begin{array}{c}\text { RAMO ÚNICO } \\
\text { MÉDIO-LATERAL }\end{array}$ & RAMO LATERAL & RAMO MEDIAL & TOTAL \\
\hline \multirow{6}{*}{ LATERAL } & \multirow{2}{*}{ Pequeno } & (n.) & 0 & 5 & 0 & 5 \\
\hline & & $(\%)$ & 0 & 100,0 & 0 & 100,0 \\
\hline & \multirow{2}{*}{ Médio } & (n.) & 4 & 17 & 5 & 26 \\
\hline & & $(\%)$ & 15,4 & 65,4 & 19,2 & 100,0 \\
\hline & \multirow{2}{*}{ Grande } & (n.) & 1 & 12 & 4 & 17 \\
\hline & & $(\%)$ & 5,9 & 70,6 & 23,5 & 100,0 \\
\hline & TOTAL & & 5 & 34 & 9 & 48 \\
\hline
\end{tabular}

Tabela 4. Distribuição das artérias perfurantes em relação à origem no ramo da artéria epigástrica inferior (ramo único médio-lateral, medial e lateral) e ao calibre (pequeno, médio e grande) na região lateral do músculo reto do abdome $(n=48)$.

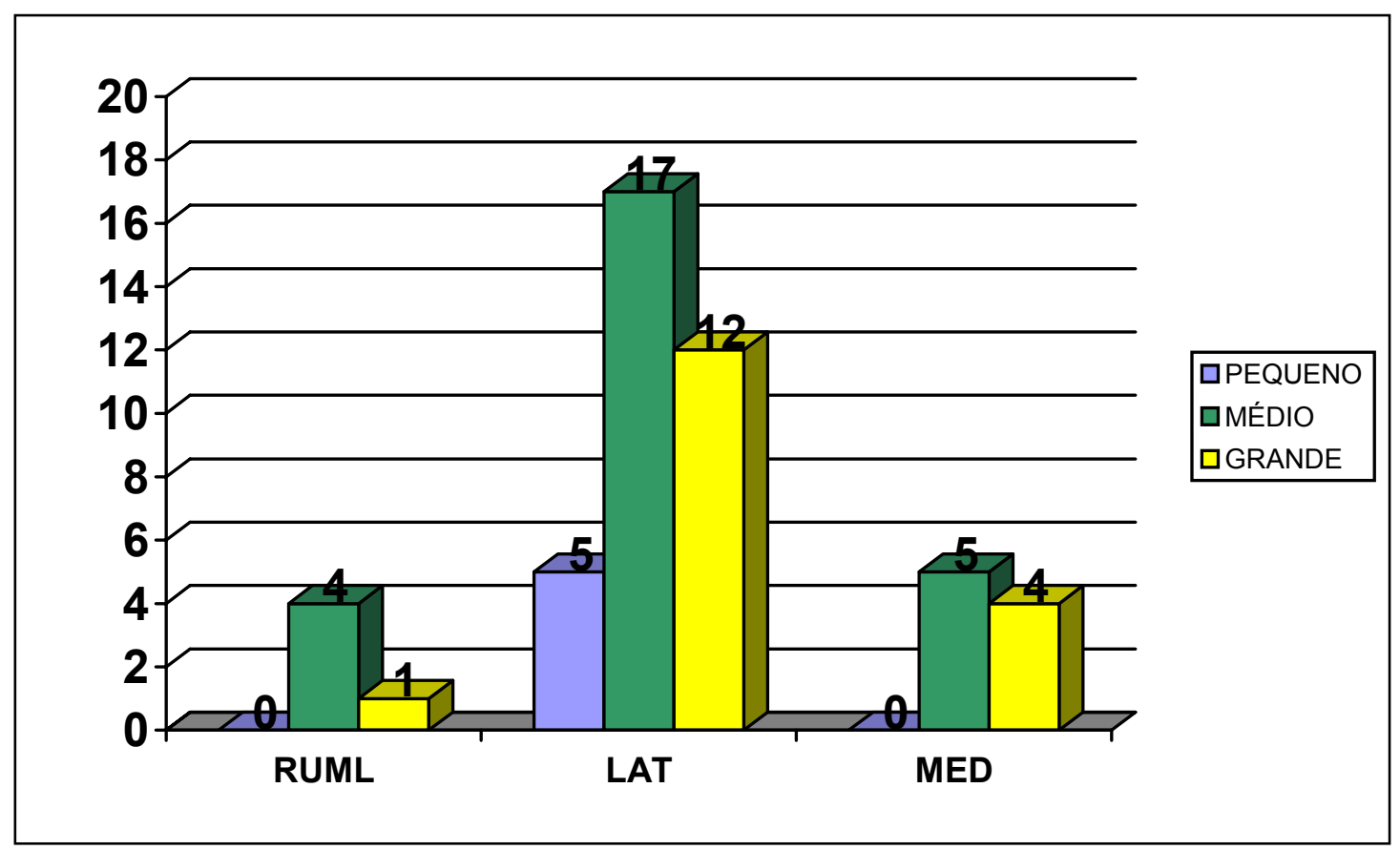

Figura 26. Distribuição das artérias perfurantes em relação à origem no ramo da artéria epigástrica inferior (ramo único médio-lateral, medial e lateral) e ao calibre (pequeno, médio e grande) na região lateral do músculo reto do abdome $(n=48)$. 


\begin{tabular}{|c|c|c|c|c|c|c|}
\hline LOCAL & CALIBRE & & $\begin{array}{c}\text { RAMO ÚNICO } \\
\text { MÉDIO-LATERAL }\end{array}$ & RAMO LATERAL & $\begin{array}{l}\text { RAMO } \\
\text { MEDIAL }\end{array}$ & TOTAL \\
\hline \multirow{6}{*}{ MEDIAL } & \multirow{2}{*}{ Pequeno } & (n.) & 0 & 0 & 0 & 0 \\
\hline & & $(\%)$ & 0,0 & 0,0 & 0,0 & 100,0 \\
\hline & \multirow{2}{*}{ Médio } & (n.) & 9 & 26 & 9 & 44 \\
\hline & & (\%) & 20,5 & 59,1 & 20,5 & 100,0 \\
\hline & \multirow{2}{*}{ Grande } & (n.) & 2 & 9 & 0 & 11 \\
\hline & & $(\%)$ & 18,2 & 81,8 & 0,0 & 100,0 \\
\hline & TOTAL & & 11 & 35 & 9 & 55 \\
\hline
\end{tabular}

Tabela 5. Distribuição das artérias perfurantes em relação à origem no ramo da artéria epigástrica inferior (ramo único médio-lateral, medial e lateral) e ao calibre (pequeno, médio e grande) na região medial do músculo reto do abdome $(n=55)$.

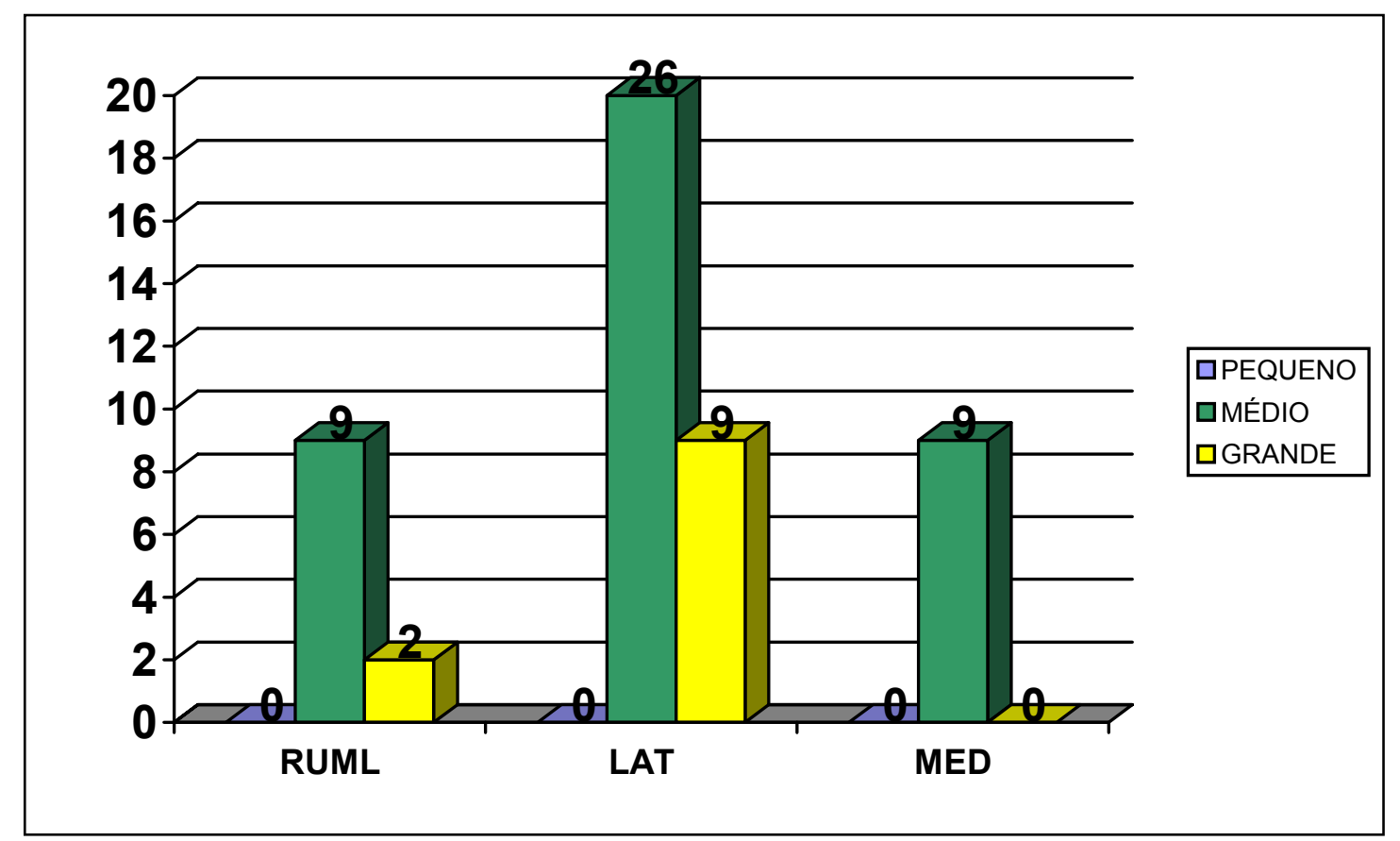

Figura 27. Distribuição das artérias perfurantes em relação à origem no ramo da artéria epigástrica inferior (ramo único médio-lateral, medial e lateral) e ao calibre (pequeno, médio e grande) na região medial do músculo reto do abdome $(n=55)$. 
$\mathrm{Na}$ análise estatística dos dados apresentados observou-se significância em relação ao calibre da artéria perfurante (médio e grande) e à sua origem nos ramos da artéria epigástrica inferior (ramo lateral, medial e único médio-lateral). Para esta análise não foi considerada a inclusão do grupo das artérias perfurantes de pequeno calibre (5 artérias da região lateral) uma vez que o número de amostras do grupo se apresentou estatisticamente pequeno em relação aos demais calibres.

Em ambas as regiões, lateral e medial observou-se maior incidência de artérias perfurantes de médio e grande calibres com origem no ramo lateral da artéria epigástrica inferior.

$\mathrm{Na}$ região lateral, por meio da construção dos intervalos de confiança de $95 \%$, pode-se observar no ramo lateral o intervalo de $[53,4 \% ; 81,4 \%]$, no ramo medial o intervalo de $[8,8 \% ; 33,2 \%]$ e no ramo único médio-lateral o intervalo de $[2,03 \% ; 21,2 \%]$. Como o intervalo de confiança no ramo lateral não apresentou intersecção com os intervalos nos ramos medial e único médio-lateral, conclui-se que a porcentagem de artérias perfurantes de médio e grande calibres que apresentaram origem no ramo lateral é significativamente maior do que a porcentagem de artérias que apresentaram origem nos outros ramos. Em contrapartida, a porcentagem de artérias originadas nos ramos medial e único médio-lateral não são diferentes uma vez que os intervalos não apresentam intersecção (Tabela $6)$.

Na região medial, por meio da construção dos intervalos de confiança de $95 \%$, pode-se observar no ramo lateral o intervalo de $[50,9 \% ; 76,3 \%]$, no 
ramo medial o intervalo de $[6,6 \% ; 26,2 \%]$ e no ramo único médio-lateral o intervalo de $[9,4 \% ; 30,6 \%]$. Da mesma forma que na região lateral, como o intervalo de confiança do ramo lateral não se intersecciona com os intervalos dos ramos medial e único médio-lateral, conclui-se que a porcentagem de artérias perfurantes de médio e grande calibres que apresentavam origem no ramo lateral é significativamente maior do que a porcentagem de artérias que apresentavam origem nos outros ramos. As porcentagens de artérias com origem nos ramos medial e único médio-lateral não foram diferentes já que os intervalos de confiança não se interseccionavam (Tabela 7). 


\begin{tabular}{cccccc}
\hline LOCAL/RAMOS & & $\begin{array}{c}\text { RAMO ÚNICO } \\
\text { MÉDIO- } \\
\text { LATERAL. }\end{array}$ & RAMO LATERAL & RAMO MEDIAL & TOTAL \\
\hline LATERAL & $(\mathrm{n})$. & 5 & 29 & 9 & $\mathbf{4 3}$ \\
INTERVALO DE & $(\%)$ & 11,6 & 67,4 & 20,9 & $\mathbf{1 0 0 , 0}$ \\
CONFIANÇA & {$[2,03 \% ; 21,2 \%]$} & {$[53,4 \% ; 81,4 \%]$} & {$[8,8 \% ; 33,2 \%]$} & \\
\hline
\end{tabular}

Tabela 6. Distribuição das artérias perfurantes de médio e grande calibres em relação à origem no ramo da artéria epigástrica inferior (ramo médio-lateral, medial e lateral) na região lateral do músculo reto do abdome. Análise com o teste dos intervalos de confiança de $95 \%$ das proporções.

\begin{tabular}{cccccc}
\hline LOCAL/RAMOS & & $\begin{array}{c}\text { RAMO ÚNICO } \\
\text { MÉDIO- } \\
\text { LATERAL }\end{array}$ & RAMO LATERAL & RAMO MEDIAL & TOTAL \\
\hline MEDIAL & $(\mathrm{n})$. & 11 & 35 & 9 & $\mathbf{5 5}$ \\
INTERVALO DE & $(\%)$ & 20,0 & 63,6 & 16,3 & $\mathbf{1 0 0 , 0}$ \\
CONFIANÇA & {$[9,4 \% ; 30,6 \%]$} & {$[50,9 \% ; 76,3 \%]$} & {$[6,6 \% ; 26,2 \%]$} & \\
\hline
\end{tabular}

Tabela 7. Distribuição das artérias perfurantes de médio e grande calibres em relação à origem no ramo da artéria epigástrica inferior (ramo médio-lateral, medial e lateral) na região medial do músculo reto do abdome. Análise com o teste dos intervalos de confiança de $95 \%$ das proporções. 


\subsection{Comprimento da Artéria Perfurante e do Pedículo}

\section{Arterial}

\subsubsection{Comprimento da artéria perfurante}

Como parâmetro clínico foi mensurado o comprimento da artéria perfurante de maior calibre em cada retalho, totalizando 30 artérias perfurantes medidas. Observou-se que o comprimento médio era de $5,3 \mathrm{~cm}$ $(3,0$ a $9,0 \mathrm{~cm})$.

Não se observou diferença estatística entre o lado direito e o lado esquerdo do abdome ( $p=0,925)$ (Tabela 8).

\begin{tabular}{cccccc}
\hline ARTÉRIAS & NÚMERO & $\begin{array}{c}\text { COMPRIMENTO } \\
\text { MÉDIO } \\
\text { (CM) }\end{array}$ & $\begin{array}{c}\text { DESVIO } \\
\text { PADRÃO }\end{array}$ & MÍNIMO & MÁXIMO \\
\hline Lado Direito & 15 & 5,33333 & 1,65603 & 3,00000 & 9,00000 \\
Lado Esquerdo & 15 & 5,29167 & 1,64397 & 3,00000 & 9,00000 \\
\hline
\end{tabular}

Tabela 8. Comprimento das artérias perfurantes em relação aos lados direito e esquerdo do abdome. 
Quando comparado o comprimento da artéria perfurante da região lateral ao da artéria perfurante da região medial do músculo reto do abdome, houve diferença estatística em apenas um lado. No lado direito, a artéria perfurante da região lateral apresentou comprimento médio de $2,7 \mathrm{~cm}$ enquanto que a artéria da região medial apresentou comprimento médio de $5,5 \mathrm{~cm}(\mathrm{p}=0,0204)$ (Tabelas 9 e 11).

\begin{tabular}{|c|c|c|c|c|c|}
\hline $\begin{array}{c}\text { ARTÉRIAS } \\
\text { PERFURANTES } \\
\text { LADO DIREITO }\end{array}$ & NÚMERO & $\begin{array}{l}\text { COMPRIMENTO } \\
\begin{array}{lr}\text { MÉDIO } & \text { (CM) }\end{array}\end{array}$ & $\begin{array}{l}\text { DESVIO } \\
\text { PADRÃO }\end{array}$ & MíNIMO & MÁXIMO \\
\hline Lateral & 15 & 2,75000 & 1,35680 & 1,00000 & 5,00000 \\
\hline Medial & 15 & 5,50000 & 2,46798 & 2,00000 & 11,0000 \\
\hline
\end{tabular}

Tabela 9. Comprimento das artérias perfurantes no lado direito do abdome e a relação com as regiões do músculo reto do abdome (lateral e medial).

No lado esquerdo do abdome, a artéria perfurante da região lateral apresentou comprimento médio de $2,7 \mathrm{~cm}$ enquanto que a artéria perfurante da região medial apresentou comprimento médio de $4,9 \mathrm{~cm}$. Este resultado não demonstrou significância estatística $(p=0,0636)$ (Tabelas 10 e 11).

\begin{tabular}{|c|c|c|c|c|c|}
\hline $\begin{array}{c}\text { ARTÉRIAS } \\
\text { PERFURANTES } \\
\text { LADO } \\
\text { ESQUERDO }\end{array}$ & NÚMERO & $\begin{array}{l}\text { COMPRIMENTO } \\
\begin{array}{lr}\text { MÉDIO } & \text { (CM) }\end{array}\end{array}$ & $\begin{array}{l}\text { DESVIO } \\
\text { PADRÃO }\end{array}$ & MÍNIMO & MÁXIMO \\
\hline Lateral & 15 & 2,75000 & 1,35680 & 1,00000 & 4,00000 \\
\hline Medial & 15 & 4,91667 & 2,64432 & 2,00000 & 11,0000 \\
\hline
\end{tabular}

Tabela 10. Comprimento das artérias perfurantes no lado esquerdo do abdome e a relação com as regiões do músculo reto do abdome (lateral e medial). 


\begin{tabular}{ccc}
\hline RAMO/LADO & DIREITO (média) & ESQUERDO (média) \\
\hline Lateral $(\mathbf{c m})$ & 2,75 & 2,75 \\
Medial $(\mathbf{c m})$ & 5,50 & 4,91 \\
Lateral X Medial $(\mathbf{p})$ & 0,0204 & 0,0636 \\
\hline
\end{tabular}

Tabela 11. Comprimento das artérias perfurantes e distribuição em relação aos lados do abdome (direito e esquerdo) e à origem da artéria perfurante no músculo reto do abdome (lateral e medial). $\mathrm{Na}$ análise estatística, apenas o lado direito demonstrou diferença significativa $(p=0,0204)$.

4.4.2 Comprimento do pedículo arterial

O pedículo arterial do retalho apresentou comprimento médio de 15,7 cm. A mensuração do comprimento total do pedículo do retalho apresentou diferença de acordo com a origem da artéria perfurante no músculo reto do abdome. Deste modo, a inclusão da artéria perfurante de maior comprimento e, portanto com origem na região medial do músculo reto do abdome, demonstrou diferença estatística. 
O pedículo arterial que apresentava a artéria perfurante proveniente da região lateral apresentou comprimento médio de $15,2 \mathrm{~cm}(7$ a $22 \mathrm{~cm}$ ) enquanto que o pedículo que continha a artéria perfurante proveniente da região medial apresentou comprimento médio de $16,2 \mathrm{~cm}(10$ a $23 \mathrm{~cm})$ $(p=0,0041)($ Tabelas 12 e 13).

\begin{tabular}{|c|c|c|c|c|}
\hline $\begin{array}{l}\text { PEDíCULO } \\
\text { ARTERIAL }\end{array}$ & $\begin{array}{l}\text { COMPRIMENTO } \\
\text { MÉDIO } \quad \text { (CM) }\end{array}$ & DESVIO & MíNIMO & MÁXIMO \\
\hline Lateral & 15,23095 & 3,27302 & 7,00000 & 22,0000 \\
\hline Medial & 16,27660 & 3,70635 & 10,0000 & 23,0000 \\
\hline \multicolumn{5}{|c|}{$\begin{array}{l}\text { Tabela 12. Comprimento médio do pedículo arterial do retalho e a relação com } \\
\text { vascularização a partir da localização da artéria perfurante (lateral e medial). }\end{array}$} \\
\hline \multicolumn{2}{|c|}{ REGIÃO/COMPRIMENTO } & \multicolumn{2}{|c|}{ COMPRIMENTO (cm) } & \\
\hline \multicolumn{2}{|c|}{ Lateral } & \multicolumn{2}{|c|}{15,23} & \\
\hline \multicolumn{2}{|c|}{ Medial } & \multicolumn{2}{|c|}{16,27} & \\
\hline \multicolumn{2}{|c|}{ Lateral X Medial (p) } & \multicolumn{2}{|c|}{0,0041} & \\
\hline
\end{tabular}

Tabela 13. Comprimento médio do pedículo arterial do retalho de acordo com a origem da artéria perfurante incluída na mensuração (lateral e medial). $\mathrm{Na}$ análise estatística houve diferença no comprimento do pedículo de acordo com a origem da artéria perfurante $(p=0,0041)$. 
5. Discussão

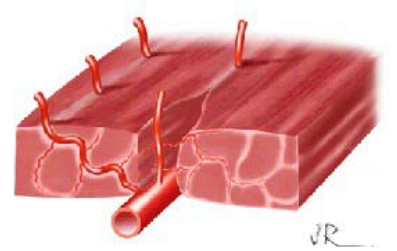


O estudo anatômico em cadáveres constitui fonte importante de conhecimento médico nas mais diversas áreas da medicina. $\mathrm{O}$ conhecimento detalhado da anatomia humana, a compreensão da fisiopatologia das doenças, o estabelecimento de técnicas cirúrgicas para o tratamento das mais variadas patologias e o julgamento na prática médica diária tiveram relação direta ou indireta com pesquisas realizadas em necrópsias.

No presente estudo foi empregada a análise em cadáveres frescos onde, de maneira prospectiva, foram realizadas dissecções anatômicas em região específica do corpo humano. Toda a investigação foi realizada no Serviço de Verificação de Óbitos da Capital (SVOC) e em cadáveres que foram encaminhados para a elucidação da "causa mortis". A população estudada apresentava seleção demográfica e clínica de acordo com os critérios pertinentes à análise individual de cada cadáver.

Em pesquisa clínica, a amostra de estudo é geralmente composta por indivíduos que atendem os critérios de entrada e são de fácil acesso ao pesquisador (VIEIRA, 1991). A técnica de amostragem da população é denominada de conveniência, e torna-se a única maneira de avaliar-se adequadamente a proposição do estudo.

Os critérios de inclusão definem as características principais da população-alvo e permitem a melhor inferência da amostra coletada. Incluíram-se desta forma apenas os cadáveres do sexo feminino. Este fato deve-se à idéia inicial de aplicação do retalho DIEP nas pacientes 
portadoras de câncer de mama e candidatas à reconstrução pós mastectomia. Desta forma, tivemos o cuidado de selecionar cadáveres com idade entre 45 e 70 anos, que corresponde à maior incidência do câncer de mama (HANKEY, 1992) e, portanto de melhor correspondência dos dados coletados com a aplicação clínica do retalho DIEP.

Em relação às estruturas anatômicas analisadas, alguns fatores relacionados aos antecedentes clínicos da população foram rigidamente controlados. Como se pretendia estudar a anatomia do sistema vascular e, em específico as artérias de pequeno calibre, excluíram-se os cadáveres cujos prontuários médicos revelassem risco para arteriosclerose como hipertensão arterial sistêmica, diabetes melitus, insuficiência arterial periférica, insuficiência coronariana e tabagismo.

De fato, estudos realizados em necrópsias de pacientes portadores de hipertensão arterial sistêmica e diabetes mostraram maior prevalência de lesões ateroscleróticas em graus avançados quando comparados com os não afetados (WILKINS et al., 1959; STRANDNESS et al., 1964). Da mesma forma, é consenso entre a maioria dos autores que o tabagismo constitui o mais importante fator de risco para a doença vascular periférica (JANZON, 1974; STRONG; RICHARDS, 1976).

Procedemos à análise de dissecção anatômica na região abdominal inferior, que corresponde aos limites do umbigo, sínfise púbica e espinhas ilíacas ântero-superiores. Como é comum a presença de cirurgias prévias nesta região excluímos todos os casos com estas características, pois poderia interferir no posicionamento normal das estruturas e assim 
prejudicar a correta avaliação e mensuração dos dados pesquisados. Assim, foram excluídos os cadáveres que apresentaram antecedentes ou sinais físicos de laparotomias transversas, medianas e paramedianas, de herniorrafias inguinais e umbilicais.

Utilizou-se a nomenclatura proposta pela TERMINOLOGIA ANATÔMICA (2001), que define os termos anatômicos em português baseado nos termos originais em latim. Esta terminologia reflete o consenso da Comissão Federativa da Terminologia Anatômica (CFTA) e de 56 associações que integram a Federação Internacional de Associações de Anatomistas (FIAA), a única entidade internacional que representa todos os aspectos da anatomia.

A terminologia anatômica é o fundamento da terminologia médica e, portanto é de suma importância que pesquisadores de todo o mundo utilizem o mesmo nome para cada estrutura.

Neste consenso, os autores estabeleceram definições específicas para as diversas estruturas anatômicas citadas e analisadas neste estudo. São definidos os termos médicos para o músculo reto do abdome, suas respectivas bainhas formadas pela lâmina anterior e posterior, as intersecções tendíneas, a fáscia transversal e a linha arqueada.

Em relação à vascularização do músculo reto do abdome, a TERMINOLOGIA ANATÔMICA define a artéria ilíaca externa e a artéria epigástrica inferior, sendo esta última sem a utilização do termo profundo que é amplamente utilizado na literatura internacional. De modo semelhante, o termo profundo também não é empregado junto à artéria epigástrica 
superior. A nomeação da artéria epigástrica inferior superficial, ramo da artéria femoral descarta a possibilidade de conflito com a artéria epigástrica inferior que é ramo da artéria ilíaca externa.

Na revisão bibliográfica não existem publicações prévias em língua portuguesa específica relatando o retalho DIEP e os principais termos habitualmente relacionados. Tal fato nos levou a refletir e a buscar a melhor maneira de descrever o retalho sem acarretar conflito com os termos já definidos na TERMINOLOGIA ANATÔMICA e o real significado da definição do retalho. Este fato confere à presente dissertação a originalidade na denominação do retalho na língua portuguesa bem como o ineditismo na definição e a aplicação dos termos.

$\mathrm{Na}$ terminologia não há menção sobre as artérias perfurantes musculares ou músculo-cutâneas, ramos da artéria epigástrica inferior. Ficaram estabelecidos os termos usualmente descritos e consagrados na literatura inglesa, quais sejam, a artéria perfurante muscular e a artéria perfurante músculo-cutânea. Consoante o dicionário da língua portuguesa HOUAISS (2003) e GRISOLIA; SBORGIA (2003), o termo perfurante é um adjetivo e como tal atribui ao substantivo artéria, a qualidade ou o estado de "perfurar furando". Na comparação do termo original da língua inglesa com a tradução para a língua portuguesa, não observamos interpretação errônea no significado nem tampouco discordância com a real definição do termo.

No que se refere ao retalho perfurante da artéria epigástrica profunda inferior, definição traduzida da língua inglesa, o mesmo raciocínio não apresenta significado na língua portuguesa uma vez que o retalho não 
apresenta a qualidade de "perfurar furando". Associado a este detalhe, o termo profundo não é utilizado na terminologia anatômica vigente. Portanto, a definição mais aceitável, do ponto de vista da língua portuguesa, seria: o retalho vascularizado pela artéria perfurante muscular da artéria epigástrica inferior. Da mesma forma, evitou-se a utilização do termo profundo associado à artéria epigástrica inferior e superior em toda a dissertação.

Na TERMINOLOGIA ANATÔMICA, o tecido celular subcutâneo é denominado como tela subcutânea e o panículo adiposo, como a sua camada constituída essencialmente por tecido adiposo.

Em relação aos epônimos habitualmente utilizados na região do abdome, manteve-se a nomenclatura também caracterizada na TERMINOLOGIA ANATÔMICA. Define-se a linha alba como a linha mediana do abdome e as linhas semilunares, como o ponto de transição do músculo reto do abdome com o músculo oblíquo externo.

A dissecção da artéria epigástrica inferior e das artérias perfurantes do músculo reto do abdome apresenta, do ponto de vista técnico, relativa facilidade e depende da qualidade de conservação do cadáver, da técnica empregada e do calibre vascular das estruturas analisadas.

Foram utilizados cadáveres frescos e não formolizados, fato este que permitiu a maior conservação das estruturas e a menor distorção dos parâmetros anatômicos estudados.

As artérias perfurantes musculares estão habitualmente localizadas na região compreendida entre a linha alba e as linhas semilunares. Sua 
identificação é realizada pela separação do panículo adiposo da aponeurose do músculo reto do abdome através da utilização de tesoura ou de bisturi.

Para a dissecção do trajeto intramuscular é necessária a abertura da lâmina anterior da bainha do músculo reto do abdome e a dissecção da artéria perfurante entre as fibras musculares. Nesta etapa é necessário, além de tesoura e de bisturi, a utilização de instrumentos delicados e afastadores com o intuito de melhor expor o trajeto. As manobras, durante a dissecção, foram realizadas com delicadeza, com o objetivo de preservar os ramos arteriais menores e os ramos venosos que apresentavam íntima relação com o trajeto das artérias perfurantes.

Visando a melhor visualização das artérias perfurantes na região do panículo adiposo e no trajeto intramuscular, utilizou-se o sistema de injeção intra-arterial de tinta corante associado ao látex. Foi padronizado o corante de cor azul para injeção arterial devido ao maior contraste da tinta no tecido muscular. Além do melhor contraste das artérias com as estruturas adjacentes, o látex permitiu maior facilidade técnica de dissecção das estruturas vasculares uma vez que conferia também maior rigidez à parede vascular das artérias perfurantes.

Para a dissecção do trajeto intramuscular foram necessários, além do material básico de dissecção, o uso de instrumentos específicos de microcirurgia e a utilização de lentes de magnificação pela maior dificuldade técnica de manipulação das artérias perfurantes e do calibre reduzido das estruturas vasculares analisadas. 
Na mensuração das variáveis contínuas como o calibre das artérias perfurantes, as distâncias em relação aos pontos de referência e os comprimentos arteriais, empregou-se 0 instrumento de metrologia dimensional digital. O instrumento permitiu maior precisão dos dados coletados, uma vez que o sistema de mensuração apresenta alta sensibilidade e permite a medida de valores com até 2 centésimos de milímetro.

Apesar da utilização do material de coloração e de instrumentos específicos, não foi possível a dissecção do trajeto intramuscular de todos as artérias perfurantes identificadas. Este fato não constituiu limitação na análise da amostra, uma vez que em $91,5 \%$ das artérias de grande calibre e em 53,9\% das artérias de médio calibre, o estudo da anatomia intramuscular foi executado com sucesso. Nestes subgrupos, a lesão inadvertida da artéria perfurante durante a sua dissecção, foi a razão da não inclusão de todo o material na análise. Nas artérias com calibre inferior a $1 \mathrm{~mm}$, a dificuldade técnica de dissecção e a pouca representação clínica na vascularização do retalho DIEP, justificaram a exclusão deste subgrupo do estudo da anatomia intramuscular. Ademais, é consenso que a maioria dos autores utilizam o retalho DIEP vascularizado em artérias perfurantes de médio e grande calibres e, portanto as artérias de pequeno calibre apresentariam pouco significado prático (KOSHIMA et al., 1992; ALLEN; TREECE, 1994; BLONDEEL et al., 1998; HAMDI et al., 1999; HEITMANN et al., 2000; MUNHOZ et al., 2001; MRAKBY; MILNER, 2002; VANDEVOORT et al., 2002; CRAIGIE et al., 2003; MUNHOZ et al., 2004a; GILL et al., 2004). 
O estudo anatômico pelos métodos radiológicos (HADDAD, 1968; BOYD et al., 1984; TAYLOR et al., 1984; MOON; TAYLOR, 1988) é válido e permite a visualização das artérias epigástricas inferiores e dos principais ramos perfurantes musculares. Porém, o emprego da radiologia pela injeção intra-arterial de material de contraste e a obtenção de imagens por meio de raios-X não permitem o estudo detalhado do trajeto intramuscular e de suas variantes, além da relação espacial com os tecidos adjacentes.

O uso de métodos de imagens dinâmicas como a ultra-sonografia Doppler (BLONDEEL et al., 1998; GRAF et al., 2004; MUNHOZ et al., 2004b) é de grande importância no estudo da anatomia vascular da parede do abdome. A principal vantagem refere-se à possibilidade de investigação em condições fisiológicas, uma vez que esta técnica se apresenta como método não invasivo e habitualmente usado em pacientes. Como limitações, existe a dificuldade técnica de visualização de artérias com calibre inferior a $2 \mathrm{~mm}$ e, portanto inferior à análise realizada em cadáveres frescos e pelo método de dissecção.

O método de injeção de substâncias moldantes e a posterior corrosão das estruturas não vasculares com ácidos (YAMADA et al., 1993) propicia moldes que possibilitam o estudo da forma e das dimensões do sistema arterial. Apesar de não haver relatos prévios da aplicação deste método no estudo das artérias perfurantes do abdome, pode-se inferir que a corrosão das estruturas musculares adjacentes levaria à perda do parâmetro anatômico na avaliação do trajeto intramuscular. A correlação das artérias 
perfurantes com a situação espacial no músculo reto do abdome também apresentaria limitações nesta forma de avaliação.

O estudo por meio de cortes plastinados (HAGENS et al., 1987; RODRIGUES et al., 1993a; RODRIGUES et al., 1993b) permite definir a localização das artérias perfurantes, da artéria epigástrica inferior e dos respectivos diâmetros. Todavia, a análise ao longo do trajeto intramuscular seria por demais trabalhoso devido à característica tridimensional do percurso das artérias por meio das fibras musculares.

As medidas antropométricas coletadas do prontuário médico permitiram estudar as dimensões de cada cadáver e a correlação com a média da população brasileira e a aplicação clínica dos dados coletados. Segundo MARCONDES (1991), a população adulta brasileira feminina apresenta média de altura de 1,64 m e média de peso de $65 \mathrm{~kg}$. Estes dados são próximos aos obtidos nos cadáveres estudados, de onde podemos inferir que a amostra da população analisada é representativa, quanto às medidas antropométricas da altura e peso.

No que se refere à correlação dos dados anatômicos coletados com as medidas antropométricas coletadas, não achamos necessário tal análise devido à pequena casuística de cadáveres e ao grande número de variáveis envolvidas.

O número e a localização das artérias perfurantes do músculo reto do abdome são relatados na literatura. A análise da distribuição das artérias perfurantes bem como detalhes referentes ao trajeto intramuscular apresentam fundamental importância, haja vista a relevância do preciso 
conhecimento da anatomia local no planejamento e na dissecção do retalho DIEP.

Em relação ao número de artérias perfurantes por segmento de músculo reto do abdome, os dados coletados apresentaram concordância com vários trabalhos presentes na literatura. BLONDEEL et al. (1998), MUNHOZ et al. (2004b) e GRAF et al. (2004) utilizando a metodologia do ultra-som Doppler relataram a presença de 4 a 5 artérias perfurantes por segmento de músculo reto do abdome. KOSHIMA; SOEDA (1989), na primeira descrição clínica do retalho DIEP também observaram o mesmo número de artérias. Outros autores como ITOH; ARAI (1993) e MRAKBY; MILNER (2002) notaram em estudos anatômicos a média de 5,4 e 6,5 artérias perfurantes respectivamente.

No presente estudo foram dissecadas 191 artérias perfurantes em 30 peças anatômicas. O resultado obtido apresentou média de 6,3 artérias perfurantes de pequeno, médio e grande calibre por segmento muscular analisado e, portanto, próximo aos estudos antecedentes.

Apesar da existência de investigação anatômica em vários centros e da presença de diversos estudos publicados, não há consenso entre os autores em relação às regiões de maior concentração das artérias perfurantes na região infra-umbilical. Este fato pode ser decorrente do uso de metodologias de pesquisa diferentes, da utilização de parâmetros anatômicos não padronizados e da qualidade das peças anatômicas avaliadas em estudos conduzidos em cadáveres. Associado a estes fatores, o desconhecimento da relevância da informação relacionada ao calibre e à localização das artérias, 
na época de realização de alguns estudos, também pode ter contribuído para a pouca precisão dos dados e até a contradição de algumas informações.

O ponto de referência anatômico representado pelo umbigo é citado por diversos autores como a localização preferencial das artérias perfurantes (HADDAD, 1968; BROWN et al., 1975; BOYD et al., 1984; TAYLOR et al., 1984; MILLER et al., 1988; MOON; TAYLOR, 1988; KOSHIMA; SOEDA, 1989; MATHES; NAHAI, 1997; HEITMANN et al., 2000; CRAIGIE et al., 2003).

Este dado se apresenta em concordância com o presente estudo onde foi constatado o maior número absoluto de artérias perfurantes na região medial do músculo reto do abdome e, portanto mais próximo ao umbigo.

Outros autores relataram a maior concentração de artérias perfurantes em outras regiões. ITOH; ARAI (1993) e MRAKBY; MILNER (2002) observaram a maior concentração de artérias perfurantes nas regiões mais laterais do músculo reto do abdome e BLONDEEL et al. (1998) e HEITMANN et al. (2000) definiram uma ampla área na região abdominal inferior contendo o maior número de artérias perfurantes.

A maior concentração de artérias perfurantes em regiões específicas do músculo reto do abdome também é relatada e está em concordância com os achados do nosso estudo. MUNHOZ et al. (2004b) na avaliação da região supra-umbilical, relatam o maior número de artérias perfurantes na porção compreendida entre 2 e $6 \mathrm{~cm}$ lateral à linha alba. Estes dados corroboram 
com os achados observados por BLONDEEL et al. (1998) na região infraumbilical do músculo reto do abdome.

No presente estudo foram observados dois tipos de distribuição das artérias perfurantes de acordo com a situação em relação às margens do músculo reto do abdome. As artérias se localizaram preferencialmente na região lateral, isto é, mais próximas ao músculo oblíquo externo e medial, isto é, mais próximas à linha alba. Na quantificação desta distribuição, foi observado o maior número absoluto de artérias perfurantes na região medial, fato este que representou $66 \%$ das artérias perfurantes mapeadas.

Na programação da reconstrução com o retalho DIEP é de fundamental importância o conhecimento das regiões que apresentem maior concentração de artérias perfurantes com maior calibre. Desta forma, consegue-se a melhor configuração da área de pele de sorte a incluir as artérias perfurantes de maior calibre no retalho a ser transferido.

Apesar da relevância deste dado no planejamento, são controversos os estudos que descrevem a distribuição preferencial das artérias perfurantes de acordo com o calibre.

Alguns autores citaram o ponto de referência representado pelo umbigo como a localização preferencial para as artérias perfurantes de maior calibre (HADDAD, 1968; BROWN et al., 1975; TAYLOR et al., 1984; MILLER et al., 1988; MOON; TAYLOR, 1988; KOSHIMA; SOEDA, 1989; MATHES; NAHAI, 1997; HEITMANN et al., 2000; CRAIGIE et al., 2003). Outros autores como PENNINGTON et al. (1980) descreveram a presença de artérias perfurantes 
com calibre entre 2,5 e 3,0 mm, porém não houve especificação das regiões que apresentam maior concentração.

BOYD et al. (1984) descreveram a presença de artérias perfurantes de maior calibre (>0,5 mm) como originárias do músculo reto do abdome e as de menor calibre $(<0,5 \mathrm{~mm})$ como as artérias perfurantes fáscio-cutâneas e provenientes da linha alba e da aponeurose do músculo oblíquo externo. Afirmaram que a região medial do músculo reto do abdome apresentava maior concentração de artérias perfurantes com maior calibre. De maneira contrária, ITOH; ARAI (1993) e MRAKBY; MILNER (2002) verificaram o mesmo dado em relação à região lateral.

MOON; TAYLOR (1988) relataram a distribuição preferencial das artérias de maior calibre na região localizada superiormente à linha arqueada e BLONDEEL et al. (1998) e HEITMANN et al. (2000) definiram regiões mais amplas sem estabelecer relação precisa com as regiões do músculo reto do abdome.

Foram analisadas no presente estudo apenas as artérias perfurantes músculo-cutâneas originárias do músculo reto do abdome uma vez que as artérias perfurantes fáscio-cutâneas não apresentam aplicação clínica no planejamento do retalho DIEP. Observou-se o calibre arterial compreendido entre 0,3 e $3 \mathrm{~mm}$. A correlação do calibre arterial com a linha arqueada do abdome não foi observada conforme proposto por MOON e TAYLOR (1988).

$\mathrm{Na}$ presente análise observou-se a relação entre as artérias perfurantes de maior calibre e as regiões específicas do músculo reto do abdome. $\mathrm{Na}$ comparação entre as duas regiões, lateral e medial, pode-se inferir que na 
região medial do músculo reto do abdome, o calibre das artérias perfurantes é menor quando comparado com o calibre das artérias perfurantes da região lateral. Apesar de, em números absolutos, a região medial apresentar maior concentração de artérias perfurantes, a região lateral apresentou proporcionalmente a maior concentração de artérias de médio e grande calibres. Este fato é determinado de maneira estatística através da diferença de escore obtido entre as duas regiões analisadas.

Desde 1989, quando KOSHIMA publicou os dois primeiros casos do retalho DIEP, inúmeros outros trabalhos clínicos e estudos anatômicos surgiram avaliando os detalhes técnicos relacionados à sua dissecção (KOSHIMA; SOEDA 1989; KOSHIMA et al. 1992; ALLEN; TREECE, 1994; BLONDEEL; BOECKX, 1994; BLONDEEL et al. 1997; BLONDEEL et al. 1998; HAMDI et al. 1998; BLONDEEL et al. 2000; HEITMANN et al. 2000; CRAIGIE et al., 2003). Na literatura, porém, verificou-se que são poucos e limitados os trabalhos que analisam a trajetória das artérias perfurantes através das fibras do músculo reto do abdome (ITOH; ARAI, 1993; BLONDEEL et al. 1999; MUNHOZ et al. 2001; MRAKBY; MILNER 2002; VANDEVOORT et al. 2002; MUNHOZ et al. 2004a).

Em 1993, por meio de estudos anatômicos e clínicos conduzidos por ITOH e ARAI, houve a primeira indagação em relação à importância do trajeto intramuscular e as repercussões clínicas na execução do retalho DIEP. Apesar de não apresentarem dados estatísticos, os autores observaram a presença de artérias perfurantes de maior calibre na região 
lateral do músculo reto do abdome, e a presença do menor trajeto intramuscular até o ramo lateral dominante da artéria epigástrica inferior.

Outros autores como BLONDEEL et al. (1999) e MUNHOZ et al. (2004a), colocaram importantes ressalvas na escolha da artéria perfurante e na facilidade de dissecção do trajeto intramuscular. As artérias perfurantes localizadas na região lateral do músculo reto do abdome apresentavam o trajeto intramuscular em posição perpendicular ao ramo lateral da artéria epigástrica inferior e, portanto com maior facilidade técnica de dissecção. Todavia, as artérias perfurantes localizadas na região medial apresentavam o trajeto intramuscular mais longo e, portanto de dissecção mais difícil.

No presente estudo anatômico foram observados dados e conclusões semelhantes às propostas por ITOH; ARAI (1993) e BLONDEEL et al. (1999) com a identificação de dois tipos de trajetos intramusculares.

Em uma situação, a artéria perfurante apresentou o trajeto intramuscular curto e localizado exclusivamente no septo muscular. Do ponto de vista técnico houve maior facilidade de dissecção uma vez que a separação da artéria perfurante era realizada através do afastamento das fibras musculares sem a necessidade de secção das fibras do músculo reto do abdome.

Em uma outra situação, a artéria perfurante apresentou o trajeto intramuscular longo até a sua origem no ramo da artéria epigástrica inferior. Durante o seu curso havia a necessidade de secção de algumas fibras musculares e o trajeto não se localizou em um único septo muscular. 
Na correlação do tipo de trajeto intramuscular com a localização da artéria perfurante no músculo reto do abdome, podem-se observar importantes diferenças.

Na região lateral do músculo reto do abdome, a maioria das artérias perfurantes apresentavam o trajeto retilíneo e a minoria, o trajeto oblíquo. Contudo, na região medial, a minoria das artérias perfurantes apresentavam o trajeto retilíneo. Estes dados demonstraram diferença estatística quando analisados comparativamente.

O menor comprimento do trajeto e a orientação longitudinal das fibras musculares do músculo reto do abdome em relação ao ramo da artéria epigástrica inferior, permitem a inclusão do trajeto da artéria perfurante em um único septo muscular. Este fato corrobora para o planejamento da dissecção do retalho DIEP uma vez que há maior facilidade técnica na dissecção das artérias que apresentem esta configuração.

Todavia, nas artérias perfurantes localizadas na região medial, há a necessidade de dissecção do longo trajeto através das fibras musculares até a origem da artéria perfurante no ramo da artéria epigástrica inferior. A orientação longitudinal das fibras musculares e o trajeto da artéria perfurante da região medial para a região lateral levariam à impossibilidade do seu percurso em um único septo muscular.

A previsibilidade anatômica em relação ao tipo de trajeto intramuscular e a possibilidade de sua aplicação no planejamento da escolha da artéria perfurante favorecem a dissecção do retalho DIEP. A maior incidência do trajeto retilíneo nas artérias perfurantes laterais além da maior facilidade 
técnica da dissecção intramuscular, podem favorecer para a redução do risco de lesão iatrogênica da artéria perfurante e a eventual perda do retalho. A maior extensão do trajeto intramuscular, além da característica da ausência da artéria perfurante em um único septo muscular podem interferir no tempo operatório da reconstrução e, portanto na maior morbidade do procedimento.

A dificuldade técnica da dissecção da artéria perfurante no trajeto intramuscular constitui a grande limitação para a ampla difusão da técnica do retalho DIEP. Associado a isto, o nível de dificuldade encontrado na dissecção pode estar relacionado ao maior risco de lesão iatrogênica da artéria perfurante e ao maior tempo operatório (KOSHIMA; SOEDA, 1989; BLONDEEL et al., 1999; HAMDI et al., 1999; MUNHOZ et al., 2001; VANDEVOORT et al., 2002; MUNHOZ et al., 2004a).

BLONDEEL et al. (1999) salientaram a maior facilidade de dissecção das artérias perfurantes da região lateral e, portanto menor risco de lesão vascular. Nas artérias perfurantes de localização medial, os autores enfatizaram que a dissecção das artérias perfurantes é, na maioria das situações, mais elaborada, além da necessidade de extensa dissecção intramuscular.

HAMDI et al. (1999) na análise entre a dissecção dos retalhos TRAM microcirúrgico e DIEP relataram o maior tempo operatório advindo da necessidade de dissecção do trajeto intramuscular. A dissecção da artéria perfurante nas fibras do músculo reto do abdome é trabalhosa e pode 
acrescentar até 30 minutos no tempo cirúrgico total da reconstrução mamária com o retalho DIEP.

VANDEVOORT et al. (2002) observaram a relação direta entre o tempo operatório da reconstrução e o tipo de trajeto intramuscular da artéria perfurante. Apesar de não caracterizarem o tipo de trajeto oblíquo nem tampouco a correlação com a localização da artéria perfurante, os autores relataram importantes dados com relação à dificuldade técnica e ao tempo operatório. Nas situações onde a artéria perfurante apresentava o trajeto intramuscular curto houve maior facilidade na dissecção e menor tempo cirúrgico. Todavia, nas situações onde a artéria perfurante apresentava o trajeto intramuscular longo ou através da intersecção tendínea, houve maior dificuldade técnica na dissecção e, por conseguinte maior tempo operatório.

Apesar da maior facilidade técnica de dissecção das artérias perfurantes que se localizam na região lateral, este fator não deve ser o único critério de escolha da artéria perfurante principal do retalho. Alguns autores citaram a localização das artérias perfurantes, o calibre vascular arterial e venoso e o número artérias perfurantes presentes no retalho como critérios importantes utilizados no processo de escolha. (BLONDEEL et al., 1999; KROLL 1999; KROLL 2001; BLONDEEL et al., 2000; CRAIGIE et al., 2003; GILL et al., 2004; MUNHOZ et al., 2004a).

BLONDEEL et al. (1999) relataram a importância da localização das artérias perfurantes como critério de escolha na perfusão do retalho DIEP. Afirmaram que as artérias perfurantes localizadas na região medial promovem melhor vascularização do retalho uma vez que se localizam mais 
próximas à linha alba. Deste modo, consegue-se maior vascularização da extremidade contra-lateral do retalho e, portanto menor incidência de necroses parciais nas regiões mais distais à artéria perfurante.

KROLL em 1999, na análise comparativa entre o retalho TRAM microcirúrgico e o retalho DIEP, afirmou que o critério mais importante na escolha da artéria perfurante está relacionado ao calibre vascular. Nas situações onde se observava a presença de pequeno calibre arterial, preferia a conversão intra-operatória para o retalho TRAM microcirúrgico.

BLONDEEL et al. (2000) enfatizaram a importância do calibre vascular e, sobretudo do calibre da veia perfurante na escolha do pedículo perfurante principal para o retalho DIEP. A maioria das complicações observadas na reconstrução mamária com o retalho DIEP são secundárias à insuficiência de drenagem venosa e não de irrigação arterial.

CRAIGIE et al. (2003) descreveram os detalhes técnicos da dissecção do retalho DIEP e enfatizaram alguns critérios relacionados ao processo de escolha da artéria perfurante principal. Existia a preferência na utilização das artérias localizadas na região lateral, nas situações onde estas demonstrassem calibre adequado. Na presença de artérias perfurantes com pequeno calibre, preferiam a escolha das artérias situadas na região medial ou mesmo a dissecção do retalho contralateral.

GILL et al. (2004) por meio de casuística expressiva, referiram maior incidência de necroses de gordura e pele nos retalhos que apresentavam maior número de artérias perfurantes. Apesar da assertiva contraditória, na análise estratificada da casuística, os autores observaram a utilização do 
maior número de artérias perfurantes nas pacientes que apresentavam maior risco para doenças cardiovasculares. Da mesma forma, a indicação do maior número de artérias perfurantes por retalho deveu-se ao fato que neste grupo as artérias, de maneira isolada, não apresentavam calibre arterial suficiente. Enfatizaram que uma única artéria perfurante com maior calibre seria suficiente para a irrigação do retalho nas pacientes que não apresentassem fatores de risco cardiovasculares.

MUNHOZ et al. (2004a) descreveram a anatomia intramuscular das artérias perfurantes na reconstrução mamária com o retalho DIEP. Apesar da maior facilidade técnica de dissecção das artérias perfurantes da região lateral, os autores enfatizaram a importância do calibre arterial no critério de escolha da artéria principal do retalho.

A análise de todos estes fatores implica que o processo de escolha da artéria perfurante principal para a irrigação do retalho se baseia em critérios multifatoriais e não apenas no detalhe anatômico do tipo de trajeto intramuscular. A localização da artéria perfurante, os calibres arterial e venoso associados ao detalhe técnico do tipo de trajeto intramuscular, constituem em associação, os principais fatores utilizados no processo de seleção da artéria perfurante principal.

A artéria epigástrica inferior tem origem na artéria ilíaca externa e após o trajeto ascendente látero-medial de aproximadamente $5 \mathrm{~cm}$, atinge a margem lateral do músculo reto do abdome. Neste local, a artéria epigástrica inferior apresenta o trajeto próximo à face profunda do músculo reto do abdome e anterior à lâmina posterior da sua respectiva bainha. Próxima à 
região do ponto médio entre a sínfise púbica e o umbigo, a artéria epigástrica inferior pode emitir alguns ramos principais ou manter o trajeto ascendente até a anastomose intramuscular com a artéria epigástrica superior (TESTUT; LATARGET, 1902; MILLOY et al., 1960; GARDNER et al., 1975; HOLLINSHEAD, 1980; KAMINA, 1983; MRAKBY; MILNER, 2002).

Não existe consenso em relação ao número de ramos da artéria epigástrica inferior nem tampouco ao padrão de calibre vascular destes ramos (MILLOY et al., 1960; BOYD et al., 1984; MILLER et al., 1988; MOON; TAYLOR, 1988; ITOH; ARAI, 1993; BLONDEEL et al., 1998; MRAKBY; MILNER, 2002).

MILLOY et al. (1960) descreveram a artéria epigástrica inferior com um único ramo central na maioria das dissecções, e a presença de dois ramos na minoria das amostras analisadas. Todavia, MILLER et al. (1988) observaram a presença de dois ramos principais, um ramo em posição lateral e outro medial com calibres semelhantes. BOYD et al. (1984), relataram a divisão da artéria epigástrica inferior em dois ramos principais e ocasionalmente, em três ramos.

Outros autores como MOON; TAYLOR (1988) e ITOH; ARAI (1993) descreveram três variações anatômicas principais. Existiu a presença de um padrão com um único ramo lateral, outro padrão com dois ramos principais, sendo um ramo lateral e outro medial e, menos freqüentemente, a presença de três ramos principais com calibres semelhantes.

BLONDEEL et al. (1998) identificaram dois padrões anatômicos distintos. Na maioria das avaliações foram observados dois ramos principais 
e na minoria das análises foi observada a presença de um único ramo central da artéria epigástrica inferior.

Na presença de dois ramos principais, há a concordância entre alguns autores em relação ao maior calibre do ramo lateral sobre o ramo medial. (ITOH; ARAI 1993; BLONDEEL et al. 1998; MRAKBY; MILNER 2002). Outros autores, apesar de evidenciarem a artéria epigástrica inferior com dois ramos principais, não relatam a quantificação do maior calibre vascular dos ramos principais (MILLOY et al., 1960; BOYD et al., 1984; MOON; TAYLOR, 1988).

No presente estudo foram observados achados semelhantes aos dados propostos por BLONDEEL et al. (1998) e MRAKBY; MILNER (2002) onde se constatou a presença de dois padrões diferentes de ramificação e o maior calibre do ramo lateral quando comparado ao calibre do ramo medial da artéria epigástrica inferior.

A distribuição das artérias perfurantes de maior calibre pode apresentar associação com a sua origem nos ramos da artéria epigástrica inferior. Apesar deste fato ser evidenciado em dissecções anatômicas, não existe consenso na literatura em relação à veracidade desta afirmação (BOYD et al., 1984; MILLER et al., 1988; MOON; TAYLOR, 1988; ITOH; ARAI, 1993; BLONDEEL et al., 1998; MRAKBY; MILNER, 2002). Tal fato pode ser decorrente da variabilidade anatômica presente nos ramos da artéria epigástrica inferior bem como da inexistência de consenso em relação às regiões de maior e menor concentração de artérias perfurantes de maior calibre. 
BOYD et al. (1984), ITOH; ARAI (1993) e MRAKBY; MILNER (2002) observaram que as artérias perfurantes de maior calibre se apresentavam localizadas sobre os ramos da artéria epigástrica inferior. Outros autores, porém não estabeleceram esta relação (MILLER et al., 1988; MOON; TAYLOR, 1988; BLONDEEL et al., 1998).

No presente estudo pode-se observar que a maioria das artérias perfurantes estudadas apresentavam origem no ramo lateral da artéria epigástrica inferior. A análise comparativa através da construção de intervalos de confiança entre o calibre e os ramos da artéria epigástrica inferior demonstrou maior incidência de artérias perfurantes de médio e grande calibres proveniente do ramo lateral de maior calibre. Este dado corrobora com as descrições de BOYD et al., (1984), ITOH; ARAI, (1993) e MRAKBY; MILNER, (2002), ou seja, existe associação entre o calibre da artéria perfurante e o ramo de maior calibre da artéria epigástrica inferior.

O comprimento da artéria perfurante reflete o comprimento do trajeto intramuscular e, portanto a extensão da sua dissecção. Na literatura, porém não há estudos que avaliam de maneira objetiva e comparativa, o comprimento das artérias perfurantes da artéria epigástrica inferior.

No presente estudo foi realizada a mensuração da artéria perfurante de maior calibre em cada retalho DIEP dissecado, totalizando 30 artérias perfurantes. A escolha da artéria perfurante de maior calibre ocorreu pela melhor aplicação clínica dos dados coletados, uma vez que as artérias de menor calibre não são empregadas na vascularização do retalho. 
$\mathrm{Na}$ análise comparativa do comprimento da artéria perfurante da região lateral com a artéria perfurante da região medial, foram observadas algumas diferenças pertinentes. Estes resultados díspares podem ser compatíveis com a anatomia de cada região bem como com a distância até a origem nos ramos da artéria epigástrica inferior.

As artérias perfurantes da região lateral apresentaram comprimento e, portanto a extensão do trajeto intramuscular, inferior às artérias perfurantes da região medial. Apesar da existência de diferença de comprimento em ambos os lados do abdome, a análise estatística demonstrou significância apenas no lado direito. A não significância estatística no lado esquerdo pode ser decorrente de erro técnico na dissecção ou na mensuração arterial. O número da casuística analisada também pode estar envolvido uma vez que o valor $\mathrm{p}$ do lado direito mostrou-se próximo ao nível mínimo de significância adotado.

A constatação anatômica do menor comprimento do trajeto intramuscular das artérias perfurantes provenientes da região lateral, corrobora com os dados previamente descritos neste estudo em relação à maior incidência do trajeto retilíneo nesta região. As artérias perfurantes laterais apresentaram comprimento menor devido à menor distância em relação ao ramo dominante lateral da artéria epigástrica inferior. Todavia, as artérias perfurantes mediais apresentaram maior trajeto através das fibras do músculo reto do abdome até o ramo dominante situado na região lateral.

Na programação do retalho microcirúrgico, o comprimento do pedículo é de fundamental importância para o sucesso do procedimento. A 
possibilidade de anastomose vascular com maior número de alternativas de pedículos receptores, a maior mobilidade do retalho durante a sua fixação e o não emprego de enxertos vasculares, são os principais benefícios advindos da maior extensão do pedículo (O'BRIEN et al., 1990; MATHES; NAHAI,1997; WEISS; PRIBAZ, 2000; GILL et al. 2004).

Embora não constitua contra-indicação absoluta, a presença de pedículos arteriais curtos torna o procedimento mais complexo uma vez que há maior tração na região da anastomose vascular. Associado a este dado há menor exposição cirúrgica do campo operatório uma vez que o retalho permanece mais próximo, ou mesmo sobre a anastomose microcirúrgica.

O retalho DIEP demonstra vantagens em relação aos demais retalhos microcirúrgicos habitualmente utilizados para a reconstrução mamária. A presença do pedículo com extensão superior a $10 \mathrm{~cm}$ torna o procedimento da anastomose microcirúrgica mais fácil, uma vez que há a possibilidade de ampla exposição do campo operatório. Associado a isto, existe a maior mobilidade de posicionamento favorecendo assim a montagem da mama reconstruída.

A presença de pedículos arteriais com maior comprimento permite a possibilidade de realização da anastomose em regiões anatômicas mais profundas e distantes da região da reconstrução (O'BRIEN et al., 1990; WEISS; PRIBAZ, 2000; GILL et al. 2004). Este fato é observado nos vasos receptores presentes na região da axila como ocorre nos vasos circunflexos da escápula e subescapulares. Na presença de pedículos menores, a 
realização da anastomose nesta região é tecnicamente mais difícil e em alguns casos inviável sem a utilização de enxertos vasculares associados.

Poucos são os estudos que avaliam o comprimento do pedículo arterial dos retalhos vascularizados pela artéria epigástrica inferior (HÖLMSTROM, 1979; PENNINGTON et al., 1980; MATHES; NAHAI, 1997; ALLEN; TREECE, 1994; HEITMANN et al., 2000; CRAIGIE et al., 2003; GILL et al. 2004). Em algumas descrições, principalmente nos relatos relacionados ao retalho TRAM microcirúrgico, existem controvérsias em relação ao comprimento do pedículo arterial.

É fato que o retalho TRAM microcirúrgico apresenta o pedículo arterial com menor extensão quando comparado ao retalho DIEP, porém alguns autores citam comprimentos semelhantes (HÖLMSTROM, 1979; PENNINGTON et al. 1980). No retalho DIEP, o detalhe técnico que permite a separação do tecido muscular da artéria perfurante e dos ramos da artéria epigástrica inferior favorece a extensão final do comprimento do pedículo. Deste modo, soma-se o comprimento do ramo e da artéria epigástrica inferior ao trajeto intramuscular da artéria perfurante.

HÖLMSTROM (1979) e PENNINGTON et al. (1980) descreveram o comprimento total do pedículo do retalho TRAM microcirúrgico entre 12 e 15 cm, contudo não há descrição sobre os parâmetros anatômicos utilizados na obtenção desta medida e na inclusão do ramo da artéria epigástrica inferior na mensuração do comprimento do pedículo. De maneira controversa, MATHES; NAHAI (1997) citaram o comprimento médio da artéria epigástrica inferior de $5 \mathrm{~cm}$ e enfatizaram que os pedículos que apresentassem 0 
comprimento inferior a esta medida poderiam tornar a anastomose microcirúrgica de execução mais difícil e a eventual necessidade da utilização de enxertos venosos associados.

ALLEN; TREECE (1994) e CRAIGIE et al. 2003 observaram comprimento do pedículo arterial entre 9 e 14,5 cm na reconstrução mamária com retalho DIEP. De modo semelhante, HEITMANN et al. (2000), em medidas realizadas em cadáveres, descreveram o pedículo do retalho DIEP com comprimento médio de $10,3 \mathrm{~cm}$.

GILL et al. (2004) enfatizaram que o retalho DIEP apresentava o comprimento do pedículo maior que o do retalho TRAM microcirúrgico fato este que permitiu a realização da anastomose arterial sem tensão e o melhor posicionamento medial do retalho.

Determinou-se no presente estudo que o comprimento do pedículo arterial seria a distância compreendida entre a origem da artéria epigástrica inferior, próximo à sua origem na artéria ilíaca externa, e a região de entrada da artéria perfurante no panículo adiposo do retalho. Diferente dos autores precedentes (ALLEN; TREECE, 1994; HEITMANN et al., 2000), foram observados comprimentos de pedículos maiores. Na análise comparativa do retalho vascularizado pela artéria perfurante proveniente das regiões lateral e medial do músculo reto do abdome foi observada diferença estatística. Este fato é atribuído ao menor comprimento do trajeto intramuscular da artéria perfurante da região lateral. 
O conceito de retalhos vascularizados por artérias perfurantes apresentou grande impacto na cirurgia reconstrutora a partir dos trabalhos pioneiros propostos por TAYLOR; PALMER (1987). Por meio de estudos radiográficos e do mapeamento da vascularização cutânea em diversas topografias do corpo humano, foi possível estabelecer o conceito do angiossomo. O angiossomo é definido como o território cutâneo específico que recebe a sua vascularização a partir de uma única artéria perfurante.

Este impulso inicial levou à reflexão e à busca por novas alternativas técnicas nos procedimentos habitualmente realizados na época. Assim, a nova opção de vascularização dos tradicionais retalhos músculo-cutâneos apenas na artéria perfurante principal e não mais no segmento muscular, tornaram-se possibilidade real e serviram de base científica para inúmeras linhas de pesquisa a serem conduzidas a partir da década de 90. Como principal vantagem advinda da vascularização dos retalhos na artéria perfurante pode-se salientar a completa preservação muscular e aponeurótica.

Com demarcação anatômica e territórios cutâneos semelhantes aos retalhos TRAM pediculado e TRAM microcirúrgico, o retalho DIEP apresenta, como única diferença, o detalhe da completa preservação muscular e aponeurótica advinda da dissecção do pedículo vascular perfurante. Por meio da manutenção destas importantes estruturas consegue-se maior integridade na área doadora do retalho e, por conseguinte, mínimas seqüelas na parede do abdome (KOSHIMA; SOEDA, 1989; KOSHIMA et al., 1992; ALLEN; TREECE, 1994; BLONDEEL et al., 
1997; BLONDEEL et al., 1998; BLONDEEL et al., 1999; HAMDI et al., 1999; MUNHOZ et al., 2001; ISHIDA et al., 2002; VANDEVOORT et al., 2002; CRAIGIE et al., 2003; MUNHOZ et al., 2003; MUNHOZ et al., 2004a; GILL et al., 2004).

A vascularização da região do abdome inferior é relatada na literatura. A maioria dos trabalhos descritivos são provenientes de revistas específicas de cirurgia plástica a partir da maior aplicação clínica do retalho TRAM e do retalho DIEP na reconstrução mamária pós mastectomia. Esta investigação torna-se válida uma vez que a correta quantificação das artérias perfurantes e, sobretudo a sua precisa localização, constituem fatores importantes no planejamento e na execução destes retalhos.

Parece-nos óbvio e sensato o estudo detalhado da anatomia, não apenas no âmbito da cirurgia plástica, mas em qualquer outra área cirúrgica. O preciso conhecimento da forma anatômica e da presença de eventuais variações favorecem o desenvolvimento e aprimoramento de técnicas e procedimentos. A previsibilidade em relação às variações previne o erro, que por sua vez promove melhores resultados e com menor índice de complicações.

Assim, o presente estudo fornece dados importantes sobre a anatomia vascular do retalho DIEP para que este seja abordado com mais propriedade. O conhecimento anatômico refinado da localização, da distribuição e do trajeto intramuscular das artérias perfurantes, além das características do pedículo arterial são de fundamental importância no planejamento da reconstrução com o retalho DIEP. 
A maior concentração de artérias perfurantes de médio e grande calibre e a presença do trajeto retilíneo na região lateral do músculo reto do abdome constituíram parâmetros anatômicos importantes no planejamento da técnica. Os resultados obtidos nesta dissertação reforçam a relevância do papel dos estudos sobre anatomia arterial na programação da reconstrução com retalhos vascularizados por artérias perfurantes. 
6. Conclusão

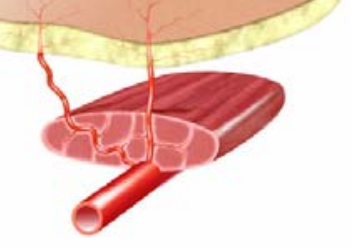


O presente estudo permitiu-nos concluir que:

1. Foi observada a média de 6,3 artérias perfurantes por segmento infraumbilical de músculo reto do abdome analisado. A região medial apresentou a maior concentração absoluta de artérias, e a região lateral, a maior concentração de artérias de maior calibre.

2. As artérias perfurantes apresentaram o trajeto retilíneo caracterizado pela extensão curta e perpendicular às fibras musculares e oblíquo com extensão longa e não perpendicular. Na região lateral houve a maior concentração do trajeto retilíneo e na região medial o oblíquo.

3. A artéria epigástrica inferior apresentou dois ramos principais e um ramo único médio lateral. Na presença de dois ramos, o ramo lateral apresentou calibre maior que o ramo medial e o maior número de artérias perfurantes.

4. A artéria perfurante muscular e o pedículo arterial do retalho apresentaram o comprimento médio de 5,3 e 15,7 cm respectivamente. A artéria perfurante da região lateral e o pedículo que a continha apresentaram o comprimento menor quando comparados à artéria perfurante medial e o respectivo pedículo. 


\section{Anexos}

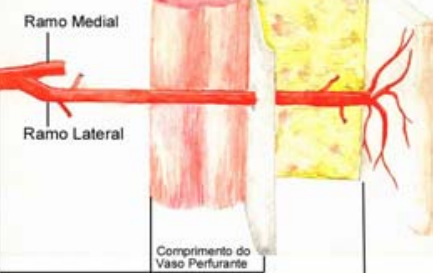


1. Identificacão:

CADÁVER No.: _ PESO:_ DATA :__ '
IDADE:

\section{Distribuicão das Artérias Perfurantes:}

LADO DIR:

No.: (PEQ:

MED:

\section{DISTÂNCIAS DIR}

1.

2.

3.

4.

5.

6.

7.

8.

9.

10. ; GDE:

No.: (PEQ:

LADO ESQ: ; MED: ; GDE:

\section{DISTÂNCIAS ESQ:}

1 .
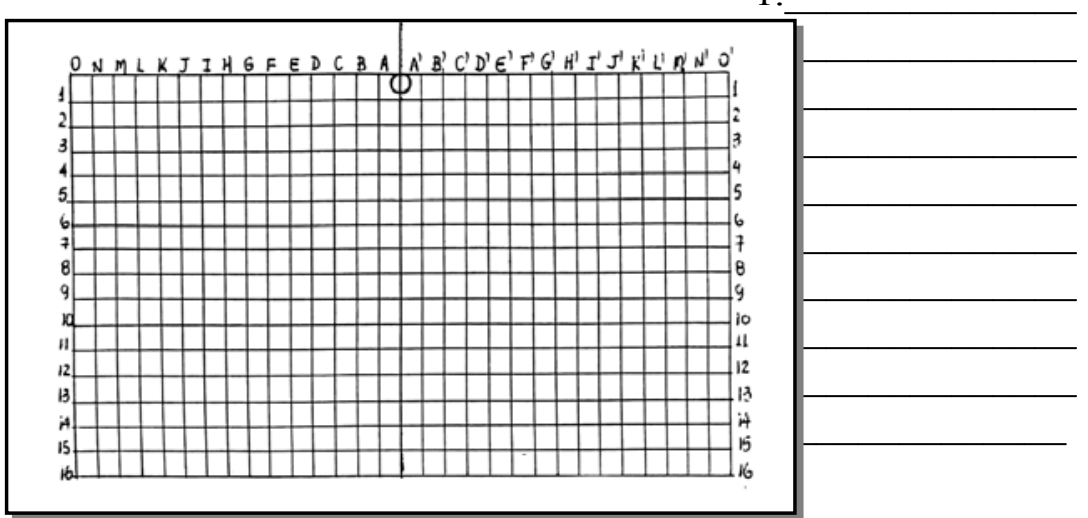

\section{Trajeto Intramuscular [VIOD/GDL]}

\section{LADO DIR:}

No. DA PERF./COMPRIM. :

No. DA PERF./COMPRIM. :

No. DA PERF./COMPRIM. :

No. DA PERF./COMPRIM. :
. TRAJ.: RET: $\square$ OBL: $\square$. ORIGEM: (RL / RM / RUML) TRAJ.: RET: $\square$ OBL: $\square$. ORIGEM: (RL / RM / RUML) TRAJ.: RET: $\square$ OBL: $\square$. ORIGEM: (RL / RM / RUML) TRAJ.: RET: $\square$ OBL: $\square$. ORIGEM: (RL / RM / RUML)

\section{LADO ESQ:}

No. DA PERF./COMPRIM. : No. DA PERF./COMPRIM. : No. DA PERF./COMPRIM. : No. DA PERF./COMPRIM. :

.
TRAJ.: RET: $\square$ OBL: $\square$. ORIGEM: (RL / RM / RUML) TRAJ.: RET: $\square$ OBL: $\square$. ORIGEM: (RL / RM / RUML) TRAJ.: RET: $\square$ OBL: $\square$. ORIGEM: (RL / RM / RUML) TRAJ.: RET: $\square$ OBL: $\square$. ORIGEM: (RL / RM / RUML)

\section{Ramos da artéria epigástrica inferior}

\section{LADO DIR:}

AEI-. 2 RAMOS:

(Dom.: RL / RM)

1 RAMO:

(RUML).

\section{LADO ESQ:}

AEI-. 2 RAMOS:

(Dom.: RL / RM) 1 RAMO:

(RUML).

5. Comprimento do pedículo arterial:

LADO DIR: Comprimento Art.Medial :

LADO ESQ: Comprimento Art.Medial : 


\section{UNIVERSIDADE DE SÃO PAULO SERVIÇO DE VERIFICAÇÃO DE ÓBITOS DA CAPITAL}

Manifestação prévia a respeito dos aspectos técnicos relacionados á obtenção de material de estudo para pesquisa científica

Título da pesquisa: Avaliação anatômica do trajeto intramuscular dos vasos perfurantes da artéria epigástrica profunda inferior.

Responsável: Alexandre Mendonça Munhoz

Em relação aos aspectos técnicos relacionados à obtenção de material de estudo para pesquisa cientifica mencionada acima, informamos não haver impedimento do ponto de vista técnico e nem risco de mutilação.

Prof. Dr. Carlos qugusto Pásqualucci 
HOSPITAL DAS CLINICAS

DA FACULDADE DE MEDICINA DA UNIVERSIDADE DE SÃO PAULO

CAIXA POSTAL, 3471 - SĀO PAULO - BRASIL

DIRETORIA CLÍNICA

\section{Comissão de Ética para Análise de Projetos de Pesquisa}

\section{APROVACÃO}

A Comissão de Ética para Análise de Projetos de Pesquisa - CAPPesq da Diretoria Clínica do Hospital das Clínicas e da Faculdade de Medicina da Universidade de São Paulo, em sessão de 16.07.03, APROVOU o Protocolo de Pesquisa $n^{\circ}$ 473/03, intitulado: "Avaliação anatômica do trajeto intramuscular dos vasos perfurantes da artéria epigástrica profunda inferior" apresentado pelo Departamento de CIRURGIA.

Pesquisador(a) Responsável: PROF. DR. ROLF GEMPERLI

Pesquisador(a) Executante: DR. ALEXANDRE MENDONÇA MUNHOZ

CAPPesq, 16 de Julho de 2003.<smiles>O=C1CCCCC1</smiles><smiles>[R]C1CCCC1</smiles><smiles>CCCCCCCCCCCCC</smiles><smiles>C1CCC(C2CCCC2)CC1</smiles>

PROF. DR. EUCLIDES AYRES DE CASTILHO Presidente da Comissão de Ética para Análise de Projetos de Pesquisa

PROF. DR, MARCUS CASTRO FERREIRA

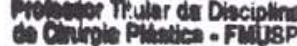

OBSERVAÇÃO: Cabe ao pesquisador elaborar e apresentar à CAPPesq, os relatórios parciais e final sobre a pesquisa (Resolução do Conselho Nacional de Saúde $n^{\circ} 196$, de 10.10.1996, inciso IX.2, letra "c")

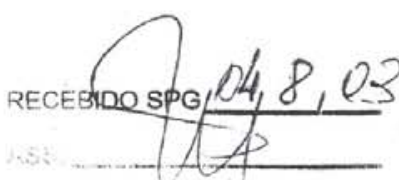


Excel : PLANILHA 1 DE DADOS ANATOMICOS - Perfurantes 2 a 73

(O): AUSENTE, (1): PRESENTE

(A) No.Cadáver / (B) Calibre da artéria perfurante ((C) grande, (D) médio, (E) pequeno) / (F) localização

\begin{tabular}{|c|c|c|c|c|c|c|}
\hline & $\begin{array}{c}\text { A } \\
\text { CADÁVER }\end{array}$ & $\begin{array}{c}\text { B } \\
\text { CALIBRE DA PERFURANTE }\end{array}$ & $\begin{array}{c}\text { C } \\
\text { GRANDE }\end{array}$ & $\begin{array}{c}\text { D } \\
\text { MÉDIO }\end{array}$ & $\begin{array}{c}\mathbf{E} \\
\text { PEQUENO }\end{array}$ & $\begin{array}{c}\text { F } \\
\text { LOCALIZAÇÃO }\end{array}$ \\
\hline 2. & 1 & & 0 & 1 & 0 & \\
\hline 3. & 1 & & 0 & 0 & 1 & \\
\hline 4. & 1 & & 1 & 0 & 0 & \\
\hline 5. & 1 & & 0 & 1 & 0 & \\
\hline 6. & 1 & & 0 & 1 & 0 & \\
\hline 7. & 1 & & 0 & 0 & 1 & \\
\hline 8. & 1 & & 1 & 0 & 0 & \\
\hline 9. & 1 & & 0 & 1 & 0 & \\
\hline 10. & 1 & & 0 & 0 & 1 & \\
\hline 11. & 1 & & 1 & 0 & 0 & \\
\hline 12. & 1 & & 0 & 1 & 0 & \\
\hline 13. & 1 & & 0 & 1 & 0 & \\
\hline 14. & 1 & & 0 & 0 & 1 & \\
\hline 15. & 2 & & 0 & 1 & 0 & \\
\hline 16. & 2 & & 0 & 1 & 0 & \\
\hline 17. & 2 & & 0 & 0 & 1 & \\
\hline 18. & 2 & & 1 & 0 & 0 & \\
\hline 19. & 2 & & 0 & 0 & 1 & \\
\hline 20. & 2 & & 0 & 1 & 0 & \\
\hline 21. & 2 & & 0 & 1 & 0 & \\
\hline 22. & 2 & & 0 & 1 & 0 & \\
\hline 23. & 2 & & 0 & 0 & 1 & \\
\hline 24. & 2 & & 0 & 1 & 0 & \\
\hline 25. & 2 & & 0 & 0 & 1 & \\
\hline 26. & 3 & & 1 & 0 & 0 & \\
\hline 27. & 3 & & 0 & 1 & 0 & \\
\hline 28. & 3 & & 0 & 1 & 0 & \\
\hline 29. & 3 & & 0 & 0 & 1 & \\
\hline 30. & 3 & & 0 & 1 & 0 & \\
\hline 31. & 3 & & 0 & 1 & 0 & \\
\hline 32. & 3 & & 1 & 0 & 0 & \\
\hline 33. & 3 & & 0 & 0 & 1 & \\
\hline 34. & 3 & & 0 & 1 & 0 & \\
\hline 35. & 3 & & 0 & 0 & 1 & \\
\hline 36. & 3 & & 0 & 1 & 0 & \\
\hline 37. & 3 & & 0 & 0 & 1 & \\
\hline 38. & 3 & & 1 & 0 & 0 & \\
\hline 39. & 4 & & 0 & 1 & 0 & \\
\hline 40. & 4 & & 0 & 0 & 1 & \\
\hline 41. & 4 & & 1 & 0 & 0 & \\
\hline 42. & 4 & & 0 & 1 & 0 & \\
\hline 43. & 4 & & 0 & 1 & 0 & \\
\hline 44. & 4 & & 0 & 0 & 1 & \\
\hline 45. & 4 & & 1 & 0 & 0 & \\
\hline 46. & 4 & & 0 & 1 & 0 & \\
\hline 47. & 4 & & 0 & 0 & 1 & \\
\hline 48. & 4 & & 1 & 0 & 0 & \\
\hline 49. & 4 & & 0 & 1 & 0 & \\
\hline 50. & 4 & & 0 & 0 & 1 & \\
\hline 51. & 4 & & 1 & 0 & 0 & \\
\hline 52. & 5 & & 0 & 1 & 0 & \\
\hline 53. & 5 & & 0 & 0 & 1 & \\
\hline 54. & 5 & & 1 & 0 & 0 & \\
\hline 55. & 5 & & 0 & 1 & 0 & \\
\hline 56. & 5 & & 0 & 0 & 1 & \\
\hline 57. & 5 & & 0 & 1 & 0 & \\
\hline 58. & 5 & & 1 & 0 & 0 & \\
\hline 59. & 5 & & 0 & 1 & 0 & \\
\hline 60. & 5 & & 1 & 0 & 0 & \\
\hline 61. & 5 & & 0 & 0 & 1 & \\
\hline 62. & 5 & & 0 & 1 & 0 & \\
\hline 63. & 5 & & 1 & 0 & 0 & \\
\hline 64. & 6 & & 0 & 0 & 1 & \\
\hline 65. & 6 & & 0 & 1 & 0 & \\
\hline 66. & 6 & & 0 & 0 & 1 & \\
\hline 67. & 6 & & 1 & 0 & 0 & \\
\hline 68. & 6 & & 0 & 0 & 1 & \\
\hline 69. & 6 & & 0 & 1 & 0 & \\
\hline 70. & 6 & & 0 & 0 & 1 & \\
\hline 71. & 6 & & 0 & 1 & 0 & \\
\hline 72. & 6 & & 1 & 0 & 0 & \\
\hline 73. & 6 & & 0 & 1 & 0 & \\
\hline
\end{tabular}


Excel : PLANILHA 2 DE DADOS ANATOMICOS - Perfurantes 74 a 146

(O): AUSENTE, (1): PRESENTE

(A) No.Cadáver / (B) Calibre da artéria perfurante ((C) gde, (D) médio, (E) pequeno) / (F) localização

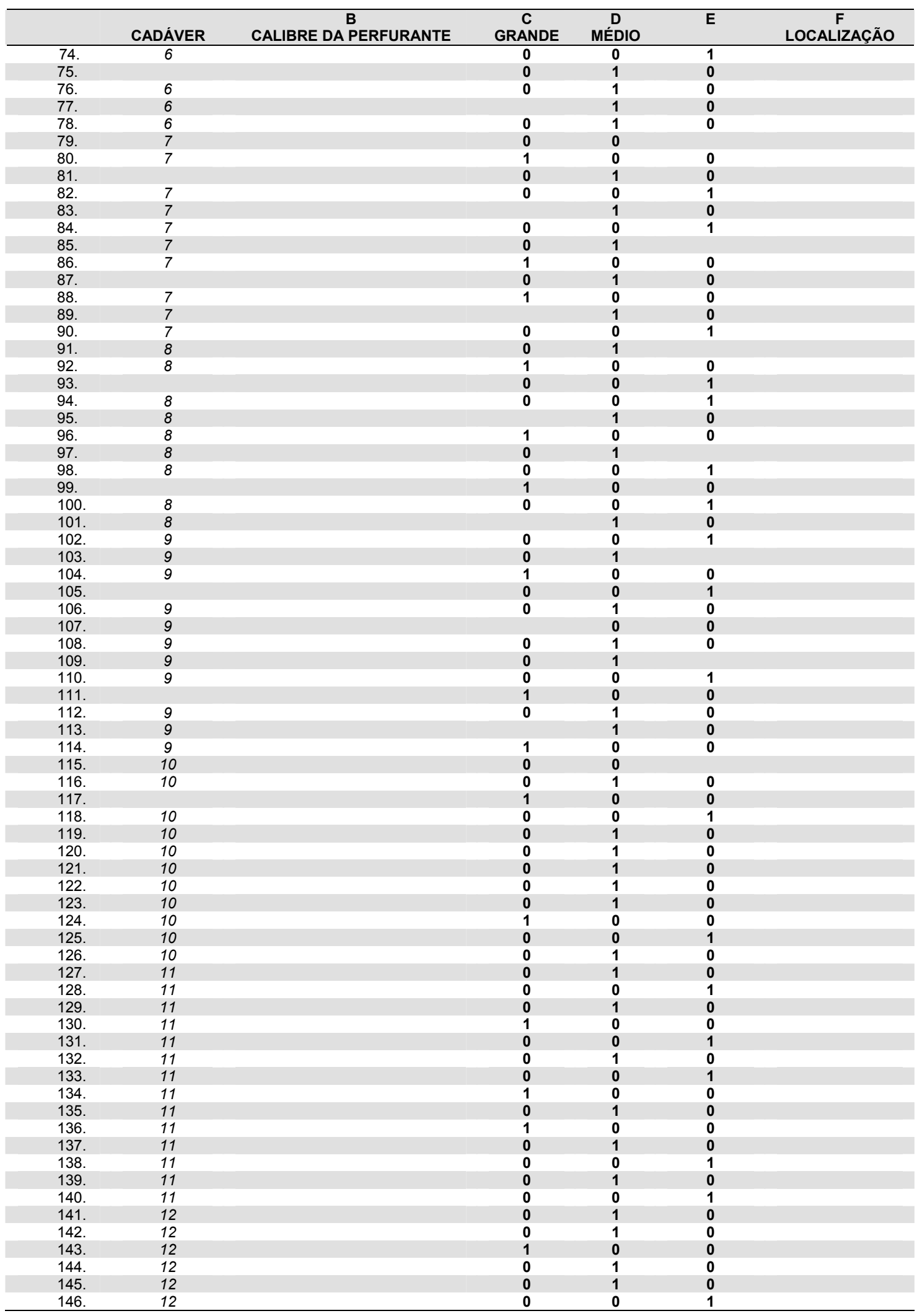


Excel : PLANILHA 3 DE DADOS ANATOMICOS - Perfurantes 147 a 192

(O): AUSENTE, (1): PRESENTE

(A) No.Cadáver / (B) Calibre da artéria perfurante ((C) gde, (D) médio, (E) pequeno) / (F) localização

\begin{tabular}{|c|c|c|c|c|c|c|}
\hline & $\begin{array}{c}\text { A } \\
\text { CADÁVER }\end{array}$ & $\begin{array}{c}\text { B } \\
\text { CALIBRE DA PERFURANTE }\end{array}$ & $\begin{array}{c}\text { C } \\
\text { GRANDE }\end{array}$ & $\begin{array}{c}\text { D } \\
\text { MÉDIO }\end{array}$ & $\begin{array}{c}\text { E } \\
\text { PEQUENO }\end{array}$ & $\begin{array}{c}\text { F } \\
\text { LOCALIZAÇÃO }\end{array}$ \\
\hline 147. & 12 & & 0 & 0 & 1 & \\
\hline 148. & 12 & & 0 & 1 & 0 & \\
\hline 149. & 12 & & 0 & 1 & 0 & \\
\hline 150. & 12 & & 0 & 1 & 0 & \\
\hline 151. & 12 & & 1 & 0 & 0 & \\
\hline 152. & 12 & & 0 & 0 & 1 & \\
\hline 153. & 13 & & 0 & 1 & 0 & \\
\hline 154. & 13 & & 0 & 1 & 0 & \\
\hline 155. & 13 & & 0 & 0 & 1 & \\
\hline 156. & 13 & & 1 & 0 & 0 & \\
\hline 157. & 13 & & 0 & 1 & 0 & \\
\hline 158. & 13 & & 0 & 0 & 1 & \\
\hline 159. & 13 & & 0 & 1 & 0 & \\
\hline 160. & 13 & & 0 & 1 & 0 & \\
\hline 161. & 13 & & 0 & 0 & 1 & \\
\hline 162. & 13 & & 0 & 1 & 0 & \\
\hline 163. & 13 & & 1 & 0 & 0 & \\
\hline 164. & 14 & & 0 & 1 & 0 & \\
\hline 165. & 14 & & 0 & 1 & 0 & \\
\hline 166. & 14 & & 0 & 1 & 0 & \\
\hline 167. & 14 & & 0 & 0 & 1 & \\
\hline 168. & 14 & & 0 & 0 & 1 & \\
\hline 169. & 14 & & 0 & 1 & 0 & \\
\hline 170. & 14 & & 1 & 0 & 0 & \\
\hline 171. & 14 & & 0 & 1 & 0 & \\
\hline 172. & 14 & & 0 & 1 & 0 & \\
\hline 173. & 14 & & 0 & 1 & 0 & \\
\hline 174. & 14 & & 0 & 0 & 1 & \\
\hline 175. & 14 & & 0 & 1 & 0 & \\
\hline 176. & 15 & & 0 & 0 & 1 & \\
\hline 177. & 15 & & 0 & 1 & 0 & \\
\hline 178. & 15 & & 1 & 0 & 0 & \\
\hline 179. & 15 & & 0 & 1 & 0 & \\
\hline 180. & 15 & & 0 & 1 & 0 & \\
\hline 181. & 15 & & 0 & 0 & 1 & \\
\hline 182. & 15 & & 1 & 0 & 0 & \\
\hline 183. & 15 & & 0 & 1 & 0 & \\
\hline 184. & 15 & & 0 & 1 & 0 & \\
\hline 185. & 15 & & 0 & 0 & 1 & \\
\hline 186. & 15 & & 0 & 1 & 0 & \\
\hline 187. & 15 & & 0 & 0 & 1 & \\
\hline 188. & 15 & & 0 & 0 & 1 & \\
\hline 189. & 15 & & 0 & 1 & 0 & \\
\hline 190. & 15 & & 0 & 1 & 0 & \\
\hline 191. & 15 & & 0 & 1 & 0 & \\
\hline 192. & & & 0 & 1 & 0 & \\
\hline & TOTAL & & 39 & 95 & 57 & \\
\hline
\end{tabular}


Excel : PLANILHA 4 DE DADOS ANATOMICOS - Perfurantes 2 a 73

(O): AUSENTE, (1): PRESENTE

(G) Lateral / (H) Medial / (I) Trajeto intramuscular / (J) Retilíneo / (K) Oblíquo

\begin{tabular}{|c|c|c|c|c|c|}
\hline & $\begin{array}{c}\mathbf{G} \\
\text { LATERAL } \\
\end{array}$ & $\begin{array}{c}\mathrm{H} \\
\text { MEDIAL }\end{array}$ & $\begin{array}{l}\text { I' } \\
\text { TRAJETO INTRAMUSCULAR }\end{array}$ & $\begin{array}{c}\text { J } \\
\text { RETILÍNEO }\end{array}$ & $\begin{array}{c}K \\
\text { OBLÍQUO } \\
\end{array}$ \\
\hline 2. & & & & & \\
\hline 3. & 1 & 0 & 0 & 0 & \\
\hline 4. & 1 & 0 & 0 & 0 & 0 \\
\hline 5. & & 1 & 0 & 0 & \\
\hline 6. & 1 & 0 & 1 & 1 & 0 \\
\hline 7. & & 1 & 0 & 0 & 0 \\
\hline 8. & 1 & 0 & 1 & 1 & 0 \\
\hline 9. & $\begin{array}{l}0 \\
1\end{array}$ & 1 & $\begin{array}{l}0 \\
1\end{array}$ & $\begin{array}{l}0 \\
1\end{array}$ & $\begin{array}{l}0 \\
0\end{array}$ \\
\hline $\begin{array}{c}11 . \\
11 .\end{array}$ & 0 & $\begin{array}{l}0 \\
1\end{array}$ & $\begin{array}{l}1 \\
0\end{array}$ & 1 & $\begin{array}{l}0 \\
0\end{array}$ \\
\hline 12. & 1 & 0 & 1 & 1 & 0 \\
\hline 13. & 1 & 0 & 1 & & 0 \\
\hline 14. & 0 & 1 & 0 & 0 & 0 \\
\hline 15. & 0 & 1 & 0 & 0 & 0 \\
\hline 16. & 1 & 0 & 1 & 1 & 0 \\
\hline 17. & 0 & 1 & 0 & 0 & 0 \\
\hline 18. & 1 & 0 & 0 & 0 & 0 \\
\hline 19 & 0 & 1 & 0 & 0 & 0 \\
\hline 20. & 1 & $\begin{array}{l}0 \\
1\end{array}$ & $\begin{array}{l}1 \\
1\end{array}$ & 1 & 0 \\
\hline $\begin{aligned} 21 . \\
22\end{aligned}$ & $\begin{array}{l}0 \\
0\end{array}$ & $\begin{array}{l}1 \\
1\end{array}$ & $\begin{array}{l}1 \\
1\end{array}$ & $\begin{array}{l}1 \\
0\end{array}$ & 0 \\
\hline 23. & 0 & 1 & 0 & 0 & 0 \\
\hline 24. & 0 & 1 & 0 & 0 & 0 \\
\hline 25. & 0 & 1 & 0 & 0 & 0 \\
\hline 26. & 0 & 1 & 1 & 0 & 1 \\
\hline 27. & 1 & 0 & 1 & 0 & 1 \\
\hline 28. & 0 & 1 & 1 & 0 & 1 \\
\hline 29. & 1 & 0 & 0 & 0 & 0 \\
\hline 30. & 0 & 1 & 1 & 0 & 1 \\
\hline $\begin{array}{l}31 . \\
32\end{array}$ & $\begin{array}{l}1 \\
1\end{array}$ & 0 & $\begin{array}{l}0 \\
1\end{array}$ & $\begin{array}{l}0 \\
1\end{array}$ & $\begin{array}{l}0 \\
0\end{array}$ \\
\hline $\begin{array}{l}32 . \\
33 .\end{array}$ & $\begin{array}{l}1 \\
0\end{array}$ & $\begin{array}{l}0 \\
1\end{array}$ & $\begin{array}{l}1 \\
0\end{array}$ & $\begin{array}{l}1 \\
0\end{array}$ & $\begin{array}{l}0 \\
0\end{array}$ \\
\hline 34. & 1 & 0 & 1 & 1 & 0 \\
\hline 35. & 0 & 1 & 0 & 0 & 0 \\
\hline 36. & 0 & 1 & 1 & 1 & 0 \\
\hline 37. & 0 & 1 & 0 & 0 & 0 \\
\hline 38. & 1 & 0 & 1 & 0 & 1 \\
\hline 39. & 0 & 1 & 0 & 0 & 0 \\
\hline 40. & 0 & 1 & 0 & 0 & 0 \\
\hline 41. & 1 & 0 & 1 & 1 & 0 \\
\hline 42. & 0 & 1 & 0 & 0 & $\begin{array}{l}0 \\
1\end{array}$ \\
\hline $\begin{array}{l}43 . \\
4\end{array}$ & $\begin{array}{l}1 \\
0\end{array}$ & $\begin{array}{l}0 \\
1\end{array}$ & $\begin{array}{l}1 \\
0\end{array}$ & $\begin{array}{l}0 \\
0\end{array}$ & $\begin{array}{l}1 \\
0\end{array}$ \\
\hline 45. & 0 & 1 & 0 & 0 & 0 \\
\hline 46. & 0 & 1 & 1 & 0 & 1 \\
\hline 47. & 0 & 1 & 0 & 0 & 0 \\
\hline 48. & 1 & 0 & 1 & 1 & 0 \\
\hline 49. & 0 & 1 & 1 & 0 & 1 \\
\hline 50. & 1 & 0 & 1 & 0 & 1 \\
\hline 51. & 0 & 1 & 0 & 0 & 0 \\
\hline 52. & $\begin{array}{l}1 \\
0\end{array}$ & 0 & 1 & 1 & 0 \\
\hline 53. & $\begin{array}{l}0 \\
0\end{array}$ & $\begin{array}{l}1 \\
1\end{array}$ & $\begin{array}{l}0 \\
0\end{array}$ & $\begin{array}{l}0 \\
0\end{array}$ & 0 \\
\hline 55. & 0 & $\begin{array}{l}1 \\
\text { S }\end{array}$ & $\begin{array}{l}0 \\
\text { S }\end{array}$ & 0 & $\begin{array}{l}0 \\
\text { I }\end{array}$ \\
\hline 56. & 0 & 1 & 0 & 0 & 0 \\
\hline 57. & & 0 & 1 & 1 & 0 \\
\hline 58. & 1 & 0 & 1 & 1 & 0 \\
\hline 59. & & 1 & 0 & 0 & 0 \\
\hline 60. & 1 & 0 & 1 & 1 & 0 \\
\hline 61. & 0 & 1 & 0 & 0 & 0 \\
\hline 62. & 0 & 1 & 1 & 0 & 1 \\
\hline 63. & $\begin{array}{l}0 \\
0\end{array}$ & $\begin{array}{l}1 \\
1\end{array}$ & $\begin{array}{l}1 \\
0\end{array}$ & $\begin{array}{l}0 \\
0\end{array}$ & $\begin{array}{l}1 \\
0\end{array}$ \\
\hline 65. & 0 & 1 & 1 & 1 & 0 \\
\hline 66. & 0 & 1 & 0 & 0 & 0 \\
\hline 67. & 1 & 0 & 1 & 1 & 0 \\
\hline 68. & 0 & 1 & 0 & 0 & 0 \\
\hline 69. & 1 & 0 & 1 & 1 & 0 \\
\hline 70. & 0 & 1 & 0 & 0 & 0 \\
\hline 71. & & 1 & 1 & 1 & 0 \\
\hline 70. & 1 & 0 & 1 & 0 & 1 \\
\hline 7. & 0 & & & & \\
\hline
\end{tabular}


Excel : PLANILHA 5 DE DADOS ANATOMICOS - Perfurantes 74 a 146

(O): AUSENTE, (1): PRESENTE

(G) Lateral / (H) Medial / (I) Trajeto intramuscular / (J) Retilíneo / (K) Oblíquo

\begin{tabular}{|c|c|c|c|c|c|}
\hline & $\begin{array}{c}\text { G } \\
\text { LATERAL }\end{array}$ & $\begin{array}{c}\mathbf{H} \\
\text { MEDIAL }\end{array}$ & $\begin{array}{c}\text { I } \\
\text { TRAJETO INTRAMUSCULAR }\end{array}$ & $\begin{array}{c}\text { J } \\
\text { RETILÍNEO }\end{array}$ & $\begin{array}{c}\text { K } \\
\text { OBLÍQUO }\end{array}$ \\
\hline 74. & 0 & 1 & 0 & 0 & 0 \\
\hline 75. & 0 & 1 & 0 & 0 & 0 \\
\hline 76. & 0 & 1 & 1 & 0 & 1 \\
\hline 77. & 0 & 1 & 0 & 0 & 0 \\
\hline 78. & 1 & 0 & 1 & 1 & 0 \\
\hline 79. & 1 & 0 & 1 & 0 & 1 \\
\hline 80. & 0 & 1 & 1 & 0 & 1 \\
\hline 81. & 0 & 1 & 1 & 0 & 1 \\
\hline 82. & 0 & 1 & 0 & 0 & 0 \\
\hline 83. & 0 & 1 & 0 & 0 & 0 \\
\hline 84. & 0 & 1 & 0 & 0 & 0 \\
\hline 85. & 1 & 0 & 1 & 0 & 1 \\
\hline 86. & 1 & 0 & 1 & 1 & 0 \\
\hline 87. & 0 & 1 & 1 & 0 & 1 \\
\hline 88. & 0 & 1 & 1 & 0 & 1 \\
\hline 89. & 0 & 1 & 1 & 1 & 0 \\
\hline 90. & 0 & 1 & 0 & 0 & 0 \\
\hline 91. & 0 & 1 & 1 & 0 & 1 \\
\hline 92. & 0 & 1 & 0 & 0 & 0 \\
\hline 93. & 0 & 1 & 0 & 0 & 0 \\
\hline 94. & 0 & 1 & 0 & 0 & 0 \\
\hline 95. & 1 & 0 & 1 & 1 & 0 \\
\hline 96. & 0 & 1 & 1 & 0 & 1 \\
\hline 97. & 0 & 1 & 1 & 0 & 1 \\
\hline 98. & 1 & 0 & 1 & 0 & 1 \\
\hline 99. & 1 & 0 & 1 & 1 & 0 \\
\hline 100. & 0 & 1 & 0 & 0 & 0 \\
\hline 101. & 0 & 1 & 0 & 0 & 0 \\
\hline 102. & 0 & 1 & 0 & 0 & 0 \\
\hline 103. & 0 & 1 & 1 & 0 & 1 \\
\hline 104. & 0 & 1 & 0 & 0 & 0 \\
\hline 105. & 0 & 1 & 0 & 0 & 0 \\
\hline 106. & 1 & 0 & 1 & 1 & 0 \\
\hline 107. & 0 & 1 & 1 & 0 & 1 \\
\hline 108. & 0 & 1 & 1 & 1 & 0 \\
\hline 109. & 0 & 1 & 0 & 0 & 0 \\
\hline 110. & 1 & 0 & 1 & 0 & 1 \\
\hline 111. & 1 & 0 & 1 & 1 & 0 \\
\hline 112. & 0 & 1 & 1 & 0 & 1 \\
\hline 113. & 1 & 0 & 1 & 1 & 0 \\
\hline 114. & 0 & 1 & 0 & 0 & 0 \\
\hline 115. & 0 & 1 & 0 & 0 & 0 \\
\hline 116. & 0 & 1 & 0 & 0 & 0 \\
\hline 117. & 1 & 0 & 1 & 1 & 0 \\
\hline 118. & 0 & 1 & 0 & 0 & 0 \\
\hline 119. & 0 & 1 & 1 & 0 & 1 \\
\hline 120. & 1 & 0 & 1 & 1 & 0 \\
\hline 121. & 0 & 1 & 1 & 0 & 1 \\
\hline 122. & 0 & 1 & 1 & 0 & 1 \\
\hline 123. & 1 & 0 & 0 & 0 & 0 \\
\hline 124. & 1 & 0 & 1 & 1 & 0 \\
\hline 125. & 0 & 1 & 0 & 0 & 0 \\
\hline 126. & 0 & 1 & 1 & 0 & 1 \\
\hline 127. & 1 & 0 & 1 & 1 & 0 \\
\hline 128. & 0 & 1 & 0 & 0 & 0 \\
\hline 129. & 0 & 1 & 1 & 0 & 1 \\
\hline 130. & 1 & 0 & 0 & 0 & 0 \\
\hline 131. & 0 & 1 & 0 & 0 & 0 \\
\hline 132. & 0 & 1 & 1 & 1 & 0 \\
\hline 133. & 1 & 0 & 0 & 0 & 0 \\
\hline 134. & 0 & 1 & 1 & 0 & 1 \\
\hline 135. & 1 & 0 & 1 & 1 & 0 \\
\hline 136. & 1 & 0 & 1 & 1 & 0 \\
\hline 137. & 0 & 1 & 0 & 0 & 0 \\
\hline 138. & 0 & 1 & 0 & 0 & 0 \\
\hline 139. & 1 & 0 & 0 & 0 & 0 \\
\hline 140. & 0 & 1 & 0 & 0 & 0 \\
\hline 141. & 0 & 1 & 1 & 0 & 1 \\
\hline 142. & 1 & 0 & 0 & 0 & 0 \\
\hline 143. & 0 & 1 & 1 & 1 & 0 \\
\hline 144. & 1 & 0 & 1 & 1 & 0 \\
\hline 145. & 0 & 1 & 1 & 0 & 1 \\
\hline 146. & 0 & 1 & 0 & 0 & 0 \\
\hline
\end{tabular}


Excel : PLANILHA 6 DE DADOS ANATOMICOS - Perfurantes 147 a 192

(O): AUSENTE, (1): PRESENTE

(G) Lateral / (H) Medial / (I) Trajeto intramuscular / (J) Retilíneo / (K) Oblíquo

\begin{tabular}{|c|c|c|c|c|c|}
\hline & $\begin{array}{c}\mathbf{G} \\
\text { LATERAL }\end{array}$ & $\begin{array}{c}\mathrm{H} \\
\text { MEDIAL }\end{array}$ & $\begin{array}{c}\text { I } \\
\text { TRAJETO INTRAMUSCULAR }\end{array}$ & J & $\begin{array}{c}\mathrm{K} \\
\text { OBLÍQUO }\end{array}$ \\
\hline 147. & 0 & 1 & 0 & 0 & 0 \\
\hline 148. & 1 & 0 & 0 & 0 & 0 \\
\hline 149. & 0 & 1 & 1 & 0 & 1 \\
\hline 150. & 1 & 0 & 1 & 1 & 0 \\
\hline 151. & 1 & 0 & 0 & 0 & 0 \\
\hline 152. & 1 & 0 & 0 & 0 & 0 \\
\hline 153. & 0 & 1 & 1 & 0 & 1 \\
\hline 154. & 1 & 0 & 1 & 1 & 0 \\
\hline 155. & 0 & 1 & 0 & 0 & 0 \\
\hline 156. & 1 & 0 & 1 & 1 & 0 \\
\hline 157. & 0 & 1 & 1 & 1 & 0 \\
\hline 158. & 0 & 1 & 0 & 0 & 0 \\
\hline 159. & 1 & 0 & 0 & 0 & 0 \\
\hline 160. & 0 & 1 & 1 & 0 & 1 \\
\hline 161. & 0 & 1 & 0 & 0 & 0 \\
\hline 162. & 0 & 1 & 1 & 0 & 1 \\
\hline 163. & 0 & 1 & 1 & 0 & 1 \\
\hline 164. & 1 & 0 & 1 & 1 & 0 \\
\hline 165. & 0 & 1 & 1 & 0 & 1 \\
\hline 166. & 1 & 0 & 0 & 0 & 0 \\
\hline 167. & 1 & 0 & 0 & 0 & 0 \\
\hline 168. & 0 & 1 & 0 & 0 & 0 \\
\hline 169. & 1 & 0 & 0 & 0 & 0 \\
\hline 170. & 0 & 1 & 1 & 0 & 1 \\
\hline 171. & 0 & 1 & 0 & 0 & 0 \\
\hline 172. & 0 & 1 & 1 & 0 & 1 \\
\hline 173. & 1 & 0 & 1 & 1 & 0 \\
\hline 174. & 0 & 1 & 0 & 0 & 0 \\
\hline 175. & 0 & 1 & 1 & 1 & 0 \\
\hline 176. & 0 & 1 & 0 & 0 & 0 \\
\hline 177. & 0 & 1 & 0 & 0 & 0 \\
\hline 178. & 1 & 0 & 1 & 1 & 0 \\
\hline 179. & 0 & 1 & 1 & 0 & 1 \\
\hline 180. & 1 & 0 & 1 & 1 & 0 \\
\hline 181. & 0 & 1 & 0 & 0 & 0 \\
\hline 182. & 0 & 1 & 1 & 0 & 1 \\
\hline 183. & 0 & 1 & 0 & 0 & 0 \\
\hline 184. & 0 & 1 & 1 & 0 & 1 \\
\hline 185. & 0 & 1 & 0 & 0 & 0 \\
\hline 186. & 0 & 1 & 1 & 0 & 1 \\
\hline 187. & 0 & 1 & 0 & 0 & 0 \\
\hline 188. & 0 & 1 & 0 & 0 & 0 \\
\hline 189. & 0 & 1 & 1 & 0 & 1 \\
\hline 190. & 0 & 1 & 1 & 0 & 1 \\
\hline 191. & 0 & 1 & 1 & 0 & 1 \\
\hline 192. & 0 & 1 & 1 & 0 & 1 \\
\hline \multicolumn{6}{|l|}{193.} \\
\hline 194. & 65 & 126 & 103 & 48 & 55 \\
\hline
\end{tabular}


Excel : PLANILHA 7 DE DADOS ANATOMICOS - Perfurantes 2 a 73

(O): AUSENTE, (1): PRESENTE

(L) Origem da artéria perfurante / $(\mathrm{M})$ ramo lateral / $(\mathrm{N})$ ramo medial / $(\mathrm{O})$ ramo único médio-lateral

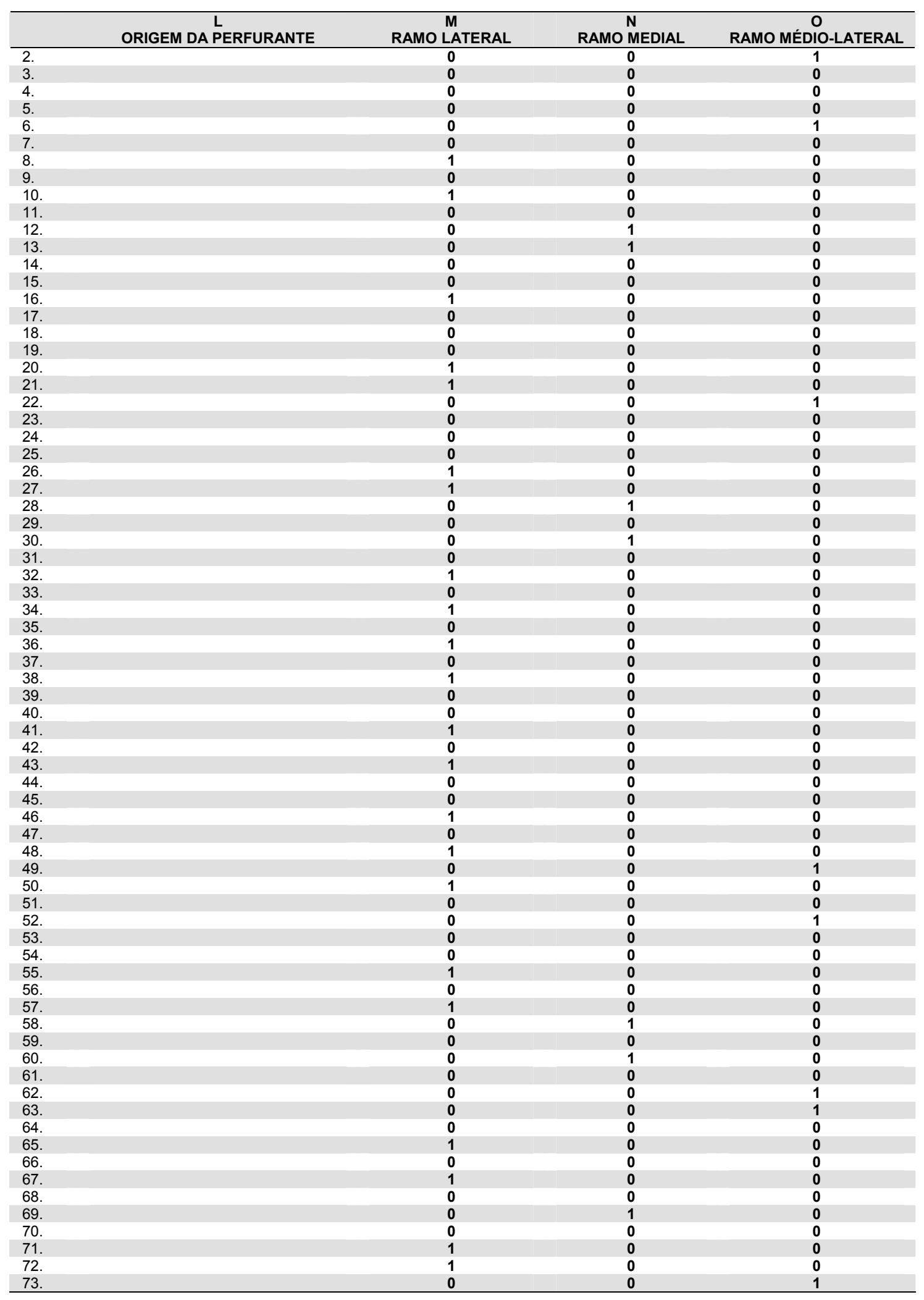


Excel : PLANILHA 8 DE DADOS ANATOMICOS - Perfurantes 74 a 146

(O): AUSENTE, (1): PRESENTE

(L) Origem da artéria perfurante / $(\mathrm{M})$ ramo lateral / $(\mathrm{N})$ ramo medial / $(\mathrm{O})$ ramo único médio-lateral

\begin{tabular}{|c|c|c|c|c|}
\hline & $\begin{array}{c}\mathrm{L} \\
\text { ORIGEM DA PERFURANTE }\end{array}$ & $\begin{array}{c}\text { M } \\
\text { RAMO LATERAL }\end{array}$ & $\begin{array}{c}\mathbf{N} \\
\text { RAMO MEDIAL }\end{array}$ & $\begin{array}{c}0 \\
\text { RAMO MÉDIO-LATERAL }\end{array}$ \\
\hline 74. & & 0 & 0 & 0 \\
\hline 75. & & 0 & 0 & 0 \\
\hline 76. & & 1 & 0 & 0 \\
\hline 77. & & 0 & 0 & 0 \\
\hline 78. & & 1 & 0 & 0 \\
\hline 79. & & 1 & 0 & 0 \\
\hline 80. & & 1 & 0 & 0 \\
\hline 81. & & 0 & 0 & 1 \\
\hline 82. & & 0 & 0 & 0 \\
\hline 83. & & 0 & 0 & 0 \\
\hline 84. & & 0 & 0 & 0 \\
\hline 85. & & 1 & 0 & 0 \\
\hline 86. & & 1 & 0 & 0 \\
\hline 87. & & 1 & 0 & 0 \\
\hline 88. & & 1 & 0 & 0 \\
\hline 89. & & 1 & 0 & 0 \\
\hline 90. & & 0 & 0 & 0 \\
\hline 91. & & 0 & 1 & 0 \\
\hline 92. & & 0 & 0 & 0 \\
\hline 93. & & 0 & 0 & 0 \\
\hline 94. & & 0 & 0 & 0 \\
\hline 95. & & 1 & 0 & 0 \\
\hline 96. & & 0 & 0 & 1 \\
\hline 97. & & 1 & 0 & 0 \\
\hline 98. & & 1 & 0 & 0 \\
\hline 99. & & 1 & 0 & 0 \\
\hline 100. & & 0 & 0 & 0 \\
\hline 101. & & 0 & 0 & 0 \\
\hline 102. & & 0 & 0 & 0 \\
\hline 103. & & 1 & 0 & 0 \\
\hline 104. & & 0 & 0 & 0 \\
\hline 105. & & 0 & 0 & 0 \\
\hline 106. & & 1 & 0 & 0 \\
\hline 107. & & 1 & 0 & 0 \\
\hline 108. & & 0 & 1 & 0 \\
\hline 109. & & 0 & 0 & 0 \\
\hline 110. & & 1 & 0 & 0 \\
\hline 111. & & 0 & 1 & 0 \\
\hline 112. & & 0 & 0 & 1 \\
\hline 113. & & 0 & 1 & 0 \\
\hline 114. & & 0 & 0 & 0 \\
\hline 115. & & 0 & 0 & 0 \\
\hline 116. & & 0 & 0 & 0 \\
\hline 117. & & 0 & 0 & 1 \\
\hline 118. & & 0 & 0 & 0 \\
\hline 119. & & 1 & 0 & 0 \\
\hline 120. & & 1 & 0 & 0 \\
\hline 121. & & 1 & 0 & 0 \\
\hline 122. & & 0 & 0 & 1 \\
\hline 123. & & 0 & 0 & 0 \\
\hline 124. & & 1 & 0 & 0 \\
\hline 125. & & 0 & 0 & 0 \\
\hline 126. & & 1 & 0 & 0 \\
\hline 127. & & 1 & 0 & 0 \\
\hline 128. & & 0 & 0 & 0 \\
\hline 129. & & 1 & 0 & 0 \\
\hline 130. & & 0 & 0 & 0 \\
\hline 131. & & 0 & 0 & 0 \\
\hline 132. & & 1 & 0 & 0 \\
\hline 133. & & 0 & 0 & 0 \\
\hline 134. & & 1 & 0 & 0 \\
\hline 135. & & 0 & 1 & 0 \\
\hline 136. & & 1 & 0 & 0 \\
\hline 137. & & 0 & 0 & 0 \\
\hline 138. & & 0 & 0 & 0 \\
\hline 139. & & 0 & 0 & 0 \\
\hline 140. & & 0 & 0 & 0 \\
\hline 141. & & 1 & 0 & 0 \\
\hline 142. & & 0 & 0 & 0 \\
\hline 143. & & 1 & 0 & 0 \\
\hline 144. & & 1 & 0 & 0 \\
\hline 145. & & 1 & 0 & 0 \\
\hline 146. & & 0 & 0 & 0 \\
\hline
\end{tabular}


Excel : PLANILHA 9 DE DADOS ANATOMICOS - Perfurantes 147 a 192

(O): AUSENTE, (1): PRESENTE

(L) Origem da artéria perfurante / $(\mathrm{M})$ ramo lateral / $(\mathrm{N})$ ramo medial / $(\mathrm{O})$ ramo único médio-lateral

\begin{tabular}{|c|c|c|c|c|}
\hline & $\begin{array}{c}\text { L } \\
\text { ORIGEM DA PERFURANTE }\end{array}$ & $\begin{array}{c}\text { M } \\
\text { RAMO LATERAL }\end{array}$ & $\begin{array}{c}\mathbf{N} \\
\text { RAMO MEDIAL }\end{array}$ & $\begin{array}{c}\text { O } \\
\text { RAMO MÉDIO-LATERAL }\end{array}$ \\
\hline 147. & & 0 & 0 & 0 \\
\hline 148. & & 0 & 0 & 0 \\
\hline 149. & & 0 & 0 & 1 \\
\hline 150. & & 1 & 0 & 0 \\
\hline 151. & & 0 & 0 & 0 \\
\hline 152. & & 0 & 0 & 0 \\
\hline 153. & & 1 & 0 & 0 \\
\hline 154. & & 1 & 0 & 0 \\
\hline 155. & & 0 & 0 & 0 \\
\hline 156. & & 0 & 1 & 0 \\
\hline 157. & & 1 & 0 & 0 \\
\hline 158. & & 0 & 0 & 0 \\
\hline 159. & & 0 & 0 & 0 \\
\hline 160. & & 1 & 0 & 0 \\
\hline 161. & & 0 & 0 & 0 \\
\hline 162. & & 0 & 0 & 1 \\
\hline 163. & & 1 & 0 & 0 \\
\hline 164. & & 1 & 0 & 0 \\
\hline 165. & & 1 & 0 & 0 \\
\hline 166. & & 0 & 0 & 0 \\
\hline 167. & & 0 & 0 & 0 \\
\hline 168. & & 0 & 0 & 0 \\
\hline 169. & & 0 & 0 & 0 \\
\hline 170. & & 1 & 0 & 0 \\
\hline 171. & & 0 & 0 & 0 \\
\hline 172. & & 1 & 0 & 0 \\
\hline 173. & & 1 & 0 & 0 \\
\hline 174. & & 0 & 0 & 0 \\
\hline 175. & & 1 & 0 & 0 \\
\hline 176. & & 0 & 0 & 0 \\
\hline 177. & & 0 & 0 & 0 \\
\hline 178. & & 1 & 0 & 0 \\
\hline 179. & & 1 & 0 & 0 \\
\hline 180. & & 0 & 0 & 1 \\
\hline 181. & & 0 & 0 & 0 \\
\hline 182. & & 1 & 0 & 0 \\
\hline 183. & & 0 & 0 & 0 \\
\hline 184. & & 0 & 1 & 0 \\
\hline 185. & & 0 & 0 & 0 \\
\hline 186. & & 1 & 0 & 0 \\
\hline 187. & & 0 & 0 & 0 \\
\hline 188. & & 0 & 0 & 0 \\
\hline 189. & & 0 & 1 & 0 \\
\hline 190. & & 0 & 1 & 0 \\
\hline 191. & & 0 & 1 & 0 \\
\hline 192. & & 0 & 1 & 0 \\
\hline \multicolumn{5}{|l|}{193.} \\
\hline 194. & & 69 & 18 & 16 \\
\hline
\end{tabular}


8. Referências bibliográficas

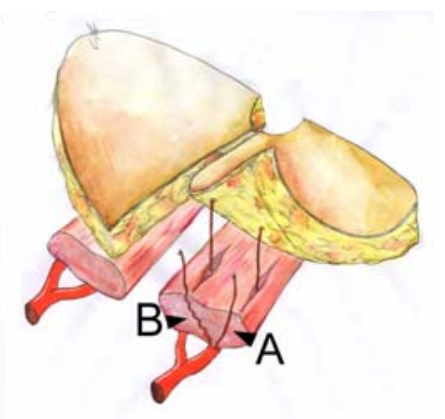


ALLEN, R.J.; TREECE, P. Deep inferior epigastric perforator for breast reconstruction. Ann. Plast. Surg. v.32, p.32-37, 1994.

ARNEZ, Z.M.; KHAN, U.; POGORELEC, D.; PLANINSEK, F. Rational selection of flaps from the abdomen in breast reconstruction to reduce donor site morbidity. Br. J. Plast. Surg. v.52, p.351-354, 1999.

AVELAR, J.M. Abdominoplasty: a new technique without undermining and fat layer removal. Arq Catarin Med. v.29, p147-149, 2000.

BESTEIRO, J.M.; AKI F.E.; FERREIRA M.C.; MEDINA L.R.; CERNEA C. Free flap reconstruction of tumors involving the cranial base. Microsurgery, v.15, p.9-13. 1994.

A normatização das referências bibliográficas foi padronizada por Annelise Carneiro da Cunha do Serviço de Biblioteca e Documentação da FMUSP e esta baseada na NBR 6023/89 da Associação Brasileira de Normas Técnicas (ABNT) com algumas adaptações aprovadas pelo Grupo de Trabalho do Conselho Supervisor do Sistema Integrado de Bibliotecas da USP e adotadas no âmbito desta Universidade.

As abreviaturas dos títulos dos periódicos estão de acordo com LIST OF JOURNALS INDEXED IN INDEX MEDICUS 
BLONDEEL, P.N.; BOECKX, W.D. Refinements in free flap breast reconstruction: The free bilateral deep inferior epigastric perforator flap anastomosed to the internal mammary artery. Br. J. Plast. Surg. v.47, p.495-501, 1994.

BLONDEEL, P.N.; BOECKX, W.D.; VANDERSTRAETEN, G.G. The fate of the oblique abdominal muscles after free TRAM flap surgery. Br. J. Plast. Surg. v.50, p.315-319, 1997.

BLONDEEL, P.N.; VANDERSTRAETEN, G.G.; MONSTREY, S.J. The donor site morbidity of the free DIEP flaps and free TRAM flaps for breast reconstructions. Br. J. Plast. Surg. v.50, p.322-327, 1997.

BLONDEEL, P.N.; VANDERSTRAETEN, G.G.; MONSTREY, S.J. Doppler flowmetry in the planning of perforator flaps. Br. J. Plast. Surg. v.51, p.202206, 1998.

BLONDEEL, P.N.; VAN LANDUYT, K.; MONSTREY, S.J. Surgical-technical aspects of the free DIEP flap for breast reconstruction. Op. Tech. Plast. Reconstr. Surg. v.6, p.27-37, 1999. 
BLONDEEL, P.N.; ARNSTEIN, M.; VERSTRAETE, K.; DEPUYDT, K.; VAN LANDUYT, K.H.; MONSTREY, S.J.; KROLL, S.S. Venous congestion and blood flow in free transverse rectus abdominis myocutaneous and deep inferior epigastric perforator flaps. Plast. Reconstr. Surg. v.106, p.12951299, 2000.

BOSTWICK, J.; VASCONEZ, L.O.; JURKIEWICZ, M.J. Breast reconstruction after radical mastectomy. Plast. Reconstr. Surg. v.61, p.682-687, 1978.

BOYD, J.B.; TAYLOR, I.G.; CORLETT, R. The vascular territories of the superior epigastric and the deep inferior epigastric systems. Plast. Reconstr. Surg. v.73, p.1-13, 1984.

BROWN, R.G.; VASCONEZ, L.O.; JURKIEWICZ, M.J. Transverse abdominal flaps and the deep epigastric arcade. Plast. Reconstr. Surg. v.55, p.416420,1975

BUNCKE, H.J.Jr.; SCHULZ, W.P. Experimental digital amputation and reimplantation. Plast. Reconstr. Surg. v.36, p.62-66, 1965.

BUNKIS, J.; WALTON, R.; MATHES, S. Experience with the transverse lower rectus abdominis operation for breast reconstruction. Plast. Reconstr. Surg. v.72, p.819-823, 1983. 
CARRAMASCHI, F.; BRICOUT, N.; SERVANT, J.M.; BANZET, P.; FERREIRA, M.C. Breast reconstruction after mastectomy. Critical analysis of 240 cases. Rev Assoc Med Bras. v.35, p.15-9. 1989.

CARRAMASCHI, F.; FERREIRA, M.C.; HERSON, M.R.; DE SOUZA, A.Z.; PINOTTI, J.A. Immediate breast reconstruction with the use of a microsurgical flap of the rectus abdominis muscle. Rev Hosp Clin Fac Med Sao Paulo. v.47, p.276-9. 1992.

CRAIGIE, J.E.; ALLEN, R.J.; DELLACROCE, F.J.; SULLIVAN, S.K. Autogenous breast reconstruction with the deep inferior epigastric perforator flap. Clin. Plast. Surg. v.30, p.359-369, 2003.

CRONIN, T.D.; UPTON, J.; McDONOUGH, J.M. Reconstruction of the breast after mastectomy. Plast. Reconstr. Surg. v.59, p.1-14, 1977.

DANIEL, R.K.; TAYLOR, G.I. Distant transfer of an island flap by microvascular anastomoses. A Clinical technique. Plast. Reconstr. Surg. v.52, p.111-115, 1973.

DREVER, J.M. Total breast reconstruction with either of two Abdominal flaps. Plast. Reconstr. Surg. v.59, p.185-190, 1977. 
ELLIOT, L.F.; HARTRAMPF C.R. Breast reconstruction: progress in the past decade. World. J. Surg. v.14, p.763-769, 1990.

ELLIOT, L.F.; ESKENAZI, L.; BEEGLE, P.H. Immediate TRAM flap breast reconstruction : 128 Consecutive cases. Plast. Reconstr. Surg. v.92, p.217221, 1993.

FERREIRA, M.C.; MARQUES, E.F.; AZZE, R.J.; MARCHESE, A.J. Hand reimplantation. Experiences of 8 cases. Rev Assoc Med Bras. v.21, p.14952. 1975.

FELLER, A.M. Free TRAM - Results and abdominal wall function. In: KROLL, S.S. ed. Clinics in Plastic Surgery An International Quarterly. Philadelphia, W.B.Saunders Company. 1994. v.21. p.2-10.

GARDNER, E.; GRAY, D.J.; RAHILLY, R.O. Anatomy - A regional study of human structure. 2.ed. Philadelphia, W.B.Saunders Company, 1975. Cap.33, p.345-355.

GILL, P.S.; HUNT, J.P.; GUERRA, A.B.; DELLACROCE, F.J.; SULLIVAN, S.K.; BORASKI, J.; METZINGER, S.E.; DUPIN, C.L.; ALLEN, R.J. A 10-year retrospective review of 758 DIEP flaps for breast reconstruction. Plast. Reconstr. Surg. v.113, p.1154-1160, 2004. 
GILLES, H.D. The tubed pedicled in plastic surgery. NY Med J. v.111, p.1-3, 1920.

GRAF, R.; FREITAS, R.; FISHER, M.; BARK, A.; LOUREIRO, A.; PIANOWSKI, R.; CRUZ, G.A. Lipoabdominoplastia - estudo de fluxometria doppler e variação técnica. In: SALDANHA, O. ed. Lipoabdominoplastia. Rio de Janeiro, Di-Livros Editora. 2004. p.87-92.

GRISOLIA, M.M; SBORGIA, R.C. Português sem mistérios. $1^{\text {a }}$ ed. São Paulo, Madras Editora, 2003. p.92.

GROTTING, J.C.; URIST, M.M.; MADOX, W.A. Conventional TRAM flap versus free TRAM flap for immediate breast reconstruction. Plast. Reconstr. Surg. v.83, p.828-833, 1989.

HADDAD, C.M. Ensaios sobre a rede arterial da parede ântero-lateral do abdome - Estudo radiológico. Rev. Assoc. Med. Bras. V.14, p.255-258, 1968.

HAGENS, G. von; TIEDEMAN, K.; KRIZ, W. The current potential of plastination. Anat. Embriol., v.175, p.411-421, 1987. 
HAMDI, M.; MITHOFF, E.; WEBSTER, M. Deep inferior epigastric perforator flap in breast reconstruction : Experience with the first 50 flaps. Plast. Reconstr. Surg. v.103, p.86-90, 1999.

HANKEY, B.F. Cancer statistics review: 1973-1989. In: MILLER, B.A.; RIES, L.A.G.; HANKEY, B.F., ed. Breast. Bethesda, National Cancer Institute, 1992.

HARII, K.; OHMORI, K.; OHMORI, S. Hair transplantation with free scalp flaps. Plast. Reconstr. Surg., v.53, p.410-414, 1974.

HARTRAMPF, C.R.; SCHEFLAN, M.; BLACK, PW. Breast reconstruction with a transverse abdominal island flap. Plast. Reconstr. Surg., v.69, p.216220, 1982.

HARTRAMPF, C.R. Abdominal wall competence in transverse abdominal island flap operations. Ann. Plast. Surg. V.12, p.139-144, 1984.

HARTRAMPF, C.R.; BENNETT G.K. Autogenous tissue reconstruction in the mastectomy patient: A critical review of 300 patients. Ann. Surg. V.205, p.508-513, 1987. 
HEITMANN, C.; FELMERER, G.; DURMUS, C.; MATEJIC, B.; INGIANNI, G. Anatomical features of perforator blood vessels in the deep inferior epigastric perforator flap. Br. J. Plast. Surg. v.53, p.205-208, 2000.

HESTER, T.R.; NAHAI, F.; BEEGLE, P.E.; BOSTWICK, J. Blood supply of the abdomen revisited with emphasis on the superficial inferior epigastric artery. Plast. Reconstr. Surg. v.74, p.657-666, 1984.

HOLLINSHEAD, W.H. Anatomia humana. Trad. de Walter Biazotto. São Paulo, Harper e Row do Brasil, 1980. Cap. 20, p.566: O Abdome.

HOLMSTROM, H. The free abdominoplasty flap and its use in breast reconstruction. Scand. J. Plast. Reconstr. Surg. V.13, p.423-425, 1979.

HOUAISS, A.; VILLAR, M.S.; FRANCO, F.M.M. Houaiss - Dicionário da língua portuguesa. Rio de Janeiro, Objetiva. 2003. p.399.

HUESTON, J.T.; McCONCHIE, I.H. A compound pectoral flap. Aust NZ J Surg. v.38, p.61-64, 1968.

ISHIDA L.H.; ISHIDA L.C.; MUNHOZ A.M.; BESTEIRO J.M. Retalhos perfurantes em cirurgia de cabeça e pescoço. In: MELEGA J.M. ed: Cirurgia Plástica Fundamentos e Arte. Rio de Janeiro, Medsi. 2002. p.1046-1050. 
ITOH, Y.; ARAI, K. The deep inferior epigastric artery free skin flap: anatomic study and clinical application. Plast. Reconstr. Surg. v.91, p.853-863, 1993.

JACOBSON, J.H; SUAREZ, E.L. Microsurgery in anastomosis of small vessels. Surg Forum, v.11, p.243-247, 1960.

JANZON, L. The effect of smoking and smoking cessation on peripheral circulation and fibrinolysis. A population study in old men. Acta Chir Scand. v.451, p.1-5, 1974

KAMINA, P. Dictionnaire atlas de anatomie. Paris, Malonie Editeur. 1983. p.86.

KOSHIMA, I.; SOEDA, S. Inferior epigastric artery skin flap without rectus abdominis muscle. Br. J. Plast. Surg. v.42, p.645-649, 1989.

KOSHIMA, I.; MORIGUSHI, T.; SOEDA, S.; TANAKA, H.; UMEDA, N. Free thin paraumbilical perforator-based flaps. Ann. Plast. Surg. v.29, p.12-17, 1992.

KROLL, S.S.; MARCHI, M. Comparison of strategies for preventing abdominal wall weakness after TRAM flap breast reconstruction. Plast. Reconstr. Surg. v.89, p.1045-1049, 1992. 
KROLL, S.S. Free TRAM or DIEP flap: Which to choose. Op. Tech. Plast. Reconstr. Surg. v.6, p.83-85, 1999.

KROLL, S.S. Fat necrosis in free transverse rectus abdominis myocutaneous and deep inferior epigastric perforator flap. Plast. Reconstr. Surg. v.106, p.576-583, 2000.

LEJOUR, M.; DOME, M. Abdominal wall function after rectus abdominis transfer. Plast. Reconstr. Surg. v.87, p.1054-1059, 1991.

MARCONDES, E. Pediatria básica. 8ª . ed. São Paulo, Sarvier, 1991, v.1, p.41.

MATHES, S.J.; ESHIMA, I. The principles of muscle and musculocutaneous flaps. In: McCARTHY, J.G., ed. Plastic Surgery. Philadelphia, W.B.Saunders Company. 1990. p.379-411.

MATHES, S.J; NAHAI, F. General Principles. In: MATHES, S.J; NAHAI, F., ed. Reconstructive surgery : Principles, anatomy and technique. New York, Churchill Livingstone. 1997. p. 3-161.

MCCRAW, J.B.; DIBBEL, D.G. Experimental definition of independent myocutaneous vascular territories. Plast. Reconstr. Surg. v.60, p.212-220, 1977. 
MCCRAW, J.B.; DIBBEL, D.G.; CARRAWAY, J.H. Clinical definition of independent myocutaneous vascular territories. Plast. Reconstr. Surg. v.60, p.341-352, 1977.

MCCRAW, J.B.; BOSTWICK, J.; HORTON, C.E. Methods of soft tissue coverage for the mastectomy defect. In: RUBIN, L.R. ed. Clinics in Plastic Surgery An International Quarterly. Philadelphia, W.B.Saunders Company. 1979. v.6. p.57-69.

MCCARTHY, J.G. Introduction to plastic surgery. In: McCARTHY, JG., ed. Plastic Surgery. Philadelphia, W.B.Saunders Company. 1990. p.1-22.

MILLARD, D.R. Breast reconstruction after a radical mastectomy. Plast. Reconstr. Surg. v.58, p.283-291, 1976.

MILLER, L.B.; BOSTWICK, J.; HARTRAMPF, C.R.; HESTER, T.R.; NAHAI, F. The superiorly based rectus abdominis flap: Predicting and enhancing its blood supply based on an anatomic and clinical study. Plast. Reconstr. Surg. v.81, p.713-720, 1988.

MILLOY, F.J.; ANSON, B.J.; McAFEE, D.K. The rectus abdominis muscle and the epigastric arteries. Surg Gynec Obst. v.60 , p. 293-302, 1960. 
MIZGALA, C.; HARTRAMPF, C.R.; BENNET, G.K. Abdominal function after pedicled TRAM flap surgery. In: KROLL, S.S. ed. Clinics in Plastic Surgery An International Quarterly. Philadelphia, W.B.Saunders Company. 1994. v.21. p.2-10.

MOON, H.K.; TAYLOR, I.G. The vascular anatomy of rectus abdominis musculocutaneous flaps based on the deep superior epigastric system. Plast. Reconstr. Surg. v.82, p.815-831, 1988.

MOORE, K.L. Clinically oriented anatomy. 2.ed. Baltimore, Williams and Wilkins, 1985. Cap.2. p.119.

MRAKBY, H.H.; MILNER, R.H. The vascular anatomy of the lower anterior abdominal wall: A microdissection study on the deep inferior epigastric vessels and the perforator branches. Plast. Reconstr. Surg. v.109, p.539$543,2002$.

MUNHOZ, A.M.; FERREIRA, M.C. Aplicação da microcirurgia na reconstrução mamária. Rev. Bras. Mastol. v.10, p.103-105, 2000.

MUNHOZ, A.M.; ISHIDA, L.H.; MONTAG, E.; STURTZ, G.; RODRIGUES, L.; FERREIRA, M.C. Perforator vessels anatomy and clinical application in deep inferior epigastric perforator (DIEP) flap. In: Kongr Verein Deutsc Plast Chir, Frankfurt, 2001, v.32, p.1-2. 
MUNHOZ, A.M.; DUARTE, G.; ISHIDA, L.; CUNHA, M.; FERREIRA, M.C. Análise crítica da aplicação da microcirurgia e evolução pós-operatória de pacientes submetidas à reconstrução mamária. Rev. Lat. Mastol. v.03, p.2130, 2002a.

MUNHOZ, A.M.; DUARTE, G.; ISHIDA, L.; CUNHA, M.; FERREIRA, M.C. Reconstrução mamária pós-mastectomia com tecido autógeno - Avaliação comparativa de resultados e complicações. Rev. Ginec. Obstet. v.13, p.60$66,2002 b$.

MUNHOZ, A.M.; ISHIDA, L.H.; DUARTE, G.; CUNHA, M.; STURTZ, G.; MONTAG, E.; GEMPERLI, R.; FERREIRA, M.C. Aesthetic refinements in breast augmentation with deep inferior epigastric perforator flap. Aesth. Plast. Surg. v.27, p.107-111, 2003.

MUNHOZ, A.M.; ISHIDA, L.H.; STURTZ, G.; CUNHA, M.S.; MONTAG, E.; SAITO, F.L.; GEMPERLI, R.; FERREIRA, M.C. Importance of the lateral row perforator vessels in deep inferior epigastric perforator flap harvesting. Plast Reconstr Surg. v. 113 (2), p.517-24, 2004a. 
MUNHOZ, A.M.; KAMAMOTO, F.; SAITO, F.L.; MENEZES, M.; GEMPERLI, R. Mapeamento anatômico dos vasos perfurantes abdominais e aplicação clínica no tratamento de deformidades estéticas da parede abdominal pela lipoabdominoplastia. In: SALDANHA, O. ed. Lipoabdominoplastia. Rio de Janeiro, Di-Livros Editora. 2004b. p.103-114.

NAHAI, F.; BROWN, R.G.; VASCONEZ, L.O. Blood supply to the abdominal wall as related to planning abdominal incisions. Am. Surg. v.42, p.691-695, 1976.

O'BRIEN, B.M.; MORRISON, W.A.; GUMLEY, G.J. Principles and techniques of microvascular surgery. In: McCARTHY, JG., ed. Plastic Surgery. Philadelphia, W.B.Saunders Company. 1990. p.412-474.

PENNINGTON, D.G.; LAI, M.F.; PELLY, A.D. The rectus abdominis myocutaneous free flap. Br J Plast Surg. v.33, p.277-282, 1980.

RODRIGUES Jr., A.J.; GERMANO, M.A.; SOUZA, C.G.; JACOMO, A.L.; FIGUEIRA, L.N.T.; BARROS FILHO, T.E.P. Anatomia seccional da origem do músculo psoas maior: estudo através do método de plastinação. Rev. Bras. Ortop., v.28, n.3, 1993a. 
RODRIGUES Jr., A.J.L.; RODRIGUES Jr., C.J.; GERMANO, M.A.; BRITTO, S.; FIGUEIRA, L.T.; BARROS, N.; CERRI, C.C. Why teach cross-sectional anatomy. Clin.Anat., n.6, p.375, 1993b (Abstract).

ROSSE, C.; GADDUM-ROSSE, P. Hollinshead's Textbook of Anatomy. 5.ed. Philadelphia, Lippincott-Raven Publishers. 1997, p.526.

RUTKOW, I.M. Surgery : an illustrated history. 1.ed. St. Louis, Mosby-Year Book, 1993. Cap.8, p.131: The Renaissance.

SALDANHA, O.R.; PINTO, E.B.S.; MATOS, W.M.; LUCON, R.L.; MAGALHÃES, F.; BELLO, E.M.L. Lipoabdominoplasty with selective and safe undermining. Aesth Plast Surg. v.21, p.518-526, 2001.

SCHUSTERMAN, M.; KROLL, S.S.; WELDON, M.E.; Immediate breast reconstruction : Why the free TRAM over the conventional TRAM flap? Plast. Reconstr. Surg. v.90, p.255-260, 1992.

SERAFIN, D.; GEORGIADE, N.G.; GIVEN, K.S. Transfer of free flaps to provide well-vascularized, thick cover for breast reconstructions after radical mastectomy. Plast. Reconstr. Surg. v. 62, p.527-535, 1978. 
SHEFLAN, M.; DINNER, M. The transverse abdominis island flap: indications, contraindications, results and complications. Ann. Plast. Surg. v.10, p.24-29, 1983.

SMITH, J.D.; PRIBAZ, J.J. Flaps. In: ACHAUER, B.M.; ERIKSSON, E., ed. Plastic surgery indications, operations and outcomes. St.Louis, Mosby, 2000. p.261-290.

STRANDNESS, D.E.; PRIEST, R.E.; GIBBONS, G.E. Combined clinical and pathological study of diabetic and nondiabetic peripheral arterial disease. Diabetes. v.13, p.366-370, 1964.

STRONG, J.P.; RICHARDS, M.L. Cigarrete smoking and atherosclerosis in autopsied men. Atherosclerosis. v.23, p451-454, 1976.

SUOMINEM, S.; ASKO-SELJAVAARA, S.; SMITTEN, K. Sequelae in the abdominal wall after pedicled or free TRAM flap surgery. Ann. Plast. Surg. v.36, p.6-11, 1996.

TAYLOR, I.G.; CORLETT, R.J.; BOYD, J.B. The versatile deep inferior epigastric (inferior rectus abdominis) Flap. Br J Plast Surg. v. 37, p. 330350, 1984. 
TAYLOR, I.G.; PALMER, J.H. The vascular territories (angiossomes) of the body: experimental studies and clinical applications. Br J Plast Surg. v. 40, p.113-119, 1987.

TERMINOLOGIA ANATÔMICA - TERMINOLOGIA ANATÔMICA INTERNACIONAL. 1ed. São Paulo, Manole Editora, 2001. 203p.

TESTUT, L.; LATARGET, A. Collection testut nouvelle bibliotheque de I'etudiant en medicine. Paris, Gaston Doin Editora. 1902. p.259.

VANDEVOORT, M.; VRANCKX, J.J.; FABRE, G. Perforator topography of the deep inferior epigastric perforator flap in 100 cases of breast reconstruction. Plast. Reconstr. Surg. v.109, p.1912-1918, 2002.

VESALIUS, A. De humani corporis fabrica. Epitome. Tabulae Six. São Paulo, Ateliê Editorial e Campinas, Imprensa Oficial do Estado: Editora Unicamp. 2002. p.162.

VIEIRA, S. Introdução à bioestatística. R.J.Campos, 1991. p.203.

WEISS, D.D.; PRIBAZ, J.J. Microsurgery. In: ACHAUER, B.M.; ERIKSSON, E., ed. Plastic surgery indications, operations and outcomes. St.Louis, Mosby, 2000. p.163-182. 
WILKINS, R.H.; ROBERT, J.C.; MOSES, C. Autopsies Studies in Atherosclerosis. III. Distribution and severity of atherosclerosis in the presence of obesity, hypertension, nephrosclerosis and rheumatic heart disease. Circulation. v.20, p527-530, 1959.

YAMADA, T.; GLOVICZKI, P.; BOWER, T.C.; NAESSENS, J.M.;

CARMICHAEL, S.W. Variations of the arterial anatomy of the foot. Am. J. Surg., v.166, p.130-135, 1993. 